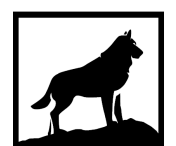

Michigan

Technological

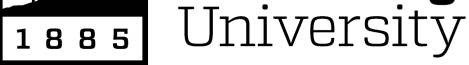

Michigan Technological University

Digital Commons @ Michigan Tech

\title{
LABORATORY AND FIELD INVESTIGATION OF MIXING, MORPHOLOGY AND OPTICAL PROPERTIES OF SOOT AND SECONDARY ORGANIC AEROSOLS
}

Noopur Sharma

Michigan Technological University, noopurs@mtu.edu

Copyright 2015 Noopur Sharma

Recommended Citation

Sharma, Noopur, "LABORATORY AND FIELD INVESTIGATION OF MIXING, MORPHOLOGY AND OPTICAL PROPERTIES OF SOOT AND SECONDARY ORGANIC AEROSOLS", Open Access Dissertation, Michigan Technological University, 2015.

https://doi.org/10.37099/mtu.dc.etdr/45

Follow this and additional works at: https://digitalcommons.mtu.edu/etdr

Part of the Atmospheric Sciences Commons 
LABORATORY AND FIELD INVESTIGATION OF MIXING, MORPHOLOGY AND

OPTICAL PROPERTIES OF SOOT AND SECONDARY ORGANIC AEROSOLS

\author{
By \\ Noopur Sharma \\ A DISSERTATION \\ Submitted in partial fulfillment of the requirements for the degree of \\ DOCTOR OF PHILOSOPHY \\ In Atmospheric Sciences
}

MICHIGAN TECHNOLOGICAL UNIVERSITY

2015

(C) 2015 Noopur Sharma 
This dissertation has been approved in partial fulfillment of the requirements for the Degree of DOCTOR OF PHILOSOPHY in Atmospheric Sciences.

\title{
Department of Physics
}

\author{
Dissertation Advisor: $\quad$ Dr. Claudio Mazzoleni \\ Committee Member: $\quad$ Dr. Will Cantrell \\ Committee Member: $\quad$ Dr. Shiliang $W u$ \\ Committee Member: $\quad$ Dr. Sarah Green
}

Department Chair: Dr. Ravindra Pandey 


\section{Table of Contents}

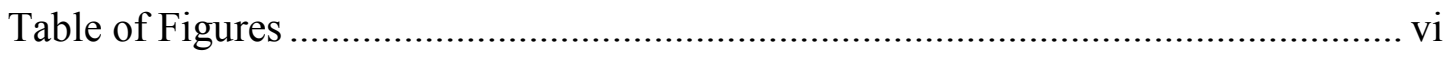

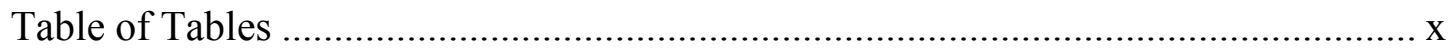

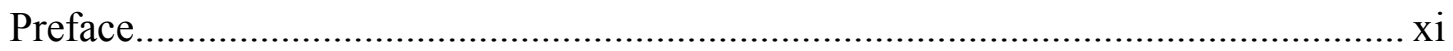

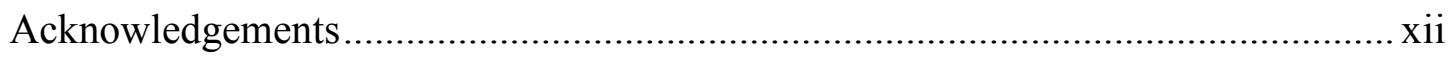

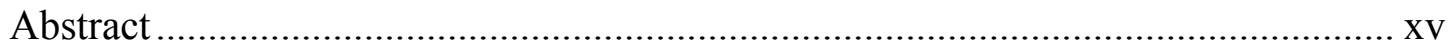

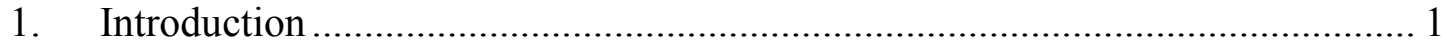

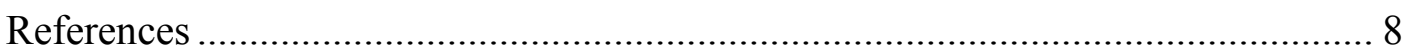

2. Photoacoustic and Nephelometric Spectroscopy of Aerosol Optical Properties

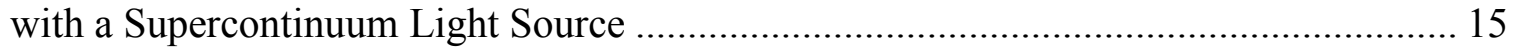

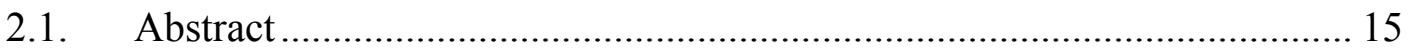

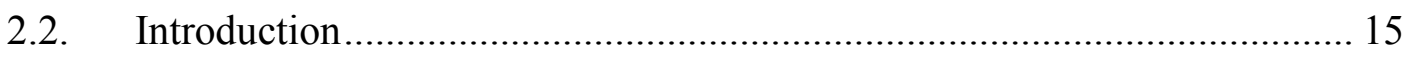

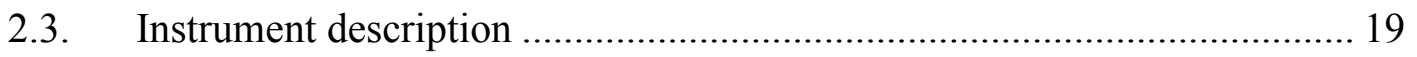

2.4. Aerosol Generation and Delivery System............................................ 25

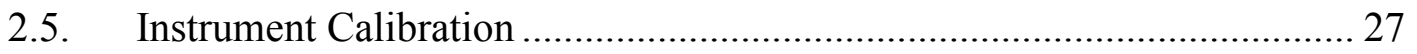

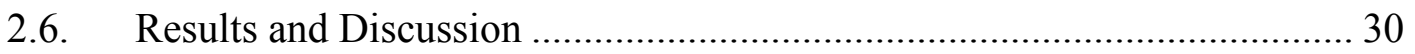

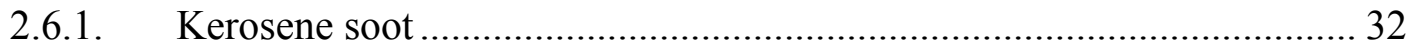

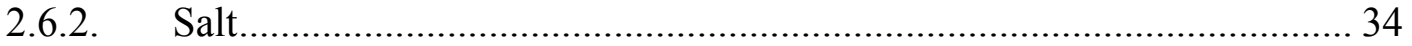

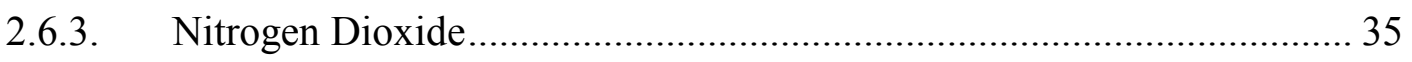

2.7. Instrumental noise and minimum detection limits versus integration time 38

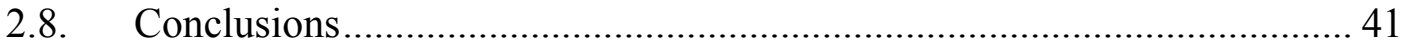

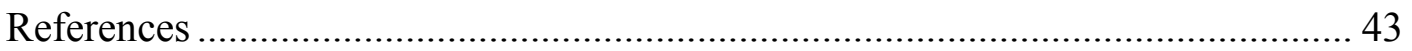


3. Links between physical properties of secondary organic aerosol and soot morphology during the Carbonaceous Aerosols and Radiative Effects Study

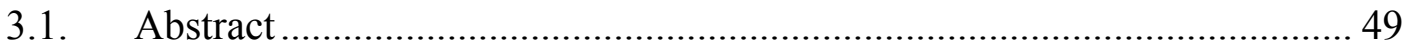

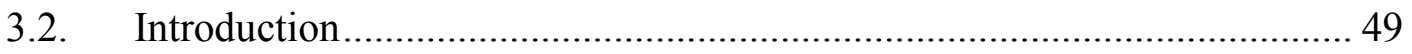

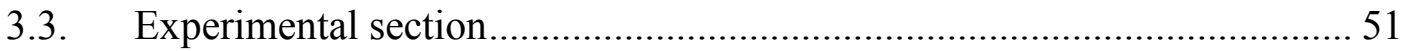

3.3.1. Sampling sites and Meteorology …....................................................... 51

3.3.2. Aerosol sample collection and measurements .................................. 53

3.3.3. Particle classification and soot mixing state ..................................... 53

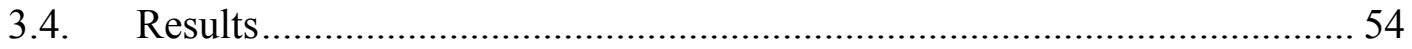

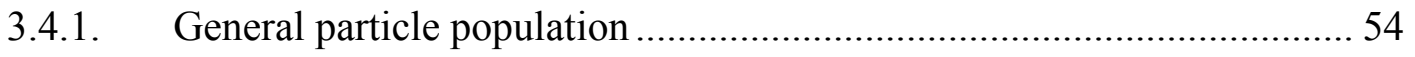

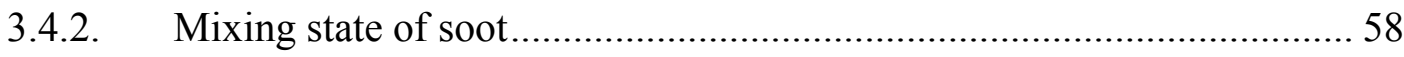

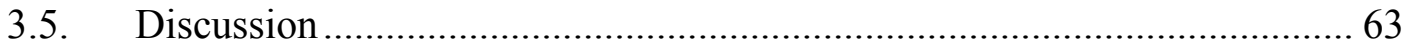

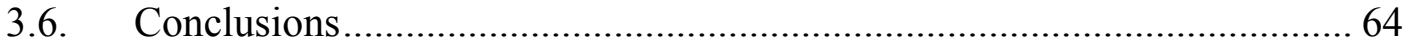

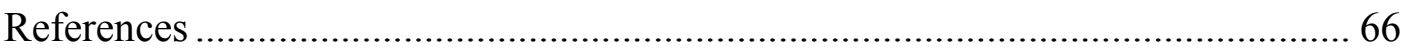

4. Secondary Organic Aerosol Processing of Diesel Soot and Effects on Condensational Rate in Different Relative Humidity Conditions ................................. 71

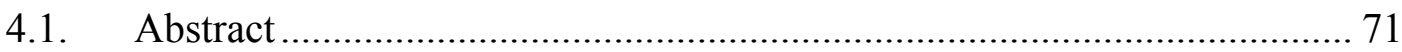

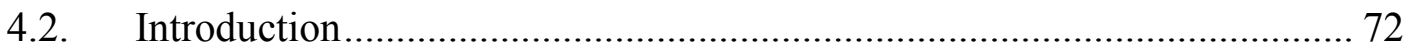

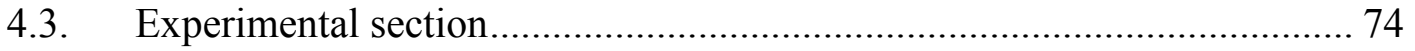

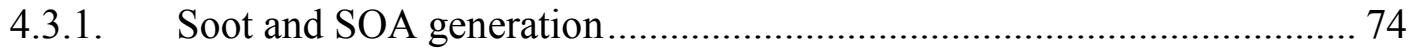

4.3.2. Particle mobility and mass measurements ...................................... 77

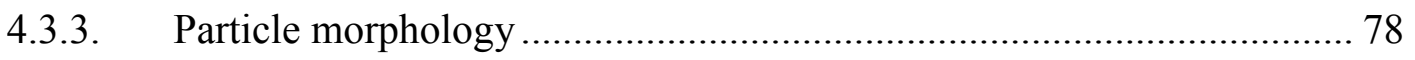

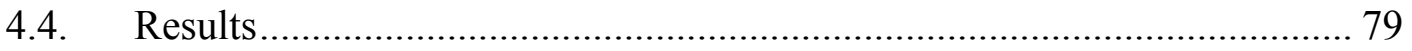

4.4.1. Growth of SOA mass on soot seeds ................................................... 79 
4.4.2. Evolution of particle size, mass and morphology in dry conditions ....... 80

4.4.3. Evolution of particle size, mass and morphology in humid conditions .. 83

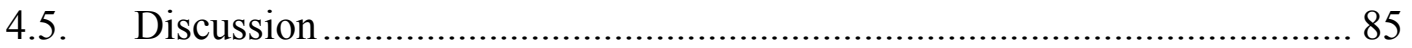

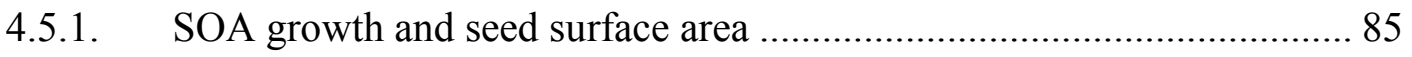

4.5.2. Slow growth of SOA in humid conditions ......................................... 86

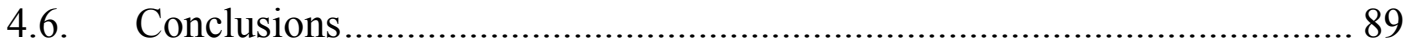

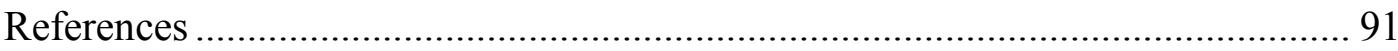

5. Research Implications \& Future Directions .................................................. 98

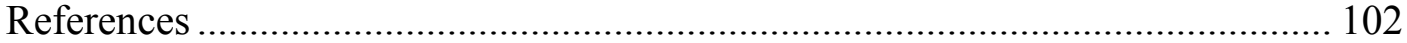




\section{Table of Figures}

Figure 2-1 Schematics of the supercontinuum integrated photoacoustic-nephelometer spectrometer 19

Figure 2-2 Supercontinuum full spectrum and spectrum with visible filter unit...... 20

Figure 2-3 Radiance spectra from single band filters (colored lines). Longer wavelengths are filtered out by using an infrared blocking filter (dashed line represents the transmission spectrum of the IR filter on the right vertical axis) 22

Figure 2-4 Normalized size distribution of (a) soot and (b) salt aerosols measured by an SMPS during the experiment. The black curve indicates the initial size distribution at the beginning of the experiment and the grey dashed curve indicates the size distribution toward the end of experiment. 27

Figure 2-5 (a) Scattering and (b) absorption calibration plots for the SC-PNS instrument at all filter wavelengths. Colors correspond to the center wavelength of each filter 30

Figure 2-6 (a) Absorption ( $\beta \mathrm{abs}$ ) and (b) scattering ( $\beta \mathrm{sca}$ ) coefficients of kerosene soot vs. wavelength $(\lambda)$ measured by PASS-3 and SC-PNS, error bars indicate square root of the sum of squares of background error, standard deviation of mean (standard error) and calibration variability. (c) Wavelength dependence of single scattering albedo (SSA) of kerosene soot, error bars indicate the error propagated from absorption and scattering. . 33

Figure 2-7 (a) Absorption ( $\beta$ abs) and (b) scattering ( $\beta$ sca) coefficients of common salt $(\mathrm{NaCl})$ vs. wavelength $(\lambda)$ measured by PASS-3 and SC-PNS, error bars indicate square root of sum of squares of background error, standard deviation of mean (standard error) and calibration variability. (c) Single scattering albedo of salt, error bars indicate the error propagated from absorption and scattering. 35

Figure 2-8 (a) Extinction, photoacoustic signal measured by SC-PNS and absorption estimated from the HITRAN database vs. wavelength. (b) Extinction and absorption measured by SC-PNS vs. absorption estimated from the HITRAN database. The vertical 
error bars on the photoacoustic signal measured and corrected for photodissociation indicate the square root of the sum of squares of the standard deviation of the mean (standard error) and the calibration variability. Vertical error bars on $\beta_{\text {ext }}$ indicate the square root of the sum of squares of the standard deviation of the mean (standard error) and the propagated error from the laser power measurement. Horizontal errors on the absorption coefficient calculated from the HITRAN database include 2\% uncertainty in $\mathrm{NO}_{2}$ absorption cross section data and $2 \%$ uncertainty in the $\mathrm{NO}_{2}$ concentration.

Figure 2-9 Allan deviation vs. integration time plots for (a) absorption ( $\beta$ abs) and (b) scattering (ßsca) coefficients at different wavelength bands for SC-PNS and at different wavelengths for PASS-3. Black dotted vertical and grey dashed lines indicate 60s integration time and 1/square root of integration time, respectively as guides to the eye.39

Figure 3-1 (a) Map showing the CARES sampling sites $\mathrm{T} 0$ and $\mathrm{T} 1$ and the wind patterns during the field campaign. Straight arrows in the direction from T0 to T1 indicate the typical wind directions (adapted from Zaveri, Shaw et al. (2012)). (b) Temperature and humidity at the T1 site during the sampling period used in this study. Grey rectangles indicate the sampling periods for samples $\mathrm{A}, \mathrm{B}$ and $\mathrm{C}$

Figure 3-2 (a) Particle number concentration and sampling periods. Grey rectangles indicate the sampling periods of sample A, B and C respectively. (b) Mobility size distribution of the particles at the beginning and end times of each filter sampling periods.

Figure 3-3 (a, b) SEM images obtained by tilting the sample at 75 degree showing bright and dark spherical particles (encircled). (c, d) Tilted SEM images of partially encapsulated soot particles. Each scale bar is $100 \mathrm{~nm}$. (e) Aspect ratio of bright and dark particles for samples B (solid line) and C (dashed line) measured from tilted (75 degree) SEM images. (f) Relative abundance of bright and dark spherical particles in the three samples. Spherical particles (g) before and (h) after 10-15s of electron beam exposure. (h) Shows the damaged dark particles (encircled in black) due to electron beam bombardment. Note that the bright particle (encircled in red) remains unchanged. Note that the dark circles pointed by white arrows are holes of the filter. 57 
Figure 3-4 Classification of soot particles: $(a, b)$ top-view SEM images of various soot particles in different categories encircled by their respective colors used in the column plots in (c) and (d). (c) Relative abundance of different soot categories in each sample. (d) Categories of soot in partially encapsulated (PE) particles of sample B and C only (due to the low relative abundance of PE particles in sample A, it is not shown in (d)) 60

Figure 3-5 (a) Size distribution of PE soot and host compared to the size distribution of the coated soot ( $\mathrm{C} 0-\mathrm{C} 3)$ population categorized in figure 4. (b) Roundness and convexity of PE soot is compared to the coated soot $(\mathrm{C} 0-\mathrm{C} 3)$ population categorized in figure $4 \ldots 62$

Figure 4-1 Morphological parameters: Ap: projected area of the particle, Ac: Area of convex hull polygon, Lmax: maximum length. The convexity of the upper particle is 0.56 and that of the lower particle is 0.9 79

Figure 4-2 Time series of $\alpha$ - pinene concentration (circles) and of SOA mass concentrations (triangles) from experiments 1 and 2. In red are the data for the low $\mathrm{RH}$ experiment, and in black the data for the high $\mathrm{RH}$ experiment. Time $\mathrm{t}=0$ indicates when UV lights were turned on and the photochemical oxidation of $\alpha$-pinene started. Vertical lines indicate when samples were collected for electron microscopy, with sampling times of 15-60 sec. Solid lines indicate nascent soot (phase 1), dashed lines indicate samples collected within 30-40 minutes from the beginning of the SOA formation (phase 2), and dotted lines indicate samples collected when the SOA concentration was stabilized, i.e. when all $\alpha$-pinene was consumed (phase 3$)$ ). 80

Figure 4-3 (a) Mass growth factor (GFM) ( $\log$ scale) (b) vacuum aerodynamic diameter growth factor (GFDva) ( linear scale) and (c) mobility diameter growth factor (GFDm) (linear scale) for the soot-SOA internally mixed particles in humid and dry experiments. The horizontal axes represent the time elapsed since the SOA generation began ( $\mathrm{t}=0$ when the UV lights were turned on), in minutes. The grey dashed line in the $\mathrm{GFD}_{\mathrm{m}}$ plot represents a diameter growth factor of 1 (nascent soot at $\mathrm{t}=0$ ). 81

Figure 4-4 (a) Area equivalent diameter number distribution for phase 1, 2 and 3 from high (solid lines) and low (dashed lines) relative humidity conditions. Particle growth is 
evident in dry conditions by the shift in mode diameter from $D_{A e q} \approx 150 \mathrm{~nm}$ in phase 1 to

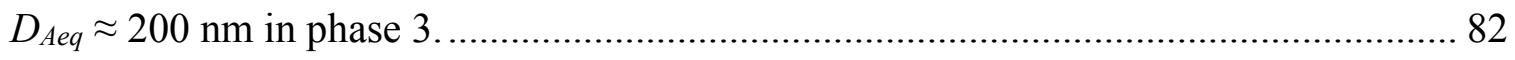

Figure 4-5 (a) convexity and (b) roundness of nascent soot particles from phase 1, 2 and 3 for dry (dashed lines) and humid experiments (solid lines). In humid conditions, the distributions of convexity and roundness of phase 2 particles (filled black circles) approach the distributions of phase 3 particles from the dry experiment (open blue circles), indicating

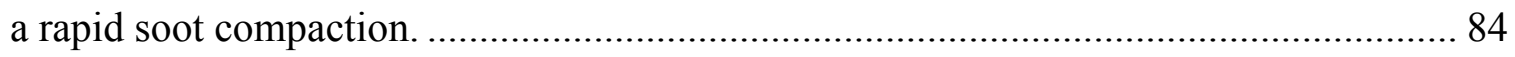

Figure 4-6 TEM images of sample particles for (i) phase 1, (ii) phase 2 and (iii) phase 3 for (a) Experiment 2 (humid) and (b) Experiment 1 (dry)............................................. 85

Figure 4-7 Fraction of free surface area vs. fractal dimension for different values of the prefactor 88 


\section{Table of Tables}

Table 2-1: Optical specifications of single-band bandpass filters used in the supercontinuum integrated photoacoustic-nephelometer spectrometer.

Table 2-2: Statistics (average, standard deviation and count) for absorption and scattering background measurements. ................................................................ 25

Table 2-3: Minimum detectable absorption (MDA) and scattering (MDS) coefficients

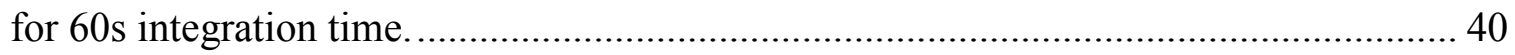

Table 4-1: Mean single particle morphological parameters of samples from all the

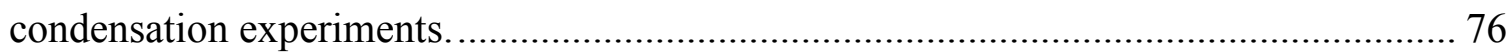




\section{Preface}

Chapter two of this diessertation is based on a paper published in the journal Atmospheric Measurement Techniques (Sharma et al., AMT, 2014). This paper discusses the design of a novel instrument developed by us in collaboration with Desert Research Institute, Reno, NV. Results from the laboratory testing of the instrument are also discussed in this chapter. I contributed to the instument development and testing, performed the data analysis and interpretation and lead the paper with input from my advisor Dr. Claudio Mazzoleni and other co-authors from Desert Research Institute, Reno, NV. All articles published under Copernicus Publications (AMT publisher) are licensed under the Creative Commons Attribution 3.0. together wih an author copyright ${ }^{1}$. Chapters three and four are based on two collaborative field and laboratory studies led by Pacific Northwest National Laboratory, Richland WA. Myself and co-authors took part in experiments. I carried out SEM/TEM analysis of samples collected during these studies and lead the manuscripts. Our co-authors contributed to measurements, data analysis and interpretation data and provided inputs to the manuscripts. Chapter three is in preparation for submission to Geophysical Research Letters by spring 2016. We plan to finalize and submit chapter four to Environmental Science and Technology by spring 2016. These chapters will be revised based on suggestions and comments from co-authors. We sincerely thank our co-authors for their contributions.

${ }^{1} \mathrm{http}: / /$ www.atmospheric-measurement-techniques.net/about/licence_and_copyright.html

All articles published by Copernicus Publications are licensed under the Creative Commons Attribution 3.0 License (see details above) together with an author copyright. Therefore, there is no need from the publisher's side to give permission for the reproduction of articles. We suggest contacting the author to inform him/her about the further usage of the material. However, as the author decided to publish the scientific results under the CC-BY licence, he/she consented to share the work under the condition that the original authors be given credit. 


\section{Acknowledgements}

I would like to express my deepest appreciation and gratitude to my advisor Dr. Claudio Mazzoleni, for the patient guidance and mentorship he provided during the entire duration of my $\mathrm{PhD}$. I am truly fortunate to have had an opportunity to work with him, that allowed me to grow academically as well as intellectually.

I appreciate Dr. Will Cantrell, Dr. Shiliang Wu, Dr. Sarah Green for being on my PhD committee and providing thought provoking suggestions on my reseach.

I would like to thank Atmospheric Science Program and Physics department at Michigan Tech for hosting me here and supporting me during my $\mathrm{PhD}$. I also thank Graduate School for the Doctoral Finishing Fellowship, that supported me while I worked on my dissertation and defense.

I would also like to thank Mr. Owen Mills in Applied Chemial and Morphological Analysis laboratory (ACMAL) in Material Science Department for training me on the electron microscopes and making his technical expertise readily available to ensure uninterrupted work involving microscopy.

I would like to express my sincere thanks to our collaborators. Thanks to Dr. Hans Moosmüller and Ian Arnold at Desert Research Institute, Reno and Dr. Patrick Arnott at University of Nevada, Reno for their support and guidance on the development of new instrument to measure aerosol optical properties. I am thankful to the research group at the Pacific Northwest National Laboratory, especially Dr. Rahul Zaveri, Dr. John Shilling, Dr. Alla Zelenyuk, Dr. Duli Chand and Dr. Gourihar Kulkarni for getting us involved in the field and laboratory studies (CARES and PNNL-SAAS) and their invaluable help and regular scientific discussions. Thanks to our collaborators at the Los Alamos National Laboratory, Dr. Manvendra Dubey, Kyle Gorkowski, Dr. Shang Liu and Dr. Allison Aiken for making us a part of their study published recently in Nature communications (Liu et al., 2015).

I would like to experss my special thanks to Dr. Swarup China for his support as a colleague as well as a friend. My heartfelt thanks to other fellow group members, Tyler 
Capek, Janarjan Bhandari, Nicole Niedermeier, Kaelan Anderson and Kendra Wright for their support and useful discussions.

I acknowledge all of my friends for their love and support. I thank them whole heartedly for helping me stand strong always and not letting me give up.

In no words I can acknowledge the innumerable sacrifices made by my family, especially my father, Mr. M.D. Sharma and my mother, Mrs. Suman Sharma. I thank my parents for letting me chase my dreams and my brothers for supporting me always. 
To you, $6 a b a . .$. 


\begin{abstract}
Soot/ black carbon particles are believed to be the second largest anthropogenic contributor to the Earth's radiative forcing, and are emitted from combustion processes. Freshly emitted soot has a fractal-like structure in which monomers are arranged into branched chain-like configuration. In the atmosphere, soot mixes with and is processed by interacting with other co-existing particle and vapors. The processing that soot undergo after emission alters its morphology; for example, condensation of vapors results into coated, mixed or compacted soot depending upon the environmental conditions. Changes in soot morphology have a strong and direct influence on its optical properties.

The unique and complex structure of soot and its behavior and evolution in the atmosphere are difficult to quantify and to model accurately. Radiative models use simplified assumptions for soot morphology, which results in large uncertainties on the forcing and therefore on the effect that soot has on climate. The temporal and spatial variability of soot morphology and mixing state may also add to already severe biases in absorption measurements in filter-based methods traditionally used to estimate aerosol absorption in the atmosphere. Since optical properties (absorption and scattering) are key input parameters to climate models, biases associated with their measurements add to the uncertainty in the forcing estimates.

During my graduate research, I worked on the development of a new multi-wavelength instrument, capable of measuring aerosol absorption and scattering over the entire visible range of the solar spectrum. The instrument combines photoacoustic spectroscopy and nephelometry with a supercontinuum laser to measure aerosol absorption and scattering over a broad wavelength range ( $\sim 400 \mathrm{~nm}$ to $\sim 700 \mathrm{~nm})$. Since the instrument measures the aerosol optical properties while the particles are suspended in air, this instrument is free from biases common in filter based instruments due to changes in morphology of the particles when they are deposited on the filter or due to multiple scattering of light from the filter.
\end{abstract}


To complement the instrument development discussed above, my research also included an in depth study of the evolution of soot morphology and mixing state upon its interaction with organics in the atmosphere. We investigated the samples collected from a forested site during the Carbonaceous Aerosols Radiative Effects Study (CARES), conducted in June 2010 in the Sacramento area, CA. Using a scanning electron microscopy, we characterized the morphology and mixing state of soot due to its interaction with biogenic secondary organic aerosols. Based on our analysis we found that both condensation and coagulation were accountable for the mixing of soot with SOA during the episodes we studied in CARES. We found that during coagulation, the viscosity of secondary organic aerosol (SOA) plays a crucial role in determining the soot-SOA mixing state. The viscosity of SOA can be linked to environmental factors like relative humidity, therefore the mixing of soot particles with biogenic aerosol may be affected by factors controlling the viscosity of SOA.

The mixing of soot with biogenic SOA through condensation was further investigated under controlled laboratory conditions in a set of follow-up chamber experiments at the Pacific Northwest National Laboratory during the Soot Aerosol Aging Study (SAAS). In this study, the condensation of $\alpha$-pinene SOA was examined on diesel soot at different relative humidity conditions. In this study, we find that soot in humid conditions becomes compact, which results into reduction of soot surface area for condensation. The reduction in surface area results in a much slower SOA condensational growth on the soot particles. Compacted soot particles in the atmosphere have been reported in several previous studies and their compaction is attributed to the condensation of organic vapors on soot in humid conditions, ice nucleation or water processing in clouds. Our findings are relevant to mixing scenarios where preprocessed, compacted soot competes with freshly emitted soot for SOA uptake. Based on the findings of our study we expect larger SOA growths on fresh soot particles as compared to compacted particles.

The research carried out during my $\mathrm{PhD}$ contributes to the field of atmospheric science on several aspects. The results from our study can be used to reduce the uncertainties in radiative forcing estimates. 


\section{Introduction}

Soot/black carbon particles are considered to be the second largest anthropogenic contributor (after CO2) to the positive radiative forcing (Bond, Doherty et al. 2013). Soot particles are emitted into the atmosphere as a result of incomplete combustion of biomass and fossil fuels under flaming conditions (Slowik, Stainken et al. 2004). Freshly emitted soot particles have a fractal-like structure in which primary spherical particles, termed as "monomers" are arranged into branched chain-like structures. Once suspended into the atmosphere, soot interacts with various other co-existing atmospheric species like water vapor, sulfates, nitrates and organics emitted from combustion and non-combustion sources (e.g., biogenic emissions). This process is termed as 'aging' of soot. Coagulation of soot particles with co-existing aerosol species or condensation of vapors on them results into coated or internally mixed, aged soot particles (Jacobson 2001, Jacobson 2002, Pósfai, Simonics et al. 2003, Adachi and Buseck 2008, Sedlacek, Lewis et al. 2012, Adachi and Buseck 2013, China, Mazzoleni et al. 2013). Several studies have shown that aged soot particles become hygroscopic and restructure to more compacted structures when they are exposed to high relative humidity, sulfate or some organic vapors (Popovicheva, Persiantseva et al. 2008, Zhang, Khalizov et al. 2008, China, Scarnato et al. 2015). Condensation of water on (or its evaporation from) soot or formation of ice on (or its sublimation from) soot also results in its compaction (China, Kulkarni et al. 2015).

Changes in soot morphology and mixing state during aging influence its optical properties. Based on numerical simulations, China, Scarnato et al. (2015) established that compacted soot exhibits a larger scattering as compared to non-compacted soot, while the absorption is less affected. Several studies have shown that soot particles coated with nonabsorbing organic carbon absorb more light in comparison to non-coated soot particles (Jacobson 2000, Jacobson 2001, Bond and Bergstrom 2006, Lack and Cappa 2010). This behavior of coated soot is due to the so called 'lensing effect' in which the non- absorbing coating acts as a lens and focuses more photons towards the absorbing core of the particle (Fuller, Malm et al. 1999, Lack and Cappa 2010). Laboratory studies and Mie theory calculations (in which a soot particle is treated as a spherical core and the coating material 
forms a shell around it) indicate the possibility of absorption enhancement factor up to $\sim 3$ (Fuller, Malm et al. 1999, Bond, Habib et al. 2006, Schwarz, Spackman et al. 2008). However, studies from field measurements have reported much lower absorption enhancement $(\sim 1.1)$ even for very thick level of coatings (Cappa, Onasch et al. 2012, Liu, Aiken et al. 2015). Therefore, the absorption enhancement and its influence on radiative forcing has been intensely debated amongst scientists over the past decade (Jacobson 2001, Cappa, Onasch et al. 2012, Liu, Aiken et al. 2015).

Optical properties of aerosol particles are key input parameters in radiative forcing models. Optical properties are often measured at limited wavelength bands; then approximate models or interpolations are used to estimate the aerosol optical properties over the entire solar spectrum. Optical properties models calculate absorption enhancement by assuming core-shell morphology for the internally mixed soot particles. Some radiative models directly assume a constant absorption enhancement factor of $\sim 1.5$. These assumptions contribute to large uncertainties associated with the radiative forcing estimates (Bond, Doherty et al. 2013, Myhre, Shindell et al. 2013). Filter-based instruments are till date the most commonly used for the measurement of aerosol absorption. These instruments measure aerosol absorption by depositing aerosol on a filter. Due to the deposition on the filter, the measurement from filter-based instruments have artifacts and uncertainties that can be quite large depending on the atmospheric conditions at the time of the measurement (Subramanian, Roden et al. 2007, Lack, Cappa et al. 2008). Modeled and measured soot optical properties may also include uncertainties due to the complicated soot morphology (non-sphericity) and its variability during atmospheric processing. These uncertainties are also propagated to the radiative forcing estimates (Bond, Doherty et al. 2013, Myhre, Shindell et al. 2013, Stocker, Qin et al. 2013).

The research performed during my $\mathrm{PhD}$ work and discussed in this dissertation contributes to the improvement of future forcing estimates by:

(a) Providing a new instrument with improved performances for measuring the optical properties of absorbing aerosols. The new instrument developed during this thesis work, 
overcomes biases that affect more traditional methods and that arise also from variations in soot morphology and mixing states.

(b) Identifying and characterizing soot morphology and mixing states in a forested environment and highlighting the role of the physical properties of secondary organic aerosol in the evolution of soot mixing states.

(c) Presenting evidences of links between environmental factors like relative humidity with soot morphology and mixing states during mixing process involving soot and secondary organic aerosols.

The dissertation is organized into five chapters, including this introduction (chapter 1) and a concluding chapter providing a summary of the results, the main implications of the findings, and a brief discussion of future research directions (chapter 5).

In Chapter 2 we discuss the development of a new instrument for the measurement of the aerosol optical properties over a broad spectral range. The development was motivated by inherent limitations in the most common methods still commonly used to measure the aerosol absorption. These filter-based methods (e.g., the aethalometer, the multi angle absorption photometer, and the particle soot absorption photometer) measure the optical transmission through aerosol deposited on a filter, from which an estimate of the aerosol absorption is made. These instruments have been widely used over the past several decades due to their commercial availability, cost-effectiveness, simplicity, sensitivity and in some cases, capability to measure at multiple wavelengths. However, several studies have shown strong biases associated with most filter-based technique due for example to multiple scattering on the filter (Cappa, Lack et al. 2008, Lack, Cappa et al. 2008). O'Brien, Neu et al. (2014), discovered that particles with different physical properties (viscosity/surface tension) acquire different shapes when they impact on a substrate and exhibit different absorption of incident $x$-rays in STXM/NEXAFS characterization. In the filter-based instruments, changes in morphology of the particles at their impaction on the filter may affect their optical properties. This effect results in additional biases that are directly related to the particle morphology, which is the main subject of this thesis. These biases challenge the accuracy of the measurements from these instruments and require a new approach. 
Aerosol photoacoustic spectroscopy (Moosmüller, et al. 2009, Sharma, Arnold et al. 2013, Radney and Zangmeister 2015) measures the absorption by aerosols directly while they are suspended in air and it is unaffected by scattering. Therefore, photoacoustic is considered the most promising technique to measure aerosol absorption, free from the forementioned biases of the filter-based methods. Some photoacoustic instruments combine nephelometry for simultaneous scattering measurements (Abu-Rahmah, Arnott et al. 2006, Sharma, Arnold et al. 2013). Currently available commercial photoacoustic instruments are capable of measuring aerosol optical properties (absorption and scattering) for a maximum of three discrete wavelengths. Therefore, the aerosol optical properties over the remaining solar spectrum are often estimated using numerical models or interpolations, generally based on simplified assumptions, not accounting for the aerosol morphology and mixing state.

To increase the spectral range of photoacoustic-based absorption and scattering measurements, our group at Michigan Tech in collaboration with the Desert Research Institute of Reno, Nevada developed a novel multi-wavelength photoacousticnephelometer spectrometer. The instrument combines a photoacoustic and a nephelometer spectrometer with a supercontinuum laser source. This instrument is capable of simultaneous measurements of aerosol absorption and scattering from $\sim 400 \mathrm{~nm}$ to $\sim 700$ $\mathrm{nm}$ in 5 consecutive spectral bands. This instrument was used to investigate the spectral dependence of absorption and scattering by freshly generated soot and salt aerosol. Details of the instrument design, calibration scheme and results from initial tests are discussed in chapter 2. This work was published in the journal or Atmospheric Chemistry and Physics in 2013 (Sharma et al. 2013).

In chapter 3 and chapter 4 of this dissertation we discuss the morphological and mixing state characterization of single black carbon particles internally mixed with biogenically generated organic aerosols. The optical properties of soot crucially depends upon its morphology and mixing state. Over previous years scientists used a few online singleparticle instruments like the Single Particle Soot Photometer (SP2) in combination with the Single Particle Mass Spectrometer (SP-MS) (Sedlacek, Lewis et al. 2012) and the Single 
Particle Laser Ablation Time of Flight Mass Spectrometer (SPLAT) (Zelenyuk, Yang et al. 2008, Zelenyuk, Yang et al. 2009) to obtain information about soot mixing state in real time on a single particle bases. These real-time techniques in some cases, have been complemented by offline analyses such as electron microscopy (SEM and TEM) (Adachi and Buseck 2008, Adachi and Buseck 2013, China, Mazzoleni et al. 2013, Adachi, Zaizen et al. 2014, Buseck, Adachi et al. 2014, China, Salvadori et al. 2014, China, Scarnato et al. 2015) and micro-spectroscopy performed on aerosol samples collected on various substrates (STXM and NEXAFS) (Moffet, Henn et al. 2010, Moffet 2011). These microscopy techniques provide highly detailed images of the position and composition of various components mixed into a single particle.

Chapter 3 is based on the electron microscopy analysis of ambient samples collected during the Carbonaceous Aerosols and Radiative Effects Study (CARES), a campaign supported by the US Department of Energy and conducted in June 2010 in the Sacramento area, in California. During CARES, measurements and sample collection were carried out at two sites, one in the urban area of Sacramento, CA and another in Cool, CA located in the foothills of the Sierra Nevada mountains, about 40 miles East of Sacramento. The Cool site was located in a forested area and therefore it was dominated by biogenic emissions, which undergo photochemical oxidation to form biogenic secondary organic aerosols (SOA). Frequently, but not always, urban plumes from Sacramento were transported to Cool and were mixed with the biogenic SOA. In this study, we discuss the evolution of morphology and mixing state of soot particles due to their coagulation with the biogenic SOA or condensation of vapor phase SOA precursor. Soot and SOA particles collected from the forested site during CARES were investigated using a Field Emission Scanning Electron Microscopy (FE-SEM). Several studies have shown the existence of SOA with highly variable viscosities depending upon different environmental factors such as the relative humidity (Virtanen, Joutsensaari et al. 2010, Renbaum-Wolff, Grayson et al. 2013). The viscosity of the SOA material influences the growth of SOA particles (Riipinen, Pierce et al. 2011, Perraud, Bruns et al. 2012). In our study, we used the technique used by O'Brien, Neu et al. (2014) to relate the viscosity of SOA particles with the shape they take at impaction on the substrate. One of the important findings from our study is the 
importance of the viscosity of SOA in governing the mixing state of soot particles. We find that while the collision of soot with solid/nearly solid particles does not result in coagulation, collision of soot with very low viscosity SOA possibly results into coated soot particles. However, collision of soot with an SOA of intermediate viscosity results into the formation of surface attached/ partially encapsulated soot, in which a part of the soot particle sticks to or partially penetrates into the SOA particle. Surface attached/partially encapsulated particles are often treated as coated particles in numerical models, overestimating the absorption enhancement due to the "lensing" effect (Adachi and Buseck 2013). Therefore, the fraction of partially encapsulated particles in a given environment needs to be quantified and treated separately from coated particles in radiative forcing models. The work presented in chapter 3 constitute the main body of a manuscript in preparation that I expect to submit for publication to Geophysical Research Letters by spring of 2016.

A series of chamber experiments were conducted at the Pacific Northwest National Laboratory in Nov-2013 and Jan-2014 during the Soot Aerosol Aging Study. The aim of the study was to simulate the ambient mixing scenarios observed during CARES but in controlled laboratory conditions. This is the subject of chapter 4 of this dissertation. During the study, separate experiments were carried out focusing on condensation or coagulation processes of soot-SOA mixing. In chapter 4 we focus on the mixing of soot with secondary organic aerosol through condensation. In particular, we discuss the effect of relative humidity on the morphology of soot and on the condensation of secondary organic aerosol on soot seeds. Our key findings include the retarded growth of SOA on soot particles in humid conditions, in contrast to the continuous growth of SOA on soot in dry conditions. In humid conditions $(80 \% \mathrm{RH})$, we observed the restructuring of soot particles from lacey to more compact structures, as observed in several previous studies Weingartner, Baltensperger et al. (1995), Zhang, Khalizov et al. (2008), Popovicheva, Persiantseva et al. (2008), Koehler, DeMott et al. (2009), Mikhailov, Vlasenko et al. (2009), Miljevic, Surawski et al. (2012), Ma, Zangmeister et al. (2013), China, Scarnato et al. (2015). The retarded growth of SOA on soot in humid conditions may be attributed to the compaction of soot leading to a significant decrease in free surface area available for the condensation 
of SOA. In dry conditions, no significant compaction was observed and more SOA condensed on the soot particles. The material presented in chapter 4 is being assembled into a manuscript in advanced stage of preparation and that we plan to submit to the journal of Environmental Science and Technology by spring of 2016. 


\section{References}

1. Abu-Rahmah, A., W. P. Arnott and H. Moosmüller (2006). "Integrating nephelometer with a low truncation angle and an extended calibration scheme." Measurement Science and Technology 17(7): 1723.

2. Adachi, K. and P. Buseck (2008). "Internally mixed soot, sulfates, and organic matter in aerosol particles from Mexico City." Atmospheric Chemistry and Physics 8(21): 6469-6481.

3. Adachi, K. and P. R. Buseck (2013). "Changes of ns-soot mixing states and shapes in an urban area during CalNex." Journal of Geophysical Research: Atmospheres.

4. Adachi, K., Y. Zaizen, M. Kajino and Y. Igarashi (2014). "Mixing state of regionally transported soot particles and the coating effect on their size and shape at a mountain site in Japan." Journal of Geophysical Research: Atmospheres.

5. Bond, T. C. and R. W. Bergstrom (2006). "Light absorption by carbonaceous particles: An investigative review." Aerosol Science and Technology 40(1): 27-67.

6. Bond, T. C., S. J. Doherty, D. Fahey, P. Forster, T. Berntsen, B. DeAngelo, M. Flanner, S. Ghan, B. Kärcher and D. Koch (2013). "Bounding the role of black carbon in the climate system: A scientific assessment." Journal of Geophysical Research: Atmospheres 118(11): 5380-5552.

7. Bond, T. C., G. Habib and R. W. Bergstrom (2006). "Limitations in the enhancement of visible light absorption due to mixing state." Journal of Geophysical Research: Atmospheres (1984-2012) 111(D20).

8. Buseck, P. R., K. Adachi, A. Gelencsér, É. Tompa and M. Pósfai (2014). "Ns-Soot: A Material-Based Term for Strongly Light-Absorbing Carbonaceous Particles." Aerosol Science and Technology 48(7).

9. Cappa, C. D., D. A. Lack, J. B. Burkholder and A. Ravishankara (2008). "Bias in filter-based aerosol light absorption measurements due to organic aerosol loading: 
Evidence from laboratory measurements." Aerosol Science and Technology 42(12): 1022-1032.

10. Cappa, C. D., T. B. Onasch, P. Massoli, D. R. Worsnop, T. S. Bates, E. S. Cross, P. Davidovits, J. Hakala, K. L. Hayden and B. T. Jobson (2012). "Radiative absorption enhancements due to the mixing state of atmospheric black carbon." Science 337(6098): 1078-1081.

11. China, S., C. Mazzoleni, K. Gorkowski, A. C. Aiken and M. K. Dubey (2013). "Morphology and mixing state of individual freshly emitted wildfire carbonaceous particles." Nature communications 4.

12. China, S., N. Salvadori and C. Mazzoleni (2014). "Effect of Traffic and Driving Characteristics on Morphology of Atmospheric Soot Particles at Freeway OnRamps." Environmental science \& technology 48(6): 3128-3135.

13. China, S., B. Scarnato, R. C. Owen, B. Zhang, M. T. Ampadu, S. Kumar, K. Dzepina, M. P. Dziobak, P. Fialho and J. A. Perlinger (2015). "Morphology and mixing state of aged soot particles at a remote marine free troposphere site: Implications for optical properties." Geophysical Research Letters 42(4): 12431250.

14. Fuller, K. A., W. C. Malm and S. M. Kreidenweis (1999). "Effects of mixing on extinction by carbonaceous particles." Journal of Geophysical Research: Atmospheres (1984-2012) 104(D13): 15941-15954.

15. Jacobson, M. Z. (2000). "A physically-based treatment of elemental carbon optics: Implications for global direct forcing of aerosols." Geophysical Research Letters 27(2): 217-220.

16. Jacobson, M. Z. (2001). "Strong radiative heating due to the mixing state of black carbon in atmospheric aerosols." Nature 409(6821): 695-697.

17. Jacobson, M. Z. (2002). "Control of fossil-fuel particulate black carbon and organic matter, possibly the most effective method of slowing global warming." Journal of 
Geophysical Research: Atmospheres (1984-2012) 107(D19): ACH 16-11-ACH $16-22$.

18. Koehler, K. A., P. J. DeMott, S. M. Kreidenweis, O. B. Popovicheva, M. D. Petters, C. M. Carrico, E. D. Kireeva, T. D. Khokhlova and N. K. Shonija (2009). "Cloud condensation nuclei and ice nucleation activity of hydrophobic and hydrophilic soot particles." Physical chemistry chemical physics 11(36): 7906-7920.

19. Lack, D. and C. Cappa (2010). "Impact of brown and clear carbon on light absorption enhancement, single scatter albedo and absorption wavelength dependence of black carbon." Atmos. Chem. Phys 10: 4207-4220.

20. Lack, D. and C. Cappa (2010). "Impact of brown and clear carbon on light absorption enhancement, single scatter albedo and absorption wavelength dependence of black carbon." Atmospheric Chemistry and Physics 10(9): 42074220.

21. Lack, D. A., C. D. Cappa, D. S. Covert, T. Baynard, P. Massoli, B. Sierau, T. S. Bates, P. K. Quinn, E. R. Lovejoy and A. Ravishankara (2008). "Bias in filter-based aerosol light absorption measurements due to organic aerosol loading: Evidence from ambient measurements." Aerosol Science and Technology 42(12): 10331041.

22. Liu, S., A. C. Aiken, K. Gorkowski, M. K. Dubey, C. D. Cappa, L. R. Williams, S. C. Herndon, P. Massoli, E. C. Fortner, P. S. Chhabra, W. A. Brooks, T. B. Onasch, J. T. Jayne, D. R. Worsnop, S. China, N. Sharma, C. Mazzoleni, L. Xu, N. L. Ng, D. Liu, J. D. Allan, J. D. Lee, Z. L. Fleming, C. Mohr, P. Zotter, S. Szidat and A. S. H. Prevot (2015). "Enhanced light absorption by mixed source black and brown carbon particles in UK winter." Nat Commun 6.

23. Ma, X., C. D. Zangmeister, J. Gigault, G. W. Mulholland and M. R. Zachariah (2013). "Soot aggregate restructuring during water processing." Journal of Aerosol Science 66(0): 209-219. 
24. Mikhailov, E., S. Vlasenko, S. Martin, T. Koop and U. Pöschl (2009). "Amorphous and crystalline aerosol particles interacting with water vapor: conceptual framework and experimental evidence for restructuring, phase transitions and kinetic limitations." Atmospheric Chemistry and Physics 9(24): 9491-9522.

25. Miljevic, B., N. C. Surawski, T. Bostrom and Z. D. Ristovski (2012). "Restructuring of carbonaceous particles upon exposure to organic and water vapours." Journal of Aerosol Science 47: 48-57.

26. Moffet, R. C. (2011). "Scanning transmission X-ray microscopy: Applications in atmospheric aerosol research." Lawrence Berkeley National Laboratory.

27. Moffet, R. C., T. R. Henn, A. V. Tivanski, R. J. Hopkins, Y. Desyaterik, A. Kilcoyne, T. Tyliszczak, J. Fast, J. Barnard and V. Shutthanandan (2010). "Microscopic characterization of carbonaceous aerosol particle aging in the outflow from Mexico City." Atmospheric Chemistry and Physics 10(3): 961-976.

28. Moosmüller, H. , R. K. Chakrabarty and W. P. Arnott (2009). "Aerosol light absorption and its measurement: A review." Journal of Quantitative Spectroscopy \& Radiative Transfer 110(11): 844-878.

29. Myhre, G., D. Shindell, F. Bréon, W. Collins, J. Fuglestvedt, J. Huang, D. Koch, J. Lamarque, D. Lee and B. Mendoza (2013). "Anthropogenic and natural radiative forcing, Chapter 8 in Climate Change 2013: The Physical Science Basis. Contribution of Working Group I to the Fifth Assessment Report of the Intergovernmental Panel on Climate Change, edited by Stocker, TF, D. Qin, G." K. Plattner, M. Tignor, SK Allen, J. Boschung, A. Nauels, Y. Xia, V. Bex and PM Midgley, Cambridge University Press, Cambridge, UK and New York, NY.

30. O'Brien, R. E., A. Neu, S. A. Epstein, A. C. MacMillan, B. Wang, S. T. Kelly, S. A. Nizkorodov, A. Laskin, R. C. Moffet and M. K. Gilles (2014). "Physical properties of ambient and laboratory-generated secondary organic aerosol." Geophysical Research Letters 41(12): 4347-4353. 
31. Perraud, V., E. A. Bruns, M. J. Ezell, S. N. Johnson, Y. Yu, M. L. Alexander, A. Zelenyuk, D. Imre, W. L. Chang and D. Dabdub (2012). "Nonequilibrium atmospheric secondary organic aerosol formation and growth." Proceedings of the National Academy of Sciences 109(8): 2836-2841.

32. Popovicheva, O., N. Persiantseva, V. Tishkova, N. Shonija and N. Zubareva (2008). "Quantification of water uptake by soot particles." Environmental Research Letters 3(2): 025009.

33. Popovicheva, O., N. M. Persiantseva, N. K. Shonija, P. DeMott, K. Koehler, M. Petters, S. Kreidenweis, V. Tishkova, B. Demirdjian and J. Suzanne (2008). "Water interaction with hydrophobic and hydrophilic soot particles." Physical Chemistry Chemical Physics 10(17): 2332-2344.

34. Pósfai, M., R. Simonics, J. Li, P. V. Hobbs and P. R. Buseck (2003). "Individual aerosol particles from biomass burning in southern Africa: 1. Compositions and size distributions of carbonaceous particles." Journal of Geophysical Research: Atmospheres (1984-2012) 108(D13).

35. Radney, J. G. and C. D. Zangmeister (2015). "Measurement of Gas and Aerosol Phase Absorption Spectra across the Visible and Near-IR Using Supercontinuum Photoacoustic Spectroscopy." Analytical chemistry 87(14): 7356-7363.

36. Renbaum-Wolff, L., J. W. Grayson, A. P. Bateman, M. Kuwata, M. Sellier, B. J. Murray, J. E. Shilling, S. T. Martin and A. K. Bertram (2013). "Viscosity of $\alpha$ pinene secondary organic material and implications for particle growth and reactivity." Proceedings of the National Academy of Sciences 110(20): 8014-8019.

37. Riipinen, I., J. Pierce, T. Yli-Juuti, T. Nieminen, S. Häkkinen, M. Ehn, H. Junninen, K. Lehtipalo, T. Petäjä and J. Slowik (2011). "Organic condensation: a vital link connecting aerosol formation to cloud condensation nuclei $(\mathrm{CCN})$ concentrations." Atmos. Chem. Phys 11(8): 3865-3878.

38. Schwarz, J., J. Spackman, D. Fahey, R. Gao, U. Lohmann, P. Stier, L. Watts, D. Thomson, D. Lack and L. Pfister (2008). "Coatings and their enhancement of black 
carbon light absorption in the tropical atmosphere." Journal of Geophysical Research: Atmospheres (1984-2012) 113(D3).

39. Sedlacek, A. J., E. R. Lewis, L. Kleinman, J. Xu and Q. Zhang (2012). "Determination of and evidence for non-core-shell structure of particles containing black carbon using the Single-Particle Soot Photometer (SP2)." Geophysical Research Letters 39(6).

40. Sharma, N., I. Arnold, H. Moosmüller, W. Arnott and C. Mazzoleni (2013). "Photoacoustic and nephelometric spectroscopy of aerosol optical properties with a supercontinuum light source." Atmospheric Measurement Techniques Discussions 6(4).

41. Slowik, J. G., K. Stainken, P. Davidovits, L. Williams, J. Jayne, C. Kolb, D. R. Worsnop, Y. Rudich, P. F. DeCarlo and J. L. Jimenez (2004). "Particle morphology and density characterization by combined mobility and aerodynamic diameter measurements. Part 2: Application to combustion-generated soot aerosols as a function of fuel equivalence ratio." Aerosol Science and Technology 38(12): 12061222.

42. Stocker, T. F., D. Qin, G.-K. Plattner, M. Tignor, S. K. Allen, J. Boschung, A. Nauels, Y. Xia, V. Bex and P. M. Midgley (2013). Climate Change 2013. The Physical Science Basis. Working Group I Contribution to the Fifth Assessment Report of the Intergovernmental Panel on Climate Change-Abstract for decisionmakers, Groupe d'experts intergouvernemental sur l'evolution du climat/Intergovernmental Panel on Climate Change-IPCC, C/O World Meteorological Organization, 7bis Avenue de la Paix, CP 2300 CH-1211 Geneva 2 (Switzerland).

43. Subramanian, R., C. A. Roden, P. Boparai and T. C. Bond (2007). "Yellow beads and missing particles: Trouble ahead for filter-based absorption measurements." Aerosol Science and Technology 41(6): 630-637. 
44. Virtanen, A., J. Joutsensaari, T. Koop, J. Kannosto, P. Yli-Pirilä, J. Leskinen, J. M. Mäkelä, J. K. Holopainen, U. Pöschl and M. Kulmala (2010). "An amorphous solid state of biogenic secondary organic aerosol particles." Nature 467(7317): 824-827.

45. Weingartner, E., U. Baltensperger and H. Burtscher (1995). "Growth and Structural Change of Combustion Aerosols at High Relative Humidity." Environmental Science \& Technology 29(12): 2982-2986.

46. Zelenyuk, A., J. Yang, E. Choi and D. Imre (2009). "SPLAT II: An aircraft compatible, ultra-sensitive, high precision instrument for in-situ characterization of the size and composition of fine and ultrafine particles." Aerosol Science and Technology 43(5): 411-424.

47. Zelenyuk, A., J. Yang, C. Song, R. A. Zaveri and D. Imre (2008). "“Depthprofiling" and quantitative characterization of the size, composition, shape, density, and morphology of fine particles with splat, a single-particle mass spectrometer." The Journal of Physical Chemistry A 112(4): 669-677.

48. Zhang, R., A. F. Khalizov, J. Pagels, D. Zhang, H. Xue and P. H. McMurry (2008). "Variability in morphology, hygroscopicity, and optical properties of soot aerosols during atmospheric processing." Proceedings of the National Academy of Sciences 105(30): 10291-10296. 


\section{Photoacoustic and Nephelometric Spectroscopy of Aerosol Optical Properties with a Supercontinuum Light Source ${ }^{2}$}

\subsection{Abstract}

A novel multi-wavelength photoacoustic-nephelometer spectrometer (SC-PNS) has been developed for the optical characterization of atmospheric aerosol particles. This instrument integrates a white light supercontinuum laser with photoacoustic and nephelometric spectroscopy to measure aerosol absorption and scattering coefficients at five wavelength bands (centered at 417, 475, 542, 607, and $675 \mathrm{~nm}$ ). These wavelength bands were selected from the continuous spectrum of the laser (ranging from 400-2200 $\mathrm{nm}$ ) using a set of optical interference filters. Absorption and scattering measurements on laboratory-generated aerosol samples were performed sequentially at each wavelength band.

To test the instrument we measured the wavelength dependence of absorption and scattering coefficients of kerosene soot and common salt aerosols. Results were favorably compared to those obtained with a commercial 3-wavelength photoacoustic and nephelometer instrument demonstrating the utility of the SC light source for studies of aerosol optical properties at selected wavelengths. Here, we discuss instrument design, development, calibration, performance and experimental results.

\subsection{Introduction}

${ }^{2}$ Sharma, N., Arnold, I. J., Moosmüller, H., Arnott, W. P., and Mazzoleni, C.: Photoacoustic and nephelometric spectroscopy of aerosol optical properties with a supercontinuum light source, Atmos. Meas. Tech., 6, 3501-3513, doi:10.5194/amt-6-3501-2013, 2013.

All articles published by Copernicus Publications are licensed under the Creative Commons Attribution 3.0 License (see details above) together with an author copyright. Therefore, there is no need from the publisher's side to give permission for the reproduction of articles. We suggest contacting the author to inform him/her about the further usage of the material. However, as the author decided to publish the scientific results under the CC-BY licence, he/she consented to share the work under the condition that the original authors be given credit. 
Atmospheric aerosols are major players in determining the Earth's radiation budget (Horvath, 1993). Different particles have different absorption and scattering spectra. For example, soot particles absorb solar radiation over a broad wavelength range from the ultraviolet to the infrared; in contrast, most organic particles absorb weakly in the visible, while brown carbon particles absorbs mostly in the UV-blue part of the solar spectrum (Chen and Bond, 2010). Mineral dust particles also exhibit characteristic scattering and absorption spectra depending on their composition (e.g.; amount of iron oxides (Moosmüller et al., 2012)), size, and morphology. The absorption of solar radiation by these particles contributes to the heating of the surroundings atmosphere, while cooling the Earth's surface, thereby affecting convective processes and cloud properties and lifecycle. Some particles including most organics, sulphates, and salts, scatter solar radiation efficiently without absorption, hence cooling the atmosphere (Chýlek et al., 1995) and reducing atmospheric visibility (Tang et al., 1981; Moosmüller et al., 2009a). These different aerosol species are released or formed into the atmosphere as a result of anthropogenic, biogenic, and other natural processes (like wind-driven dust entrainment) and significantly affect climate by means of their direct and indirect radiative forcing (Parry et al., 2007).

The efficiency of aerosols to absorb and scatter solar radiation depends upon particle characteristics like size, morphology, and refractive index. Therefore, aerosol absorption and scattering coefficients exhibit distinct wavelength dependencies. A number of experimental studies have been conducted to investigate the wavelength dependence of scattering and absorption of atmospheric aerosol exhibiting complex mixing of different components (e.g.; (Gyawali et al., 2012; Flowers et al., 2010; Gyawali et al., 2013; Bergstrom et al., 2007)). Several controlled laboratory studies have also been performed, generating aerosols including soot, salt, and biomass burning particles and controlling or studying in detail the mixing state of different components (e.g.; (Sheridan et al., 2005; Lewis et al., 2008; Cross et al., 2010)). Absorbing carbonaceous aerosols are termed light absorbing carbon and include soot and brown carbon (Bond and Bergstrom, 2006; Andreae and Gelencsér, 2006). An inverse dependence of the absorption coefficient on wavelength $\lambda$ (i.e., $\lambda^{-1}$ ) has typically been observed for absorption by small soot particles (e.g.; 
(Bergstrom et al., 2002)). In general, over a limited wavelength range, the absorption coefficient is approximately proportional to $\lambda^{-b}$. While for small soot particle $b \sim 1$, for brown carbon particles that can be generated for example from smoldering biomass burning, the value of the exponent $b$ is wavelength dependent and is typically significantly greater than 1 for shorter visible and UV wavelengths leading to much enhanced absorption in the blue part of the solar spectrum (e.g. (Sun et al., 2007; Lewis et al., 2008; Lack et al., 2012; Ramanathan et al., 2005). Salts, such as $\mathrm{NaCl}$ and $\left(\mathrm{NH}_{4}\right)_{2} \mathrm{SO}_{4}$, are non-absorbing in the visible and contribute to light extinction mostly by scattering the incident radiation (Abu-Rahmah et al., 2006; Irshad et al., 2009; Chamaillard et al., 2003; Schnaiter et al., 2006).

Measurement of the wavelength dependence of aerosol optical properties has been a challenging task, due to the dependence of optical properties on highly variable parameters such as mixing, morphology, composition, and size, and due to the inhomogeneous distribution of aerosols in the atmosphere. Integrating nephelometry is the most common technique for measuring in-situ aerosol scattering coefficients (Heintzenberg and Charlson, 1996; Abu-Rahmah et al., 2006). The two most common types of nephelometers are: a) direct integrating nephelometer and b) reciprocal integrating nephelometer (Marcos, 1999). A number of in-situ measurement techniques for the quantification of light absorption by aerosols have been available for years. The photoacoustic technique is currently gaining recognition due to its higher accuracy with respect to filter-based instruments and due to the availability of commercial instruments (Moosmüller et al., 2009b; Lack et al., 2008). Several photoacoustic instrument designs have been developed by different groups for applications in the field of atmospheric measurements. Modern photoacoustic instruments typically exploit the high brightness and directionality of laser sources; however, these sources are generally monochromatic.

The commercially available photoacoustic spectrometer (PASS-3, by DMT Inc.), has evolved from its prototype single wavelength photoacoustic spectrometer (Arnott et al., 1999) and the dual wavelength photoacoustic spectrometer (Lewis et al., 2008) to the 3wavelength instrument at $405 \mathrm{~nm}, 532 \mathrm{~nm}$ and $781 \mathrm{~nm}$, each wavelength being generated 
by an individual laser. These instruments also simultaneously measure aerosol scattering by reciprocal nephelometric technique. From the simultaneous measurement of the extensive absorption and scattering coefficients, one can obtain the aerosol single scattering albedo (SSA), which is the ratio of the scattering to the extinction coefficients. The SSA is an intensive quantity and is one of the fundamental parameters needed to calculate the aerosol radiative forcing (e.g.; (Chylek and Wong, 1995)). The simultaneous measurement of absorption and scattering coefficients with these instruments allows obtaining additional information from the same aerosol sample, in contrast to instruments which provide only an estimate of absorption, such as the aethalometer, the Particle Soot/Absorption Photometer (PSAP), and the Multi-Angle Absorption Photometer (MAAP)).

A photoacoustic instrument discussed in Lack et al. (2006) uses a multi-pass cell to increase sensitivity at a single wavelength $(532 \mathrm{~nm})$. The latest multi-wavelength development of this instrument operates at three wavelengths: 404, 532, and $658 \mathrm{~nm}$. Another multi-wavelength photoacoustic instrument developed by Ajtai et al. (Ajtai et al., 2010) at the University of Szeged, Hungary measures the aerosol absorption simultaneously at four different wavelengths $(266,355,532$, and $1064 \mathrm{~nm})$ by using a single laser source and higher harmonics generation. In a recent development, a tunable narrow linewidth Optical Parametrical Oscillator (OPO) has been combined with a photoacoustic cell for the sequential measurement of aerosol absorption coefficients over a wide spectral range (Haisch et al., 2012).

The main motivation behind the development of new instrumentation with increasing number of operating wavelengths is the role that wavelength dependencies of aerosol absorption and scattering have on radiative forcing and climate. The use of a broadband laser source is an alternative to high power tunable lasers (such as the OPO) or the increased number of single wavelength sources in current photoacoustic spectrometers (as in the PASS-3). Supercontinuum, white light lasers are currently gaining great interest in biomedical applications, optical communications, as well as in fundamental spectroscopy due to their broad spectral bandwidth, high power, high stability, and relatively flat 
spectrum. Although supercontinuum generation has its roots in the pioneering work by Alfano and Shapiro in the early 1970's (Alfano and Shapiro, 1970), compact and robust supercontinuum lasers have become commercially available only in the last decade. Typically in these table-top systems, the supercontinuum generation is based on the spectral broadening of ultrashort laser pulses in photonic crystal fibers due to their high optical nonlinearity (Russell, 2003; Knight, 2003; Ranka et al., 2000; Dudley et al., 2006).

We present here the development of a new instrument that combines a supercontinuum light source with a photoacoustic-nephelometer spectrometer (SC-PNS) for the simultaneous measurement of the scattering and absorption coefficients of an aerosol sample at a given wavelength band. First, we describe the prototype development and its calibration, and then we discuss some preliminary tests performed with different laboratory-generated aerosols followed by a discussion on the performance of the instrument. The broad spectrum of the supercontinuum source that covers almost the entire tropospheric solar spectrum, currently enables us to characterize the aerosols at five wavelength bands in the visible, and future work will expand this capability to the nearinfrared (NIR).

\subsection{Instrument description}

In Fig. 1, we show the schematic of the multi-wavelength photoacoustic-nephelometer spectrometer discussed here. The instrument uses a supercontinuum laser as a broadband light source combined with photoacoustic and nephelometery cells which allows measuring scattering and absorption of aerosol particles over a broad wavelength range.

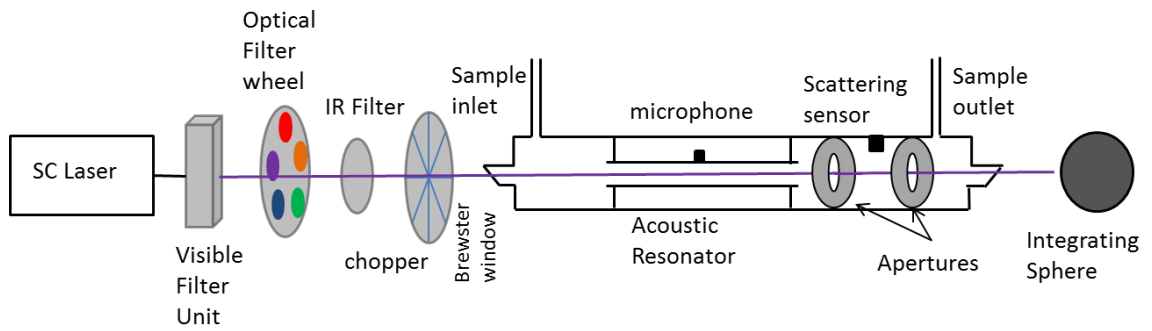

Figure 2-1 Schematics of the supercontinuum integrated photoacoustic-nephelometer spectrometer 
The supercontinuum Laser SC400 (Fianium Inc.) used in our study has a core pumped Yb-doped fiber as a master oscillator and uses a passive mode locking technique that enables the emission of short laser pulses $(<10 \mathrm{ps})$ with a high pulse repetition rate (20 $\mathrm{MHz}$ ). The radiation from the master oscillator is amplified using a polarizationmaintaining double-clad Yb-doped fiber, pumped by a high power laser diode. The high peak power pulses emitted by the amplifier enter then a highly non-linear photonic crystal fiber that causes large spectral broadening resulting in supercontinuum emission starting at a wavelength of $\sim 400 \mathrm{~nm}$, peaking around 1200-1300 nm, and extending beyond 2200 $\mathrm{nm}$. A detailed discussion of the process of supercontinuum generation in non-linear $\mathrm{Yb}$ doped double-clad fibers can be found in Roy et al. (2007). The beam exiting the fiber is collimated with a lens-based collimator. The spectrum of the collimated laser beam has been obtained with a Fieldspec 3 Portable Spectroradiometer (ASD Inc.) and is shown in Fig. 2.

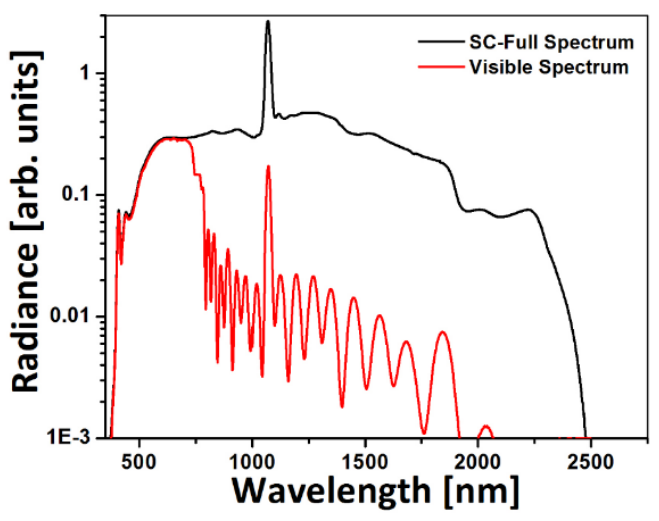

Figure 2-2 Supercontinuum full spectrum and spectrum with visible filter unit

In the SC-PNS, the collimated beam from the supercontinuum laser is passed through a combination of optical filters used to select the wavelength bands of interest. First, the visible part of the supercontinuum spectrum is selected by using a visible light bandpass filter unit. This filter unit consists of two dichroic mirrors placed diagonally and opposite to each other. These dichroic mirrors reflect the visible wavelengths, which exit the filter unit as a visible white light beam. The NIR wavelengths are transmitted through the dichroic mirrors and are dissipated. Figure 2 also shows the spectrum of the beam filtered 
by the visible light filter with a logarithmic radiance axis. Notice the peak at $1064 \mathrm{~nm}$ corresponding to the residual of the fundamental emission from the master source.

The selection of different wavelength bands is achieved by using a series of singlebandpass filters (BrightLine filters by Semrock) mounted on a filterwheel (Edmund Optics) which can be rotated manually by the operator. During the instrument calibration, the total measurement time on each filter was five to six minutes while during the experiments, it was three to four minutes, after which the filter wheel was rotated to select a different wavelength band. Aerosols do not exhibit sharp spectral features; therefore, the bandpass width of each filter was chosen as a tradeoff between the need for modest spectral resolution and significant laser power (the photoacoustic signal is directly proportional to the laser power, see Eq. (1)). The filter center wavelengths were chosen to cover most of the visible spectrum available from the supercontinuum source. The optical specifications of the single-band bandpass filters are listed in Table 1.

Table 2-1: Optical specifications of single-band bandpass filters used in the supercontinuum integrated photoacoustic-nephelometer spectrometer.

\begin{tabular}{|c|c|c|c|c|c|}
\hline $\begin{array}{c}\text { Filter } \\
\text { Identifier }\end{array}$ & $\begin{array}{c}\text { Center } \\
\text { Wavelength } \\
{[\mathrm{nm}]}\end{array}$ & $\begin{array}{c}\text { Transmission } \\
\text { Band } \\
{[\mathrm{nm}]}\end{array}$ & $\begin{array}{c}\text { FWHM } \\
\text { Bandwidth } \\
{[\mathrm{nm}]}\end{array}$ & $\begin{array}{c}\text { Average } \\
\text { Transmittance } \\
{[\%]}\end{array}$ & $\begin{array}{c}\text { Resulting } \\
\text { Laser } \\
\text { Power } \\
{[\mathrm{mW}]}\end{array}$ \\
\hline F1 & 417 & $387-447$ & 64.2 & $>90$ & 15.6 \\
\hline F2 & 475 & $450-500$ & 56.4 & $>90$ & 26.5 \\
\hline F3 & 542 & $517-567$ & 56.8 & $>93$ & 45.6 \\
\hline F4 & 607 & $572-642$ & 80 & $>92$ & 86.4 \\
\hline F5 & 675 & $641.5-708.5$ & 73.7 & $>90$ & 64.4 \\
\hline
\end{tabular}

The spectrum of the beam emerging from the visible filter unit shown in Fig. 2 contains some residual NIR light beyond $800 \mathrm{~nm}$. An IR blocking filter (FGS900 Thorlabs) was used in front of the filter wheel to greatly reduce the power of this spurious NIR component. Figure 3 represents the spectra obtained for the beam filtered with the visible filter unit, the IR blocking filter, and each one of the interference filters. 


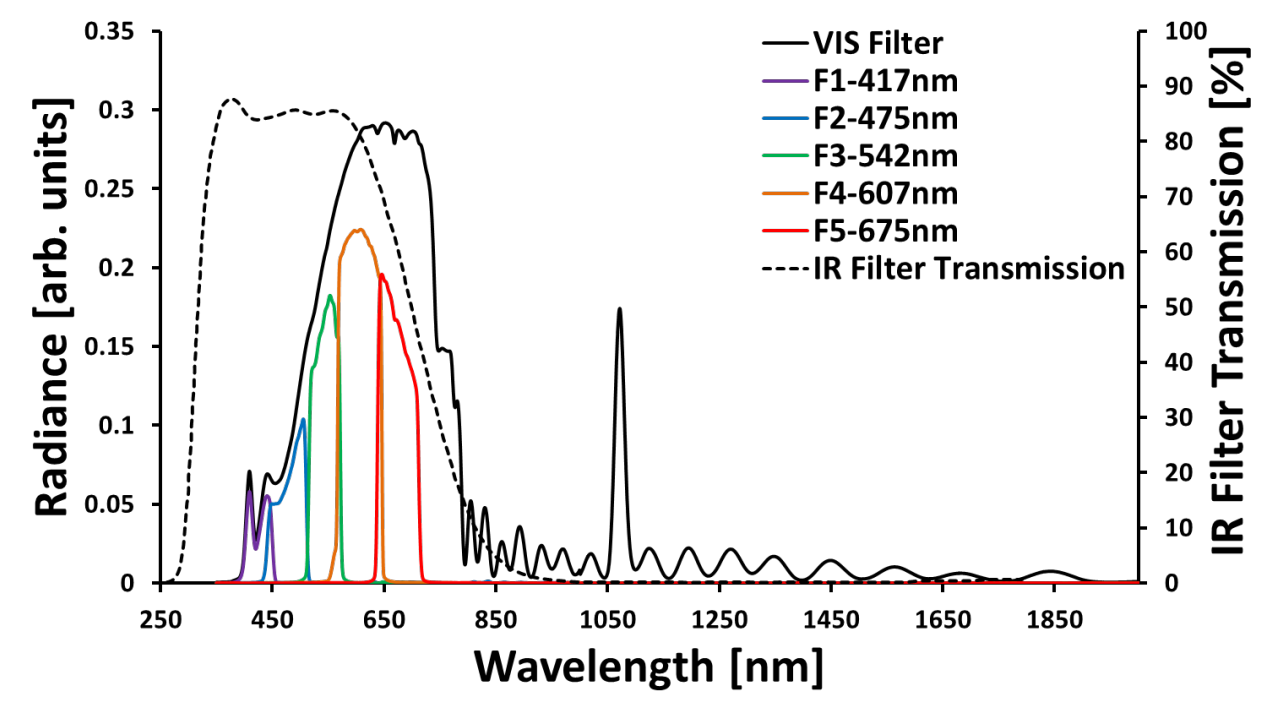

Figure 2-3 Radiance spectra from single band filters (colored lines). Longer wavelengths are filtered out by using an infrared blocking filter (dashed line represents the transmission spectrum of the IR filter on the right vertical axis)

The aerosol measurement cell unit used in our experiments consists of two cylindrical cells connected in series. The first cell is used for the measurement of absorption coefficients (photoacoustic spectrometer) and the second for the measurement of scattering coefficients (reciprocal nephelometer) (Fig. 1). Particles flow through both cells along their axis, and the laser beam propagates coaxial to the airflow. The sample flow is maintained at a rate of $\sim 0.6 \mathrm{lpm}$ by using a critical orifice and a pump. The critical orifice also acoustically isolates the photoacoustic cell from the pump.

The photoacoustic cell consists of an acoustic resonator of length $\sim 118 \mathrm{~mm}$ which is approximately equal to half of the acoustic wavelength, and diameter $6.35 \mathrm{~mm}$. The resonator is equipped with a hearing aid microphone (Knowles Inc. model\# EK 23028) to measure the acoustic signal generated in the photoacoustic process (Tam, 1986). The optical power at the filter-selected wavelength band is modulated at the resonant acoustic frequency of the cell $(\sim 1.5 \mathrm{kHz})$ by using an optical chopper (New Focus model \#3501). The modulated light enters the cell through a Brewster window. When sample particles absorb the modulated laser radiation, an acoustic signal is generated. The resonator amplifies the signal improving the signal to noise ratio. The microphone mounted in the 
resonator at the acoustic antinode detects the acoustic signal as a pressure change on its surface. The absorption coefficient of the aerosol is given by:

$$
\beta_{a b s}=\frac{P_{m}}{P_{L}} \frac{A_{r e s} \pi^{2} f_{0}}{(\gamma-1) Q}
$$

where, $P_{m}$ is the pressure at the microphone at the resonant frequency $f_{0}, P_{L}$ is the laser power; $A_{\text {res }}$ is the area of the geometric resonator cross section, $\gamma$ is the ratio of specific heat at constant pressure and volume, and $Q$ is the quality factor of the resonator (Rosencwaig, 1980; Arnott et al., 1999; Lewis et al., 2008; Moosmüller et al., 2009b) 20.9 for our cell.

The scattering cell incorporates a reciprocal integrating nephelometer design (Marcos, 1999). The cell is equipped with two apertures of $\sim 6.5 \mathrm{~mm}$ diameter, and the scattering measurements are performed in the volume between these apertures. The apertures serve to decrease background radiation and to limit the truncation angle to $\pm 5 \mathrm{deg}$. The "scattering photodiode" (ThorLabs FDS100) used to detect the scattering signal is mounted on top of the nephelometer cell between the two apertures. A Lambertian diffuser is placed in front of the photodiode to provide an integrated cosine-weighted scattering signal. The laser radiation that propagates through the photoacoustic cell without being absorbed or scattered by the aerosols and gases within the cells, is detected by a photodiode (ThorLabs FDS100, we will refer to it as the "extinction photodiode"), mounted on an integrating sphere for measuring the total optical power entering it.

A control box incorporates an HEPA filter and a solenoid switch that the operator (or a computer digital signal) can periodically turn on to let the sample flow through an HEPA filter before reaching the measurement cell; this procedure is used to measure the background signal with particles removed from the sample. The control box also contains a sensor to measure the sample air pressure. The scattering and absorption background signals are due to electronic noise, molecular Rayleigh scattering, absorption by gases like $\mathrm{NO}_{2}$ present in the sampled air, and scattering or absorption of the laser beam at the windows and walls of the cells. In our experiments, background measurements were done 
before and after every minute of sample measurement. Table 2 shows the statistics (average, standard deviation and count) for the background signals for absorption and scattering as measured at each wavelength band. All data used in the statistics, correspond to an individual measurement time of about 2-3 seconds. The background values of absorption and scattering are subtracted from the measured values to obtain the actual absorption and scattering by the aerosol particles alone. An integrated capacitive and bandgap sensor (Sensirion model\# SHT75) was used to measure relative humidity and temperature of the aerosol sample. Since the sensor is sensitive to particle contaminations, it was installed after a particle filter at the outlet of the instrument. 
Table 2-2: Statistics (average, standard deviation and count) for absorption and scattering background measurements.

\begin{tabular}{|c|c|c|c|c|c|}
\hline \multirow{2}{*}{$\begin{array}{c}\text { Filter } \\
\text { center } \\
\text { wavelength } \\
{[\mathrm{nm}]}\end{array}$} & \multicolumn{2}{|c|}{ Absorption } & \multicolumn{2}{c|}{ Scattering } & \multirow{2}{*}{$\begin{array}{c}\text { Number of } \\
\text { measurements }\end{array}$} \\
\cline { 2 - 5 } & Average & St. Dev. & Average & St. Dev. & \\
\hline 417 & 39 & 12.4 & 2264 & 345 & 1106 \\
\hline 475 & 6 & 8.0 & 2254 & 7.3 & 1061 \\
\hline 542 & 35 & 4.4 & 2134 & 6.4 & 1035 \\
\hline 607 & 80 & 3.0 & 1833 & 8.2 & 1068 \\
\hline 675 & 65 & 3.2 & 1958 & 197 & 1101 \\
\hline
\end{tabular}

Instrument data are acquired with a National Instruments data acquisition card that has 8 channels for synchronous acquisition (NI PCI-6143) and a desktop PC. The card also provides a TTL signal to drive the chopper at the reference frequency and phase. LabView software includes functions of lock-in amplifier and Fast Fourier Transform (FFT) analyzer for phase sensitive detection of the photoacoustic signal and reduction of the noise in the microphone signal (Arnott et al., 1999;Scofield, 1994;Scott et al., 2001). The FFT is also used to measure the transmitted laser and scattered power.

During some of the experiments we simultaneously operated a commercial 3wavelength photoacoustic/nephelometer spectrometer (PASS-3 by DMT Inc.) and a Scanning Mobility Particle Sizer (SMPS by TSI model\# 3080). The PASS-3 simultaneously measures the aerosol scattering and absorption at 405, 532 and $781 \mathrm{~nm}$, while our current instrument measures scattering and absorption at one wavelength at a time.

\subsection{Aerosol Generation and Delivery System}

Laboratory generated kerosene soot and nebulized salt $(\mathrm{NaCl})$ aerosols were used to calibrate and test the instrument. Soot was generated with a simple kerosene lamp sold for domestic use. Salt in aqueous solution was nebulized using an ultrasonic mist maker or an 
aerosol generator (TSI 3076). The nebulized salt solution was then dried by passing it through a dessicator (anhydrous drierite) that reduced the sample RH value to $\sim 30 \%$ before delivery to the instrument. The aerosol sample was forced through the sample line by an eductor pump which provided diluted, relatively steady aerosol concentrations.

Because our instrument operated only at one wavelength-band at a time, in order to compare the aerosol optical properties obtained at each wavelength-band, the aerosol concentration needed to vary slowly and monotonically and the size distribution needed to change as little as possible. This was achieved by using an iron lung, which is basically a steel cylindrical drum having a diameter of $64 \mathrm{~cm}$ and height of $86 \mathrm{~cm}$. It is lined with a conductive liner and has a capacity of 2771 which takes 15-20 min to be fully filled with kerosene soot (diluted with air) with a flow rate of $\sim 20 \mathrm{lpm}$ (Arnold et al., 2013). As the aerosol is drawn from the lung by the instruments, the bag gradually collapses resulting in a slow and monotonically decaying particle concentration with small variations in the size distribution. The sampling time from the lung was about 2 hours as the flow used by the instruments added up to a total of about $2 \mathrm{lpm}$. The typical absorption and scattering coefficients measured by the SC-PNS and PASS-3 at the iron lung output were in the order of 2000-3000 $\mathrm{Mm}^{-1}$. The SMPS was used for monitoring the size distribution and concentration of the aerosol sample delivered from the iron lung. The average mode number diameter (MND) and geometric standard deviation (GSD) for soot were 208 $( \pm 16)$ $\mathrm{nm}$ and $1.77( \pm 0.03) \mathrm{nm}$, respectively over a period of 2 hours and 6 minutes. For salt, the average MND and the GSD measured by SMPS were 140( \pm 7$) \mathrm{nm}$ and $1.77( \pm 0.012) \mathrm{nm}$, respectively over a period of 2 hours and 6 minutes. The number in parenthesis represents one standard deviation (Fig. 4). 

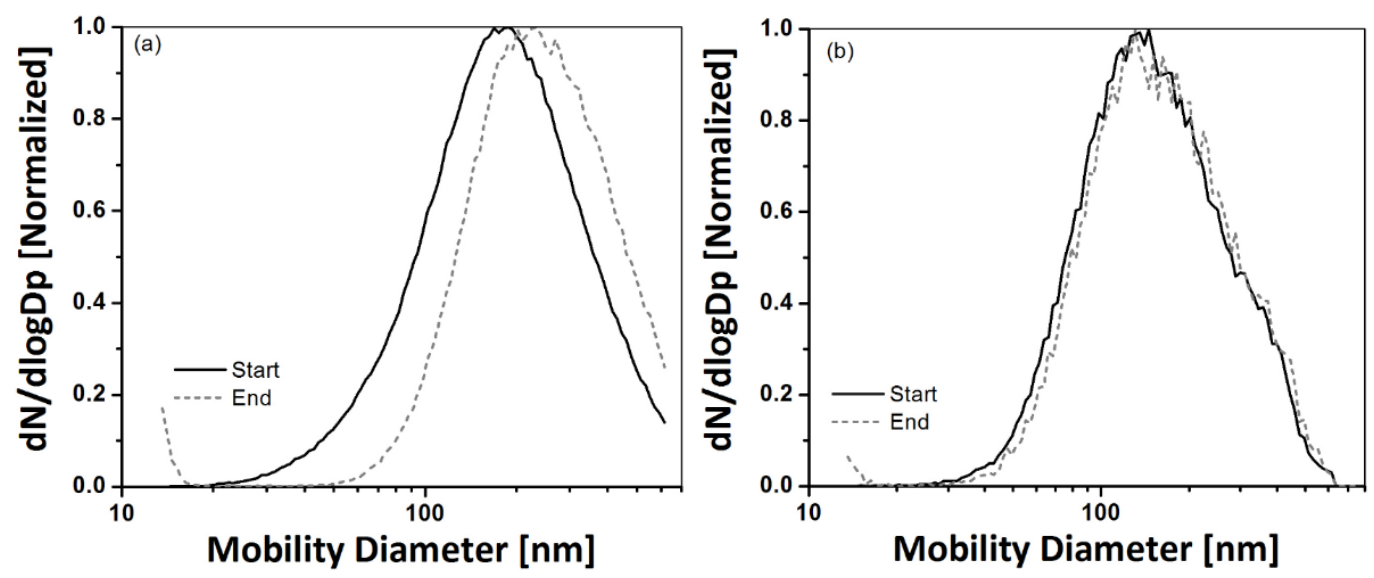

Figure 2-4 Normalized size distribution of (a) soot and (b) salt aerosols measured by an SMPS during the experiment. The black curve indicates the initial size distribution at the beginning of the experiment and the grey dashed curve indicates the size distribution toward the end of experiment.

\subsection{Instrument Calibration}

The calibration procedure of the SC-PNS involves four steps: 1) calibration of the extinction photodiode, 2) measurement of the resonance response of the acoustic cell, 3) calibration of the scattering photodiode (including the diffuser angular response), and 4) absorption calibration (calibration of the microphone response).

The extinction photodiode is calibrated by comparing the output signal of the photodiode with the power of the laser at the different wavelength bands as measured by a calibrated power meter (ThorLabs, PM100D) at the end of SC-PNS cells.

The resonance response of the acoustic cell is measured using a piezoelectric transducer by scanning its emission frequency and recording the signal at the microphone. The microphone signal is then compared to a Lorentzian resonance curve and a least square fit is performed using a second order polynomial to obtain the values of the resonator quality factor, $Q$ and the resonance frequency, $f_{0}$ Arnott et al. (1999).

The absorption and scattering calibration procedure for the SC-PNS is based on the measurement of single-pass light extinction. High sample concentrations yielding 
absorption or scattering coefficients up to $40,000-60,000 \mathrm{Mm}^{-1}$ are necessary to obtain a significant extinction signal (significantly higher than the extinction detection limit as reported in Table 3) in the order of 1-3\% (Eq. (3)) due to the short optical path $L$ within the cell $(405 \mathrm{~mm})$. The scattering calibrations at the different wavelengths, are carried out using non-absorbing aerosols (e.g.; salt) while absorbing aerosols (e.g.; soot) are used for absorption calibrations. The calibration coefficients are determined by comparing the scattering and absorption signals to the extinction signal and exploiting the optical closure relation given by:

$$
\beta_{\mathrm{ext}}=\beta_{\mathrm{sca}}+\beta_{\mathrm{abs}},
$$

where $\beta_{\text {ext }}$ is the extinction coefficient calculated from the equation:

$$
P_{P D}=P_{L} \exp \left(-\beta_{e x t} L\right),
$$

and $\beta_{a b s}$ is the absorption coefficient, $\beta_{s c a}$ is the scattering coefficient, $P_{L}$ is the laser power in absence of aerosols, $L$ is the length of the cell, and $P_{P D}$ is the transmitted laser power detected by the extinction photodiode. Abu-Rahmah et al. (2006) describe the scattering calibration technique for the nephelometer using white (non-absorbing) aerosols. Ammonium sulphate $(\mathrm{NH} 4)_{2} \mathrm{SO}_{4}$ and Sodium Chloride $(\mathrm{NaCl})$ can be considered nonabsorbing in the spectral range of interest. In our experiments we used $\mathrm{NaCl}$ dissolved in water and aerosolized with the system described earlier.

For non-absorbing aerosols $\beta_{a b s}=0$ and $\beta_{e x t}=\beta_{s c a}$, then $\beta_{\text {ext }}$ obtained from Eq. (3) is used to obtain the scattering calibration factor. With this aim, the signal measured by the scattering photodiode is plotted against the extinction signal; the slope of a linear fit gives the scattering calibration constant. 
Similarly, the calibration constant for absorption is calculated using a strongly absorbing aerosol and $\mathrm{Eq}(\mathrm{s})$. (2) and (3) with the calibrated scattering, and again using the extinction measurement. We used kerosene soot as a strongly absorbing aerosol (Arnott et al., 2000). The calibration constant for absorption is given by the slope of a linear regression of the microphone signal vs. the extinction minus the scattering signals.

Figure 5(a) shows the extinction vs. scattering plot for the scattering calibration check at all filter wavelengths during one of our experiments, and Fig. 5(b) shows the absorption vs. extinction- scattering plot for the absorption calibration check. Scattering and absorption calibration constants of $0.99( \pm 0.02)$ and $1.14( \pm 0.03)$, respectively were obtained in this instance within a confidence interval of $95 \%$. The variability in the calibration is calculated as the standard deviation of the calibration constants, as obtained from the absorption and the scattering calibrations at the five different filter wavelength bands. The variation within different calibrations is less than $15 \%$ for scattering and less than $8 \%$ for absorption. The graphs also show that there is no systematic wavelengthdependence in the calibration variability and that the instrument response is quite linear over large scattering and absorption ranges. 

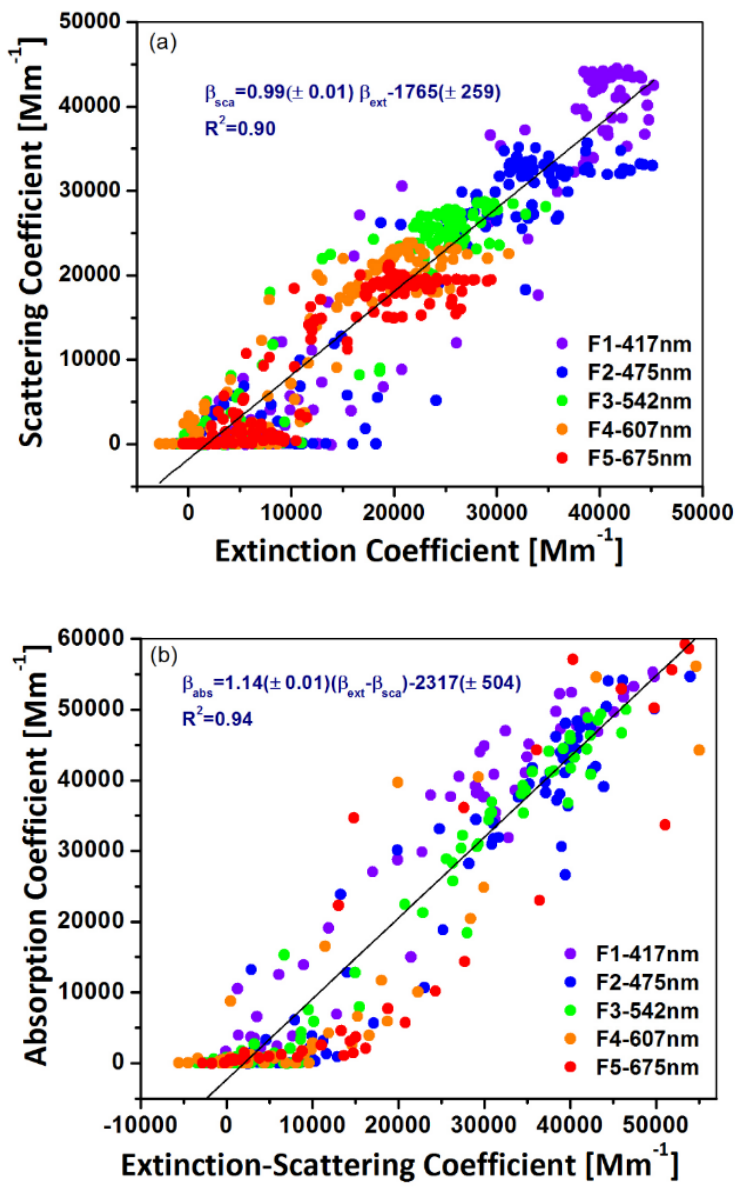

Figure 2-5 (a) Scattering and (b) absorption calibration plots for the SC-PNS instrument at all filter wavelengths. Colors correspond to the center wavelength of each filter

\subsection{Results and Discussion}

After calibration, the SC-PNS was tested with kerosene soot and nebulized $\mathrm{NaCl}$ salt in two separate experiments and the results were compared to the PASS-3 data. As mentioned earlier, the PASS-3 operated continuously during the experiment measuring at three wavelengths simultaneously, while the SC-PAS was operated in sequence, one wavelength at a time; measurements were done with each optical filter for $\sim 1$ minute. In the following discussion, we will refer to "run" as a full set of the different optical filters (from 1 to 5). We performed background measurements before and after sample measurement on each filter. The experiment for each aerosol type lasted for about 2 hours 
with 5-6 complete runs. The aerosol was sampled at a rate of $2 \mathrm{lpm}$ from the iron lung, which has a capacity 2771 so the lung is expected to be able to deliver aerosols for $\sim 2 \mathrm{~h} 20$ $\min$. The total time taken by 6 runs in an experiment was approximately $2 \mathrm{~h} 6 \mathrm{~min}$; therefore after 6 runs we started noticing a rapid drop in the aerosol concentrations by a third of the original value and we stopped measuring after that. A comparison of the data obtained from the two instruments is discussed next.

The PASS-3 and the SC-PNS data were first normalized to the average of the PASS-3 signal over the time correspondent to each wavelength of the first run. This was done to normalize for the changes in aerosol concentration over the span of the entire experiment and to allow for a direct comparison of the different SC-PAS wavelengths.

The two instruments operate at different wavelengths and different bandwidths; therefore, in order to compare the measurements, the absorption and scattering measured by the PASS-3 was interpolated over the spectrum of the supercontinuum through each filter. The interpolation for the wavelengths correspondent to the filters F1 and F2 was done using the Ångström exponent for absorption and scattering calculated from the 405 and $532 \mathrm{~nm}$ wavelengths from the PASS-3 using Eq. (4). The interpolation for the wavelengths correspondent to the filters F3, F4 and F5 was done using the Ångström exponents calculated from the $532 \mathrm{~nm}$ and $781 \mathrm{~nm}$ data from the PASS-3.

$$
\beta_{a b s(s c a)}(\lambda)=C \cdot \lambda^{-\alpha a b s(s c a)},
$$

where, $C$ is a wavelength-independent constant and $\alpha_{a b s(s c a)}$ is the Ångström exponent for absorption or scattering (Moosmüller et al., 2011). The interpolated value at each wavelength was averaged over the wavelength bandwidth for each filter weighted by the spectral radiance transmitted by each filter (the radiance data from Fig. 3 were used) using Eq. (5). 


$$
\left\langle\beta_{a b s(s c a)}\right\rangle=\frac{\int_{\min }^{\lambda \max }\left(\frac{\lambda}{\lambda_{P A S S-3}}\right)^{\alpha a b s(s c a)} \beta_{a b s(s c a)}\left(\lambda_{P A S S-3}\right) E(\lambda) d(\lambda)}{\int_{\lambda_{\min }}^{\lambda_{\max }} E(\lambda) d \lambda}
$$

Where $\lambda$ is the wavelength between minimum $\left(\lambda_{\min }\right)$ and maximum $\left(\lambda_{\max }\right)$ of a single band filter and $\mathrm{E}(\lambda)$ is the radiance transmitted by the filter at wavelength $\lambda$; $\beta_{\mathrm{abs}(\mathrm{sca})}\left(\lambda_{P A S S-}\right.$ $3)$ is the absorption or scattering measured at wavelength $\left(\lambda_{P A S S-3}\right)$ by the PASS-3; $\alpha_{a b s(s c a)}$ is the Ångström exponent for absorption or scattering obtained from PASS-3 measurements for the respective wavelength pair.

A correction for background drifts of the PASS-3 was applied by linearly interpolating the background values between two consecutive background measurements. This procedure was not necessary for the SC-PAS due to the frequent zeroing and the high stability of the laser. The data so obtained from the PASS-3 were compared to the values of absorption and scattering measured by the SC-PNS. The wavelength dependencies of absorption and scattering for kerosene soot and $\mathrm{NaCl}$ measured by the SC-PNS and the PASS-3 are compared and discussed next in this section. The SC-PNS data presented in the following figures are the average of all the measurements at each wavelength band over the different runs. The error bars represent the square root of the sum of the squares of the standard errors (standard deviation divided by the square root of the number of data) of the measurements for each run, background error, and the estimated variability in the calibration ( $8 \%$ in absorption and $15 \%$ in scattering). The error in the background is calculated as the standard error of the mean of the absorption and scattering signals obtained during background measurements (zeroing).

\subsubsection{Kerosene soot}

Figure 6(a) shows the absorption coefficient as a function of wavelength with a power law fit of the SC-PNS data yielding an Absorption Ångström Exponent (AAE) of $\sim 0.972$ $( \pm 0.001)$. This value is consistent with the $\lambda^{-1}$ dependence demonstrated in a number of theoretical and experimental studies previously conducted on kerosene soot (Sheridan et 
al., 2005; Bergstrom et al., 2002; Moosmüller et al., 2009a). During the Reno aerosol optics study (Sheridan et al., 2005) the AAE for kerosene soot was measured to be in the range of 0.94 to 1.0. The Scattering Ångström Exponent (SAE) in our experiment is $\sim 1.611$ $( \pm 0.005)$ as shown in Fig. 6(b). For comparison, Gyawali et al. (2012) obtained a SAE of 1.88 for kerosene soot; we point out that the SAE is strongly dependent on particle size. The single scattering albedo as a function of wavelength is shown in Fig. 6(c) and is decreasing with increasing wavelength above $550 \mathrm{~nm}$ for both instruments. Measurements from the two instruments agree with each other within the statistical uncertainties of the data.
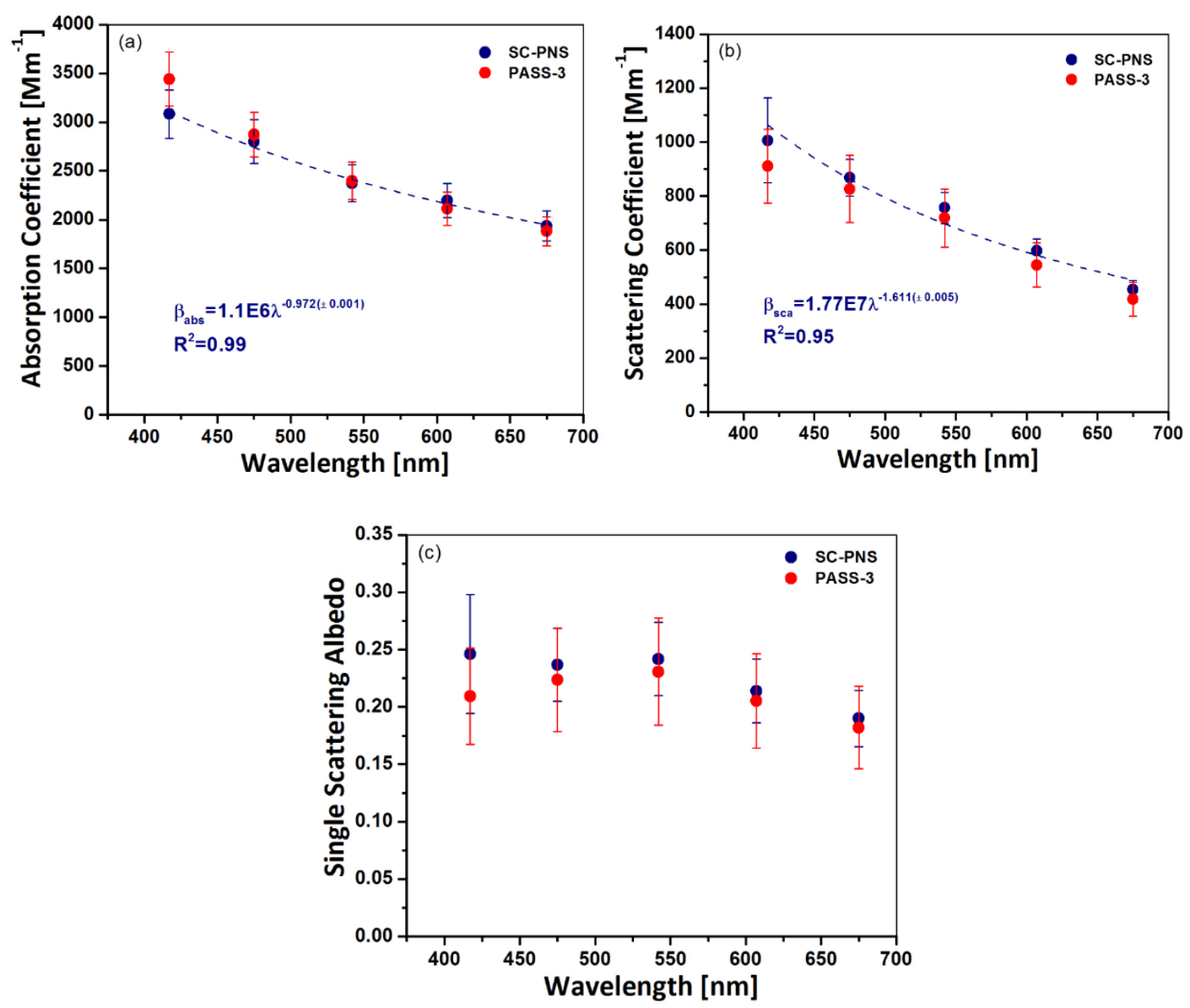

Figure 2-6 (a) Absorption ( $\beta$ abs) and (b) scattering ( $\beta$ sca) coefficients of kerosene soot vs. wavelength $(\lambda)$ measured by PASS-3 and SC-PNS, error bars indicate square root of the sum of squares of background error, standard deviation of mean (standard error) and 
calibration variability. (c) Wavelength dependence of single scattering albedo (SSA) of kerosene soot, error bars indicate the error propagated from absorption and scattering.

\subsubsection{Salt}

Common salt $(\mathrm{NaCl})$ aerosol is white $(\mathrm{SSA}=1)$ and is expected to show negligible absorption at visible wavelengths. Figure 7(a) shows the absorption coefficient of salt obtained from SC-PNS and PASS-3. The absorption coefficients from the two instruments are zero within their respective errors demonstrating, as expected, that scattering does not interfere with the absorption measurement, or in other words, the photoacoustic effect is insensitive to scattering. On the other hand, the values of scattering coefficients obtained from the two instruments show strong wavelength dependence (Fig. 7(b)). In view of the zero absorption, the single scattering albedo (Fig. 7(c)) had a constant value $\sim$, irrespective of wavelength.
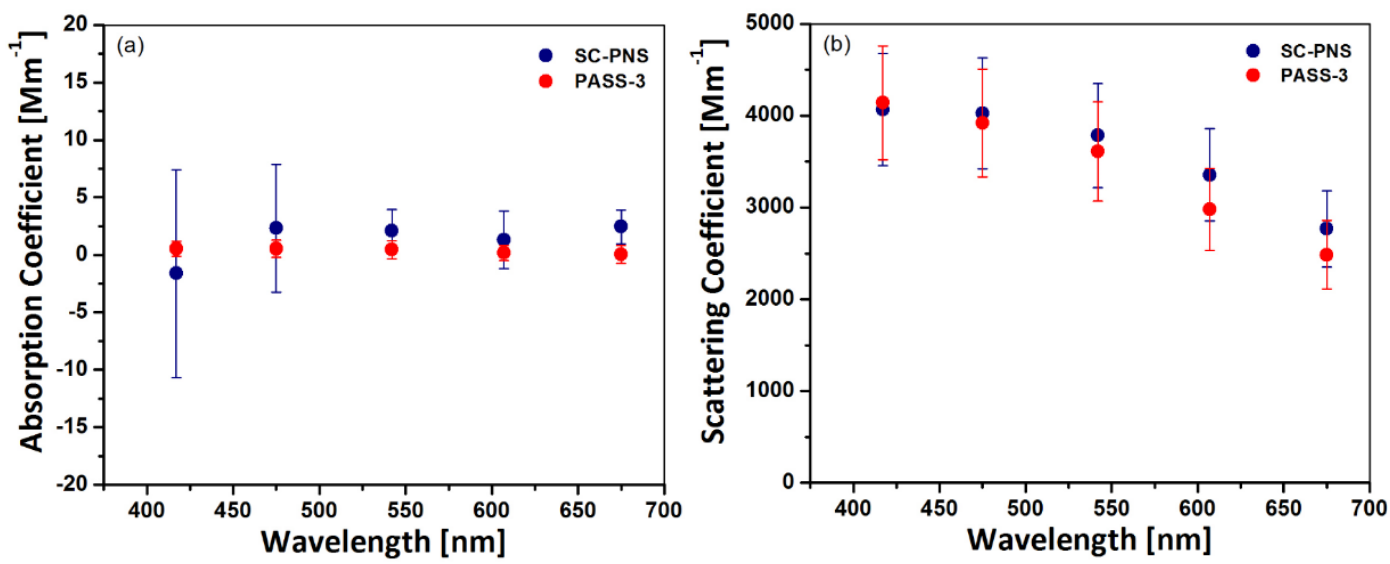


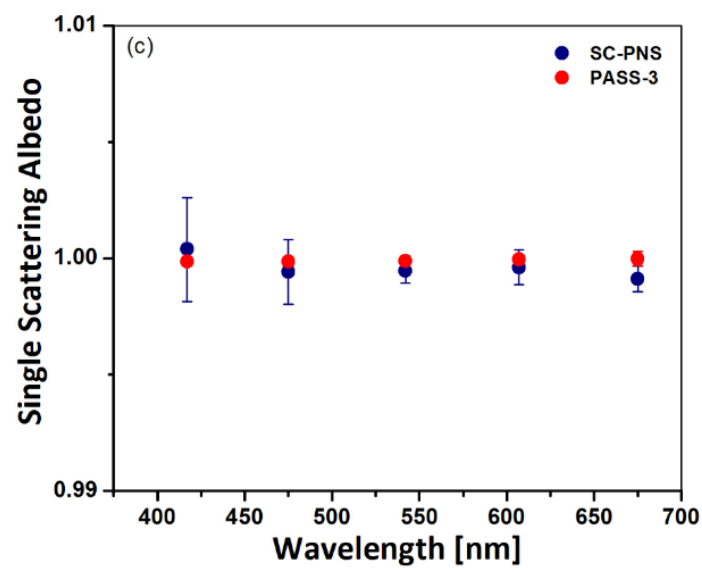

Figure 2-7 (a) Absorption ( $\beta \mathrm{abs}$ ) and (b) scattering ( $\beta$ sca) coefficients of common salt $(\mathrm{NaCl})$ vs. wavelength $(\lambda)$ measured by PASS-3 and SC-PNS, error bars indicate square root of sum of squares of background error, standard deviation of mean (standard error) and calibration variability. (c) Single scattering albedo of salt, error bars indicate the error propagated from absorption and scattering.

\subsubsection{Nitrogen Dioxide}

Nitrogen dioxide absorbs throughout the visible region and therefore can be used to evaluate the absorption measured by SC-PNS. With this aim, we conducted an experiment by maintaining a continuous flow of $101.3( \pm 2) \mathrm{ppm}($ mole $\%) \mathrm{NO}_{2}$ in air through the instrument. The difference between the scattering coefficient of particle free air and the $\mathrm{NO}_{2}$ mixture is negligible in the visible region, and therefore the measured extinction coefficient of the laser radiation should correspond to the absorption coefficient. The photoacoustic signal (expressed in units inverse megameters as calibrated with kerosene soot) and the scattering coefficient were measured directly and the extinction coefficient was calculated from the laser powers measured with the extinction photodiode at the integrating sphere using Eq. (6).

$$
\beta_{\text {ext }}=\left(\frac{-1}{L}\right) \ln \left(\frac{I}{I_{0}}\right)
$$


Where, $I_{0}$ is the laser intensity measured while particle-free dry air was flowing through the instrument, $I$ is the laser intensity measured with the $101.3 \mathrm{ppm} \mathrm{NO}_{2}$ mixture flowing in the cell, and $L$ is the cell length.

The photoacoustic signal and the extinction coefficient obtained by our instrument at each wavelength band were compared to the absorption coefficients calculated from the $\mathrm{NO}_{2}$ absorption cross sections using the HITRAN database at $294 \mathrm{~K}$ (Orphal and Chance, 2003; Rothman et al., 2003). Figure 8(a) shows a plot of the photoacoustic signal and extinction coefficient measured by our instrument and that calculated from the HITRAN database as a function of wavelength and Fig. 8(b) shows a plot of the phtoacoustic signal and extinction coefficient measured as a function of the absorption coefficient from the HITRAN database for an $\mathrm{NO}_{2}$ concentration of $101.3 \mathrm{ppm}$. For a direct comparison, the absorption coefficient from the HITRAN database was weighted by the spectral radiance at each wavelength and integrated over the complete wavelength band of each filter to obtain the absorption coefficient for the corresponding filter. Absorption by $\mathrm{NO}_{2}$ decreases rapidly with increasing wavelengths while is accompanied by photodissociation at $U V$ and blue wavelengths ( $\sim 289-422 \mathrm{~nm}$ ). The quantum yield of photodissociation for $\mathrm{NO}_{2}$ is approximately 1 up to $370 \mathrm{~nm}$ and then decreases rapidly reaching a value of 0.02 around $422 \mathrm{~nm}$ (Seinfeld and Pandis, 1998). Filter $1(417 \pm 60 \mathrm{~nm})$ has a bandwidth range from $386 \mathrm{~nm}$ to $456 \mathrm{~nm}$ which overlaps with the expected photodissociation range. Therefore, as expected, for filter 1 we measured a photoacoustic signal ( $\beta_{a b s}$ PAS), which represents the response of the microphone, that is lower than the calculated $\mathrm{NO}_{2}$ absorption coefficient and the measured extinction coefficient (Tian et al., 2013). In Figs. 8(a) and (b), the photoacoustic signal (correspondent to absorption only when photodissociation is negligible) is shown on a separate $\mathrm{Y}$-axis to differentiate it from the absorption by $\mathrm{NO}_{2}$ and to highlight the effect of photodissociation on the photoacoustic signal at the wavelength band corresponding to filter 1 . We corrected for the photodissociation effect by weighting the quantum yield $\varphi$ by the spectral radiance of filter $1\left(\varphi_{\text {net }}\right)$ and dividing the photacoustic signal by $\left(1-\varphi_{\text {net }}\right)$. The corrected $\beta_{a b s}$ (represented in the graph by the hollow circle in Fig. $8(b))$ is increased by a factor of $\sim 1.3$. No correction is needed for the other wavelength bands due to the negligible photodissociation quantum yield at these wavelengths. The 
extinction and the absorption coefficients (including the corrected value for filter 1) lie on the 1:1 line ( $\beta_{\mathrm{abs}}$ PAS and $\beta_{\mathrm{ext}}$ PAS: $\beta_{\mathrm{abs}}$ HITRAN) within the error limits. The uncertainty in the absorption coefficient calculated from the HITRAN database is calculated as the square root of the sum of squares of $2 \%$ uncertainty in $\mathrm{NO}_{2}$ concentration, as per gas specification, and $2 \%$ uncertainty in $\mathrm{NO}_{2}$ absorption cross section indicated in Orphal and Chance (2003). From our analysis and plot we omitted the absorption coefficient for the filter centered at $675 \mathrm{~nm}$ (filter 5), which was $\sim 1000 \mathrm{Mm}^{-1}$ because $\mathrm{NO}_{2}$ absorption cross sections beyond $663 \mathrm{~nm}$ are not available in the HITRAN database that we used.
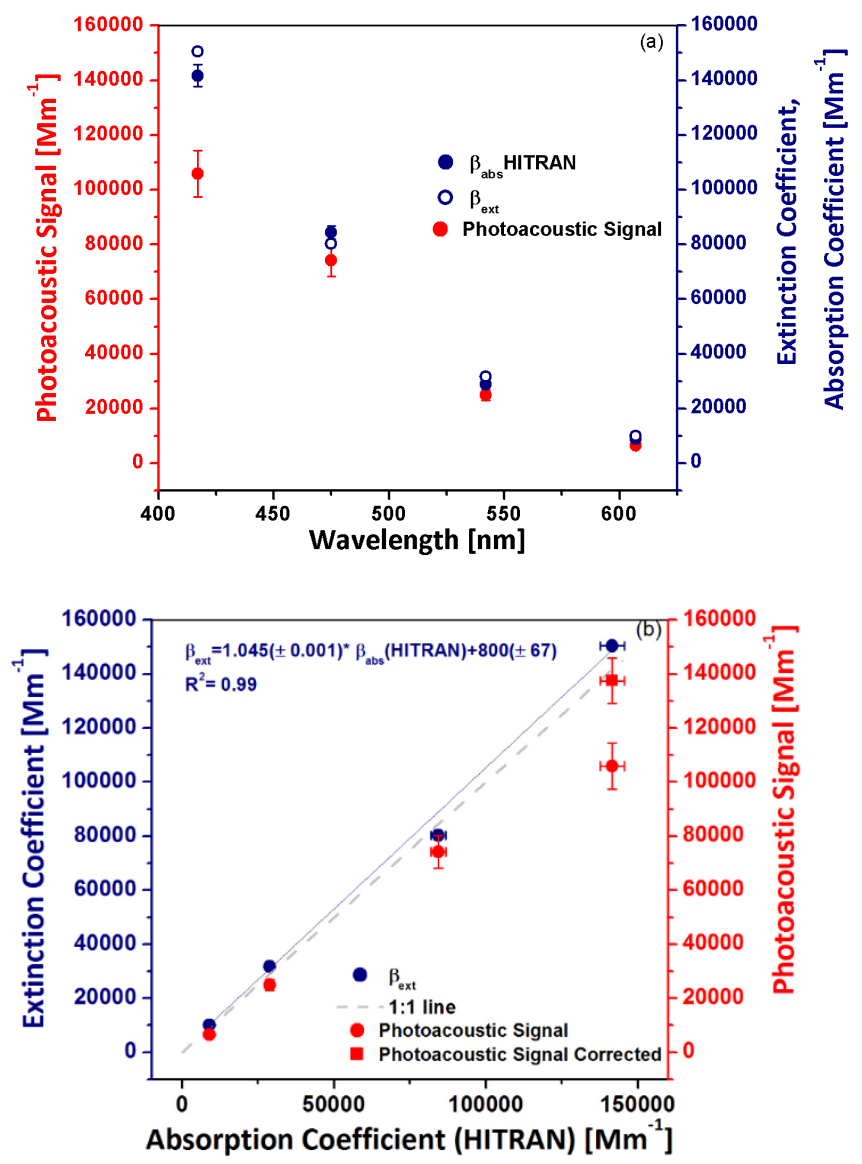

Figure 2-8 (a) Extinction, photoacoustic signal measured by SC-PNS and absorption estimated from the HITRAN database vs. wavelength. (b) Extinction and absorption measured by SC-PNS vs. absorption estimated from the HITRAN database. The vertical error bars on the photoacoustic signal measured and corrected for photodissociation 
indicate the square root of the sum of squares of the standard deviation of the mean (standard error) and the calibration variability. Vertical error bars on $\beta_{\text {ext }}$ indicate the square root of the sum of squares of the standard deviation of the mean (standard error) and the propagated error from the laser power measurement. Horizontal errors on the absorption coefficient calculated from the HITRAN database include 2\% uncertainty in $\mathrm{NO}_{2}$ absorption cross section data and $2 \%$ uncertainty in the $\mathrm{NO}_{2}$ concentration.

The results of this experiment demonstrate the validity of the absorption calibration procedure discussed earlier, and indirectly also the scattering calibration, as the absorption calibration with kerosene soot is based on the difference between the extinction and the calibrated scattering signals, as previously discussed by Arnott et al. (2000).

\subsection{Instrumental noise and minimum detection limits versus integration time}

The instrumental noise and drifts were studied by operating the instrument with aerosol-free air (using indoor air filtered with a HEPA filter) for each wavelength band. The instrument stability and the minimum detection limit of the instrument were analyzed using Allan deviation plots. The instrument is considered to be stable for a length of time when the signal is free from drifts. Averaging the signal over this time reduces the noise of the instrument improves the signal to noise ratio, and hence the minimum detection limit of the instrument. For a signal which includes random noise and instrumental drift, the Allan deviation firstly decreases proportionally with the reciprocal of the square root of the averaging (integration) time and then increases as instrumental drift becomes significant (Werle et al., 1993; Skřínský et al., 2009).

We used a Matlab code written by Fabian Czerwinski (Czerwinski, 2010) to calculate the Allan deviation for the absorption scattering and extinction signals for the SC-PNS and the PASS-3 as shown in Fig(s). 9(a) and (b), respectively. Table 3 lists the approximate values of minimum detectable absorption, scattering and extinction coefficients obtained at each wavelength band of the SC-PNS for an equal integration time of 60 seconds. For 
comparison we also added the minimum detection limits at 60 seconds integration time similarly calculated for the PASS-3.
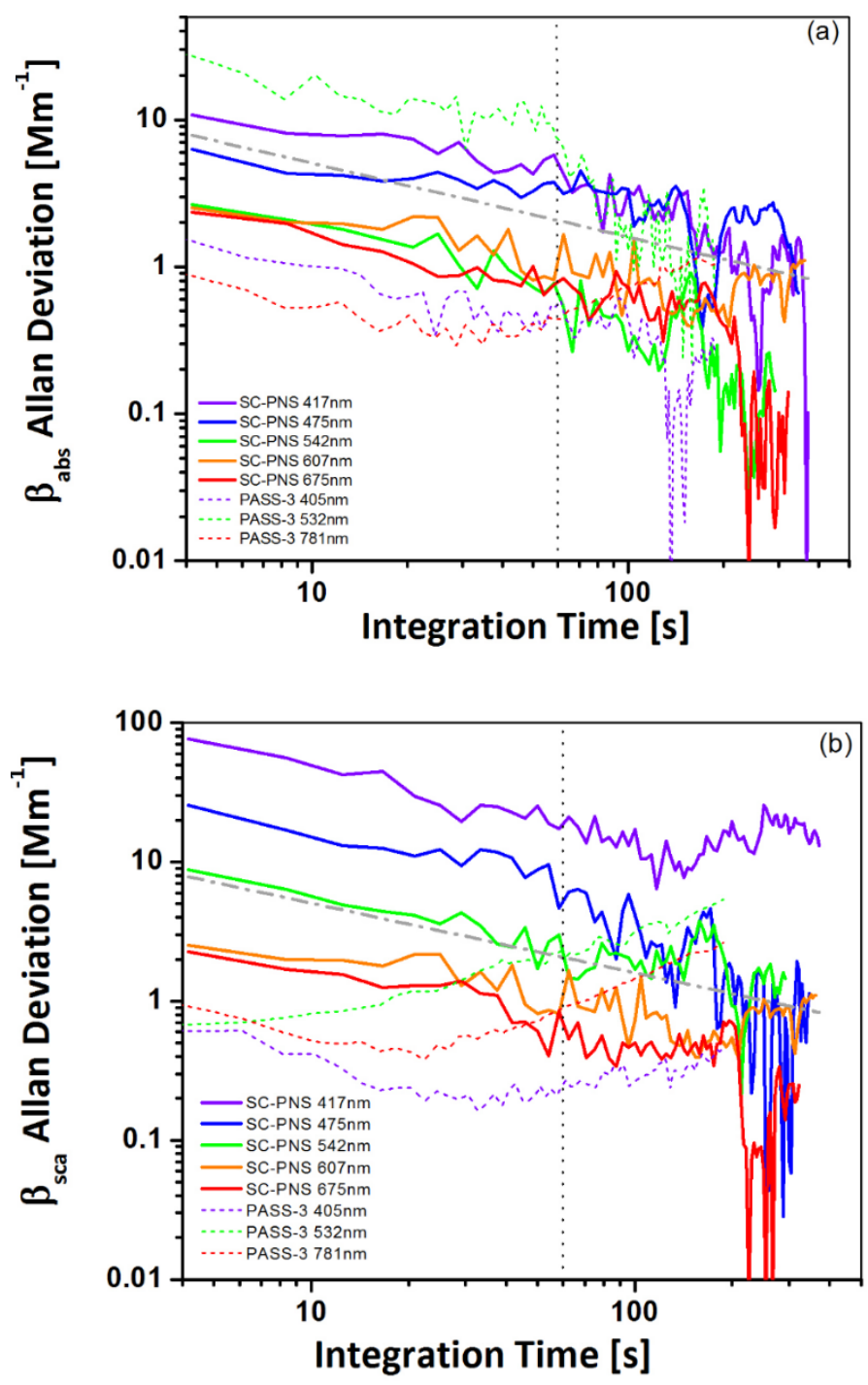

Figure 2-9 Allan deviation vs. integration time plots for (a) absorption ( $\beta a b s)$ and (b) scattering ( $\beta$ sca) coefficients at different wavelength bands for SC-PNS and at different wavelengths for PASS-3. Black dotted vertical and grey dashed lines indicate $60 \mathrm{~s}$ integration time and 1/square root of integration time, respectively as guides to the eye. 
Table 2-3: Minimum detectable absorption (MDA) and scattering (MDS) coefficients for 60s integration time.

\begin{tabular}{|c|r|r|r|r|r|r|r|r|r|}
\hline $\begin{array}{c}\text { SC-PNS } \\
\text { Center } \\
\text { wavelength } \\
{[\mathrm{nm}]}\end{array}$ & $\begin{array}{c}\mathrm{MDA} \\
{\left[\mathrm{Mm}^{-1}\right]}\end{array}$ & $\begin{array}{c}\mathrm{MDS} \\
{\left[\mathrm{Mm}^{-1}\right]}\end{array}$ & $\begin{array}{c}\mathrm{MDE} \\
{\left[\mathrm{Mm}^{-1}\right]}\end{array}$ & $\begin{array}{c}\text { Laser } \\
\text { power } \\
{[\mathrm{mW}]}\end{array}$ & $\begin{array}{c}\text { PASS-3 } \\
\text { Wavelength } \\
{[\mathrm{nm}]}\end{array}$ & $\begin{array}{c}\mathrm{MDA} \\
{\left[\mathrm{Mm}^{-1}\right]}\end{array}$ & $\begin{array}{c}\mathrm{MDS} \\
{\left[\mathrm{Mm}^{-1}\right]}\end{array}$ & $\begin{array}{c}\text { MDE } \\
{\left[\mathrm{Mm}^{-1}\right]}\end{array}$ & $\begin{array}{c}\text { Laser } \\
\text { power } \\
{[\mathrm{mW}]}\end{array}$ \\
\hline 417 & 4 & 21 & 1800 & 15.6 & 405 & 0.4 & 0.2 & 223 \\
\hline 475 & 3 & 6 & 2300 & 26.5 & - & - & - & - \\
\hline 5 & 0.5 & 1.5 & 1500 & 45.6 & 532 & 8 & 1.7 & 16500 & 89 \\
\hline 607 & 2 & 1 & 1400 & 86.4 & - & - & - & - \\
\hline 6 & 1 & 0.5 & 750 & 64.4 & - & - & - & - \\
\hline
\end{tabular}


Minimum detectable absorption of $0.5,2$ and $1 \mathrm{Mm}^{-1}$ and minimum detectable scattering of less than $2 \mathrm{Mm}^{-1}$ can be achieved for 542, 607 and $675 \mathrm{~nm}$ wavelengths by integrating the signal for $\sim 60 \mathrm{~s}$. These values of minimum detectable absorption and scattering make the instrument capable of measuring ambient aerosols even in environments with medium aerosol concentrations.

\subsection{Conclusions}

We developed a new photoacoustic-nephelometer instrument using a supercontinuum laser as light source for the measurement of absorption and scattering coefficients of aerosol samples at multiple wavelengths (i.e., 417, 475, 542, 607, and $675 \mathrm{~nm}$ ). The instrument was tested with kerosene soot and common salt for the wavelength dependence of aerosol optical properties and the results obtained were compared to a simultaneously operating commercial 3-wavelength photoacoustic and nephelometer instrument (PASS3). The value of absorption and scattering Ångström exponent obtained for soot from our instrument agreed closely with values available in literature. Salt that has negligible absorption at visible wavelengths showed negligible photoacoustic signal, demonstrating the lack of scattering interferences on the absorption measurements, in contrast to filterbased measurements. Scattering coefficients of salt aerosol as obtained by our instrument, showed strong wavelength dependence departing from a simple power law. The absorption and scattering coefficients obtained with the commercial instrument and interpolated on the supercontinuum wavelength bands agreed with the observations from the SC-PNS. The absorption coefficient as measured for the first four wavelength bands agree well with theoretical calculations when measuring a mixture of $\mathrm{NO}_{2}$ in air. As the instrument operates over broad wavelength bands, the knowledge of the spectral details of absorption by gaseous species is less critical that for single line laser-based photoacoustic systems.

The current version of the instrument measures at each wavelength band, one at a time, which requires a stable size distribution and monotonic (or at least well-constrained) variation in the concentration of the sample particles, to measure accurate aerosol absorption and scattering spectra. Efforts toward the development of a field deployable 
instrument are currently under way by improving the current instrument to measure simultaneously at different wavelengths and to expand the measurement spectral region to the NIR to allow the characterization of aerosol optical properties over most of the solar spectrum. Due to the minimum detectable absorption and scattering coefficients, the instrument can find applications in laboratory as well as in field studies down to medium pollution environmental conditions. The instrument can provide valuable and unique information on the wavelength dependence of the optical properties of ambient and laboratory-generated aerosols. 


\section{References}

1. Abu-Rahmah, A., Arnott, W. P., Moosmüller, and , H.: Integrating nephelometer with a low truncation angle and an extended calibration scheme, Meas. Sci. Technol., 17, 1723-1732, 10.1088/0957-0233/17/7/010, 2006.

2. Ajtai, T., Filep, Á., Schnaiter, M., Linke, C., Vragel, M., Bozóki, Z., Szabó, G., and Leisner, T.: A novel multi- wavelength photoacoustic spectrometer for the measurement of the UV-vis-NIR spectral absorption coefficient of atmospheric aerosols, J. Aerosol Sci., 41, 1020-1029, 2010.

3. Alfano, R., and Shapiro, S.: Observation of self-phase modulation and small-scale filaments in crystals and glasses, Phys. Rev. Lett., 24, 592, 1970.

4. Andreae, M., and Gelencsér, A.: Black carbon or brown carbon? The nature of light-absorbing carbonaceous aerosols, Atmos. Chem. Phys, 6, 3131-3148, 2006.

5. Arnold, I. J., Berger, C., Moosmuller, H., Sharma, N., and Mazzoleni, C.: The Iron Lung: A "Device for the Continuous Delivery of Fine Particulate Matter Rev. Sci. Instrum., submitted, 2013

6. Arnott, W. P., Moosmüller, , H., Rogers, C. F., Jin, T. F., and Bruch, R.: Photoacoustic spectrometer for measuring light absorption by aerosol: instrument description, Atmos. Environ., 33, 2845-2852, 1999.

7. Arnott, W. P., Moosmüller, , H., and Walker, J. W.: Nitrogen dioxide and keroseneflame soot calibration of photoacoustic instruments for measurement of light absorption by aerosols, Rev. Sci. Instrum., 71, 4545-4552, 10.1063/1.1322585, 2000 .

8. Bergstrom, R. W., Russell, P. B., and Hignett, P.: Wavelength dependence of the absorption of black carbon particles: Predictions and results from the TARFOX experiment and implications for the aerosol single scattering albedo, J. Atmos. Sci., 59, 567-577, 2002. 
9. Bergstrom, R. W., Pilewskie, P., Russell, P., Redemann, J., Bond, T., Quinn, P., and Sierau, B.: Spectral absorption properties of atmospheric aerosols, Atmos. Chem. Phys, 7, 5937-5943, 2007.

10. Bond, T. C., and Bergstrom, R. W.: Light absorption by carbonaceous particles: An investigative review, Aerosol Science and Technology, 40, 27-67, 2006.

11. Chamaillard, K., Jennings, S., Kleefeld, C., Ceburnis, D., and Yoon, Y.: Light backscattering and scattering by nonspherical sea-salt aerosols, J. Quant. Spetrosc. Radiat. Transfer, 79, 577-597, 2003.

12. Chen, Y., and Bond, T.: Light absorption by organic carbon from wood combustion, Atmos. Chem. Phys, 10, 1773-1787, 2010.

13. Chylek, P., and Wong, J.: Effect of absorbing aerosols on global radiation budget, Geophys. Res Lett., 22, 929-931, 1995.

14. Chýlek, P., Videen, G., Ngo, D., Pinnick, R. G., and Klett, J. D.: Effect of black carbon on the optical properties and climate forcing of sulfate aerosols, J. Geophys. Res., 100, 16325-16332, 10.1029/95jd01465, 1995.

15. Cross, E. S., Onasch, T. B., Ahern, A., Wrobel, W., Slowik, J. G., Olfert, J., Lack, D. A., Massoli, P., Cappa, C. D., and Schwarz, J. P.: Soot particle studiesinstrument inter-comparison-project overview, Aerosol Sci Tech, 44, 592-611, 2010.

16. Czerwinski,F.: allanv3.0 MAtlabCentral 2010 (last access: 17 December 2012), http://www.mathworks.com/matlabcentral/fileexchange/26659-allan-v3-0,

17. Dudley, J. M., Genty, G., and Coen, S.: Supercontinuum generation in photonic crystal fiber, Rev. Mod Phys, 78, 1135, doi:10.1103/RevModPhys.78.1135, 2006.

18. Flowers, B., Dubey, M., Mazzoleni, C., Stone, E., Schauer, J., Kim, S., and Yoon, S.: Optical-chemical-microphysical relationships and closure studies for mixed carbonaceous aerosols observed at Jeju Island; 3-laser photoacoustic spectrometer, particle sizing, and filter analysis, Atmos. Chem. Phys., 10, 10387-10398, 2010. 
19. Gyawali, M., Arnott, W. P., Zaveri, R. A., Song, C., Moosmüller, , H., Liu, L., Mishchenko, M. I., Chen, L. W. A., Green, M. C., Watson, J. G., and Chow, J. C.: Photoacoustic optical properties at UV, VIS, and near IR wavelengths for laboratory generated and winter time ambient urban aerosols, Atmos. Chem. Phys., 12, 2587-2601, 10.5194/acp-12-2587-2012, 2012.

20. Gyawali, M., Arnott, W., Zaveri, R., Song, C., Pekour, M., Flowers, B., Dubey, M., Setyan, A., Zhang, Q., and Harworth, J.: Evolution of multispectral aerosol optical properties in a biogenically-influenced urban environment during the CARES campaign, Atmos. Chem. Phys. Discussions, 13, 7113-7150, 2013.

21. Haisch, C., Menzenbach, P., Bladt, H., and Niessner, R. R.: A wide spectral range photoacoustic aerosol absorption spectrometer, Anal. Chem., 84, 8941-8945, doi: 10.1021/ac302194u, 2012.

22. Heintzenberg, J., and Charlson, R. J.: Design and applications of the integrating nephelometer: A review, J. Atmos. Ocean. Tech., 13, 987-1000, 1996.

23. Horvath, H.: Atmospheric light absorption - a review, Atmos. Environ A-Gen., 27, 293-317, 1993.

24. Irshad, R., Grainger, R., Peters, D., McPheat, R., Smith, K., and Thomas, G.: Laboratory measurements of the optical properties of sea salt aerosol, Atmos. Chem. Phys, 9, 221-230, 2009.

25. Knight, J. C.: Photonic crystal fibres, Nature, 424, 847-851, 2003.

26. Lack, D. A., Lovejoy, E. R., Baynard, T., Pettersson, A., and Ravishankara, A. R.: Aerosol absorption measurement using photoacoustic spectroscopy: Sensitivity, calibration, and uncertainty developments, Aerosol Sci. Tech., 40, 697-708, 10.1080/02786820600803917, 2006.

27. Lack, D. A., Cappa, C. D., Covert, D. S., Baynard, T., Massoli, P., Sierau, B., Bates, T. S., Quinn, P. K., Lovejoy, E. R., and Ravishankara, A.: Bias in filter-based aerosol light absorption measurements due to organic aerosol loading: Evidence from ambient measurements, Aerosol Sci. Tech., 42, 1033-1041, 2008. 
28. Lack, D. A., Langridge, J. M., Bahreini, R., Cappa, C. D., Middlebrook, A. M., and Schwarz, J. P.: Brown carbon and internal mixing in biomass burning particles, P. Natl. Acad. Sci. USA, 109, 14802-14807, 2012.

29. Lewis, K., Arnott, W. P., Moosmüller, , H., and Wold, C. E.: Strong spectral variation of biomass smoke light absorption and single scattering albedo observed with a novel dual-wavelength photoacoustic instrument, J. Geophys. Res.-Atmos., 113, D16203, doi: 10.1029/2007jd009699, 2008.

30. Marcos, A.: Deriving the basic cell-reciprocal integrating nephelometer equation and its use for calibration purposes: a comprehensive approach, Meas. Sci. Technol, 10, R1-R15, 1999.

31. Moosmüller, , H., and Arnott, W. P.: Particle Optics in the Rayleigh Regime, JAPCA J. Air Waste MA., 59, 1028-1031, 10.3155/1047-3289.59.9.1028, 2009a.

32. Moosmüller, , H., Chakrabarty, R. K., and Arnott, W. P.: Aerosol light absorption and its measurement: A review, J. Quant. Spectrosc. Radiat. Transfer, 110, 844878, 10.1016/j.jqsrt.2009.02.035, 2009b.

33. Moosmüller, H., Chakrabarty, R., Ehlers, K., and Arnott, W.: Absorption Ångström coefficient, brown carbon, and aerosols: basic concepts, bulk matter, and spherical particles, Atmos. Chem. Phys, 11, 1217-1225, 2011.

34. Moosmüller, H., Engelbrecht, J. P., Skiba, M., Frey, G., Chakrabarty, R. K., and Arnott, W. P.: Single scattering albedo of fine mineral dust aerosols controlled by iron concentration, J. Geophys. Res., 117, D11210, 10.1029/2011jd016909, 2012.

35. Orphal, J., and Chance, K.: Ultraviolet and visible absorption cross-sections for HITRAN, J. Quant. Spectrosc. Radiat. Transfer, 82, 491-504, 2003.

36. Ramanathan, V., Chung, C., Kim, D., Bettge, T., Buja, L., Kiehl, J., Washington, W., Fu, Q., Sikka, D., and Wild, M.: Atmospheric brown clouds: Impacts on South Asian climate and hydrological cycle, P. Natl. Acad. Sci. USA, 102, 5326-5333, 2005. 
37. Ranka, J. K., Windeler, R. S., and Stentz, A. J.: Visible continuum generation in air-silica microstructure optical fibers with anomalous dispersion at $800 \mathrm{~nm}$, Opt. Lett., 25, 25-27, 2000.

38. Rosencwaig, A.: Photoacoustics and Photoacoustic Spectroscopy, Wiley, New York NY, 1980.

39. Rothman, L., Barbe, A., Chris Benner, D., Brown, L., Camy-Peyret, C., Carleer, M., Chance, K., Clerbaux, C., Dana, V., and Devi, V. M.: The HITRAN molecular spectroscopic database: edition of 2000 including updates through 2001, J. Quant. Spectrosc. Radiat. Transfer, 82, 5-44, 2003.

40. Roy, A., Leproux, P., Roy, P., Auguste, J.-L., and Couderc, V.: Supercontinuum generation in a nonlinear Yb-doped, double-clad, microstructured fiber, J. Opt. Soc. Am. B, 24, 788-791, 2007.

41. Russell, P.: Photonic Crystal Fibers, Science, 299, 358-362, 2003.

42. Schnaiter, M., Gimmler, M., Llamas, I., Linke, C., Jäger, C., and Mutschke, H.: Strong spectral dependence of light absorption by organic carbon particles formed by propane combustion, Atmos. Chem. Phys, 6, 2981-2990, 2006.

43. Scofield, J. H.: Frequency-domain description of a lock-in amplifier, Am. J. Phys., 62, 129-132, 1994.

44. Scott, R. P., Langrock, C., and Kolner, B. H.: High-dynamic-range laser amplitude and phase noise measurement techniques, IEEE J. Sel. Top. Quant., 7, 641-655, 10.1109/2944.974236, 2001.

45. Sheridan, P. J., Arnott, W. P., Ogren, J. A., Andrews, E., Atkinson, D. B., Covert, D. S., Moosmüller, , H., Petzold, A., Schmid, B., Strawa, A. W., Varma, R., and Virkkula, A.: The Reno Aerosol Optics Study: An evaluation of aerosol absorption measurement methods, Aerosol Sci. Tech., 39, 1-16, 10.1080/027868290901891, 2005. 
46. Skřínský, J., Janečková, R., Grigorová, E., Střižík, M., Kubát, P., Herecová, L., Nevrlý, V., Zelinger, Z., and Civiš, S.: Allan variance for optimal signal averaging - monitoring by diode-laser and $\mathrm{CO}_{2}$ laser photo-acoustic spectroscopy, J. Mol. Spectrosc., 256, 99-101, 2009.

47. Sun, H., Biedermann, L., and Bond, T. C.: Color of brown carbon: A model for ultraviolet and visible light absorption by organic carbon aerosol, Geophys. Res. Lett., 34, L17813, doi:10.1029/2007GL029797, 2007.

48. Tam, A. C.: Applications of photoacoustic sensing techniques, Rev. Mod.Phys., 58, $381-431,1986$.

49. Tang, I. N., Wong, W. T., and Munkelwitz, H. R.: The relative importance of atmospheric sulfates and nitrates in visibility reduction, Atmos. Environ. (1967), 15, 2463-2471, 10.1016/0004-6981(81)90062-7, 1981.

50. Tian, G., Moosmüller, H., and Arnott, W. P.: Influence of Photolysis on Multispectral Photoacoustic Measurement of Nitrogen Dioxide Concentration, JAPCA J. Air Waste MA., 2013.

51. Werle, P., Mücke, R., and Slemr, F.: The limits of signal averaging in atmospheric trace-gas monitoring by tunable diode-laser absorption spectroscopy (TDLAS), Appl. Phys. B-Lasers O., 57, 131-139, 1993. 


\section{Links between physical properties of secondary organic aerosol and soot morphology during the Carbonaceous Aerosols and Radiative Effects Study ${ }^{3}$}

\subsection{Abstract}

Organic aerosols may constitute up to $90 \%$ of non-refractory particle mass in rural and urban atmospheres. Mixing of soot with organic matter and soot morphology play a very crucial role in determining the optical properties of soot. Condensation of vapor phase organics on soot or coagulation of soot with organic aerosols are important soot mixing processes in the atmosphere. Several modeling studies have been conducted to investigate the role of the condensation and coagulation processes in the evolution of soot mixing state.

In this manuscript, we identify and characterize various soot- SOA mixing states employing single particle tilted imaging in a scanning electron microscope. We present evidences of condensation and coagulation mixing processes occurring simultaneously in a forested environment. By imaging the deformation of SOA particles during their impaction on the substrate, we inferred that different SOA particles had variable viscosity. Low viscosity SOA dominated the SOA population ( $~ 80 \%)$. We find that $90 \%$ of partially encapsulated soot (the configuration in which soot is attached to or partially engulfed into a host particle) had a low viscosity SOA host particle, while most of the SOA particles having high viscosity remained externally mixed. Our study reveals a link between viscosity of SOA and the mixing state of soot particles.

\subsection{Introduction}

Atmospheric soot particles (often termed as black carbon) or nano-sphere soot (ns-soot) (Buseck, Adachi et al. 2014) are aggregates of carbonaceous spherules (monomers). Soot has been suggested to be the second largest contributor to the Earth's positive radiative

\footnotetext{
${ }^{3}$ Based on the manuscript in preparation for Geephysical Researrch Letters (to be submitted in spring 2016)
} 
forcing due to its ability to absorb solar radiation efficiently (Bond, Doherty et al. 2013). Soot, when freshly emitted into the atmosphere, has typically a fractal-like morphology (Sorensen and Feke 1996, Buseck, Adachi et al. 2014). As these particles age in the atmosphere due to their interaction with water vapor or other aerosol species, their morphology changes to structures which may be compacted, coated and/or coagulated with other aerosol species like organics, sulfates, dust etc. (Adachi and Buseck 2013, China, Mazzoleni et al. 2013, Adachi, Zaizen et al. 2014, China, Salvadori et al. 2014, China, Scarnato et al. 2015, Scarnato, China et al. 2015). Radiative forcing models often assume simplified spherical shape for fresh, unmixed soot and spherical core-shell structure for coated soot. Simplified treatment of the soot morphology and mixing states in radiative forcing models partly account for large uncertainties associated with radiative forcing estimates (Myhre, Shindell et al. 2013).

Coagulation of soot with other co-existing aerosols has been identified as one of the important mixing mechanisms occurring in the atmosphere (Riemer, West et al. 2009). In a numerical simulation study, Riemer, West et al. (2010), showed that for an urban plume, condensation is the dominant aging mechanism during daytime, while during night, in the absence of condensable species, coagulation takes over. Soot particles coagulated or attached to other aerosol (termed as host) have been reported in several microscopy studies and from various sources and locations (Adachi and Buseck 2008, Adachi and Buseck 2013, China, Mazzoleni et al. 2013, China, Salvadori et al. 2014, China, Scarnato et al. 2015, Scarnato, China et al. 2015). Sedlacek, Lewis et al. (2012), developed a novel method to identify non-core-shell soot containing particles using a single particle soot photometer (SP2). They reported that more than $60 \%$ of the particles in a biomass plume sampled at a measurement site in Long Island, NY in summer of 2011 exhibited non-core-shell structures. Several previous studies (Bond and Bergstrom 2006, Adachi and Buseck 2013, Bond, Doherty et al. 2013) have established the dependence of the optical properties of internally mixed soot on the location of soot within a host particle. Based on numerical simulations, Adachi and Buseck (2013) suggested that the light absorption by soot attached to other particles was overestimated by about $20 \%$ when assuming a core-shell 
morphology. These studies therefore, emphasize the need to consider the details of the soot morphology in radiative forcing and climate models.

Zhang, Jimenez et al. (2007) and Kanakidou, Seinfeld et al. (2005) have shown that organic aerosols constitute up to $90 \%$ of non-refractory submicron particle mass in urban and rural areas. The viscosity of organic aerosols has been under investigation for the past few years due to its effect on SOA phase state (Virtanen, Joutsensaari et al. 2010), chemical diffusion rates (O'Brien, Neu et al. 2014), and SOA growth mechanism and growth rates (Renbaum-Wolff, Grayson et al. 2013). Previous studies have shown that the viscosity, and hence the phase of SOA, are dependent upon the relative humidity conditions (Vaden, Song et al. 2010, Virtanen, Joutsensaari et al. 2010, Koop, Bookhold et al. 2011, Vaden, Imre et al. 2011, Virtanen, Kannosto et al. 2011, Kuwata and Martin 2012, Saukko, Lambe et al. 2012, Renbaum-Wolff, Grayson et al. 2013). Virtanen, Joutsensaari et al. (2010) have advocated the investigation of the potential influence of oxidation on the phase state of SOA.

In this paper, we present a detailed single particle analysis of samples collected at different times of the day from a forested site in Cool, California, during the Carbonaceous Aerosol and Radiative Effect Study (CARES 2010) using Scanning Electron Microscopy (SEM) for single particle imaging and analysis. The aim of this study is to investigate the evolution of soot mixing state due to condensation or coagulation with SOA. Here we provide evidences that the viscosity of SOA particles might be a key player in soot-SOA mixing via the coagulation process.

\subsection{Experimental section}

\subsubsection{Sampling sites and Meteorology}

During CARES, two sampling sites, a urban site termed T0, and a forest site termed T1, were set up to study the evolution of the mixing state of carbonaceous aerosols and their effects on radiative forcing (Figure 1(a)). The site T0, located in the city of Sacramento, CA mostly sampled emissions from anthropogenic sources. The site T1, situated in the forested areas of the foothills of the Sierra Nevada Mountains in Cool, CA, was dominated by biogenic emissions. During the campaign, there were periods when 
south-westerly winds transported the Sacramento urban plume to T1(Fast, Gustafson Jr et al. 2012). These periods are identified here as "transport events". During these transport events, substantial mixing of the Sacramento urban plume with the biogenic emissions at T1 was expected. The south-westerly wind periods were interrupted by periods in which winds swept the Sacramento urban plume towards the southeast. These periods are termed here as "non-transport events". During these non-transport events, the samples at T1 were expected to be mostly unaffected by the fresh urban emissions (Fast, Gustafson Jr et al. 2012, Zaveri, Shaw et al. 2012).
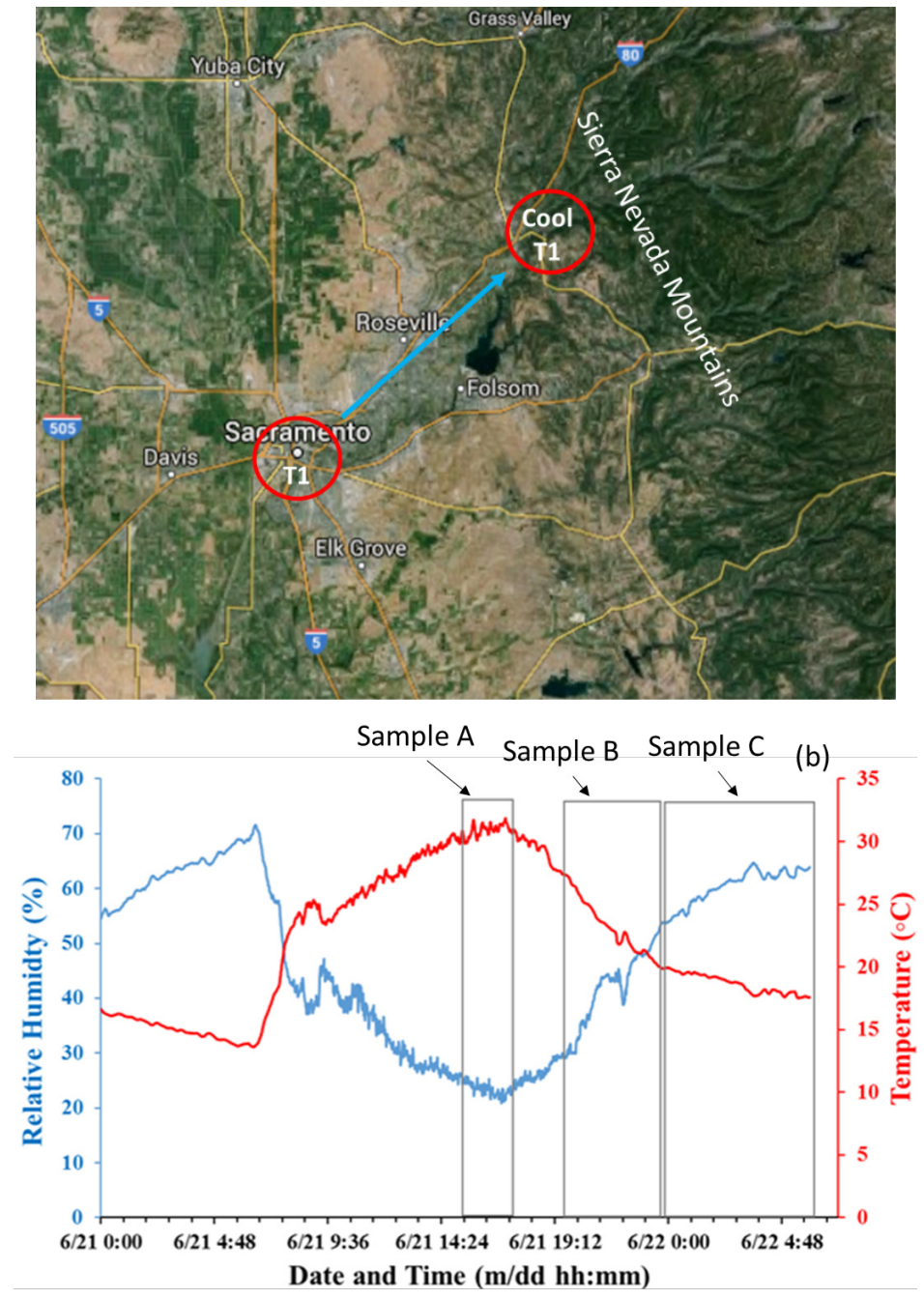

Figure 3-1 (a) Map showing the CARES sampling sites T0 and T1 and the wind patterns during the field campaign. Blue arrow in the direction from T0 to T1 indicate the typical wind direction. (b) Temperature and humidity at the T1 site during the sampling 
period used in this study. Grey rectangles indicate the sampling periods for samples A, B and $\mathrm{C}$.

\subsubsection{Aerosol sample collection and measurements}

During the field campaign, we collected ambient aerosol samples at the T0 and T1 sites to study the morphology and mixing state of individual particles using offline scanning electron microscopy. We used a custom-made sampler to collect aerosol on nuclepore polycarbonate membranes/filters $(100 \mathrm{~nm}$ pore size $)$. Details of the sampler are given in previously published work (Zaveri, Shaw et al. 2012).We collected samples continuously during CARES, using a new membrane every two hours during the day and 4-6 hours during the night time.

For this paper, we focused on samples collected on June 21-22, 2010. These days were characterized by northwesterly wind that started on June $20^{\text {th }}$. This northwesterly wind period followed a transport period that brought the urban outflow from Sacramento into the biogenically-influenced T1 site; therefore, the soot sampled during this period was expected to be 1-2 days old (Fast, Gustafson Jr et al. 2012, Zaveri, Shaw et al. 2012). We used top-view and tilted view imaging with a Field Emission-Scanning Electron Microscope (FE-SEM, Hitachi S-4700) to characterize single soot particles, their morphology and their mixing.

\subsubsection{Particle classification and soot mixing state}

Firstly, based on the geometrical structure and shape of each individual particle, the particle population of the sampled aerosols was grouped into three main categories: (1) soot, (2) spherical (3) others particles(China, Salvadori et al. 2014). Based on the observations made by Moffet, Rödel et al. (2013) using STXM/NEXAFS on ambient particles collected on different days during CARES from T1, spherical or nearly spherical shaped particles were dominated by organic material. Soot particles were further categorized into two subcategories and a total of five groups, based on their morphology and mixing state: a) coated soot in a scale of coating from 0 to 3 , based on a qualitative estimate of the thickness of the coting material visible on the soot particle. Where coated0 (C-0) are bare or very thinly coated soot particles, while coated-3 (C-3) are fully 
embedded soot particles, as discussed by China, Mazzoleni et al. (2013) and China, Scarnato et al. (2015). Soot particles that have an intermediate degree of coating, above 0 but below 3, are identified as C-1 or C-2. b) Partially encapsulated soot (PE). PE are soot particles that possibly coagulated with other co-existing particulate material. However, because the classification is based on a visual inspection and due to the surface imaging in SEM that does not allow to see through the coating material, this classification likely underestimates the $\mathrm{C} 3$ particles as soot encapsulated in large host particles might be counted as spherical or nearly spherical particle instead. In addition, loss of high volatility SOA particles and coating material on soot due to evaporation in the vacuum of the SEM or the sputter coater is unavoidable. Since the samples were collected on the filters with pores having $100 \mathrm{~nm}$ diameter, loss of particles smaller than $100 \mathrm{~nm}$ is also possible. Therefore in our analysis, we consider particles greater than $100 \mathrm{~nm}$ diameter only.

In addition to the categorization discussed earlier, we also analyzed the individual particles to quantify several morphological parameters, such as the area equivalent diameter, roundness and convexity.

We further characterized the spherical particles by imaging them at a tilt of 75 degrees (microscope operating conditions: $3 \mathrm{KV}$ accelerating voltage and $10 \mu \mathrm{A}$ beam current) and then calculated the aspect ratio (maximum length/maximum width) of the particles. The values of aspect ratio provided a hint of possible deformation of spherical particles upon their impaction on the substrate.

\subsection{Results}

\subsubsection{General particle population}

In this study we focus on measurements and samples collected in the period from 06/21/2010, 15:30 hrs to 06/22, 06:00 hrs. During this time, samples were collected on three consecutive filters. For simplicity we refer to these samples as sample A, B and C with collection times from 15:30 to 17:30 (A), and from 19:30 to 23:30 (B) on the 06/21, and from $23: 30$ on $06 / 21$ to $6: 00$ on $06 / 22$ (C). The entire sampling period was characterized by northwesterly wind, which followed a transport period, as discussed earlier (Fast, Gustafson Jr et al. 2012, Zaveri, Shaw et al. 2012). All samples discussed in 
this study were dominated by non-soot particles with spherical or nearly spherical shapes. A total of 2355 particles were classified, out of which, spherical or nearly spherical particles accounted for $\sim 15 \%, \sim 76 \%$ and $\sim 70 \%$ of the particles in samples $\mathrm{A}, \mathrm{B}$ and $\mathrm{C}$ respectively. Several dark spots were also observed on the substrate in sample A, which were not included while characterizing general particle population. Dark spots may be the residue of freshly nucleated SOA particles, having high volatility (Donahue, Kroll et al. 2012, Donahue, Robinson et al. 2012), possibly evaporated in the vacuum of the sputter coater or the microscope.

The time of the day when sample A was collected (15:30-17:30) corresponded to the period of formation and growth of new particles (Setyan, Zhang et al. 2012). Figure 2 (b) shows the mobility size distributions for the particles at the beginning and at the end of each sampling periods. The mobility size distribution at the beginning of the sampling time of sample A shows two modes, a first mode centered around 15-20 nm that corresponds to freshly nucleated SOA particles (Setyan, Zhang et al. 2012). The larger fraction of freshly nucleated SOA particles, smaller in size than the filter pores (100 nm diameter), during the collection of sample A may also account for the much smaller fraction of spherical particles (only 15\%) observed in this sample (A) with respect to the other samples (B and C).

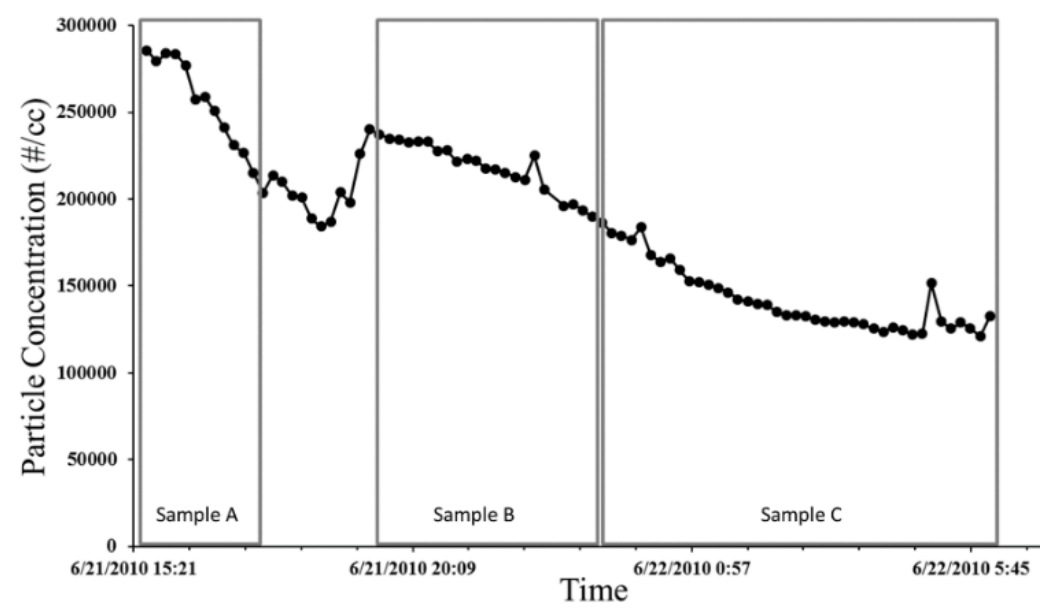




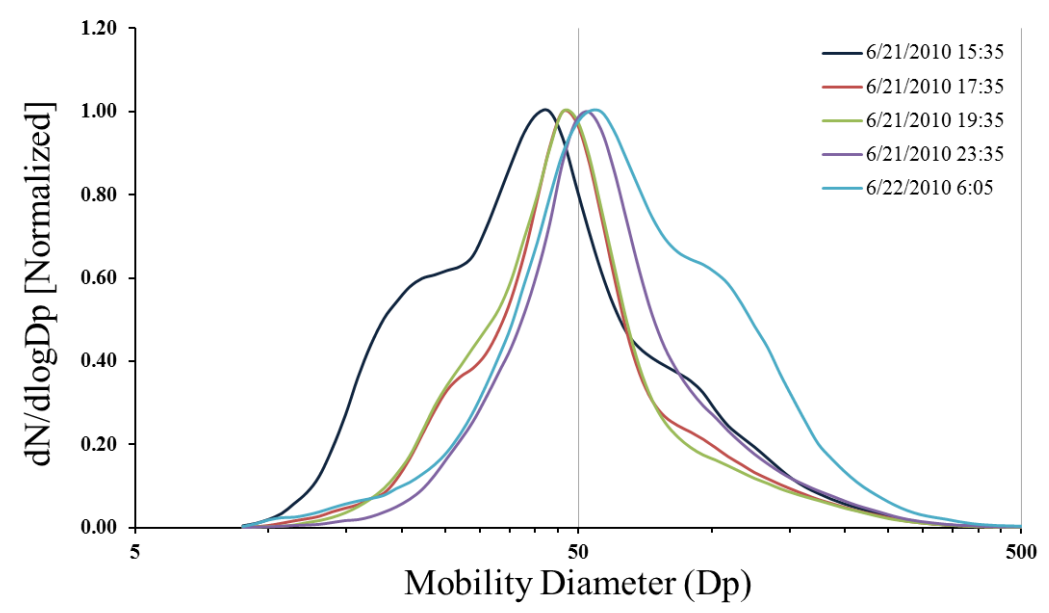

Figure 3-2 (a) Particle number concentration and sampling periods. Grey rectangles indicate the sampling periods of sample A, B and C respectively. (b) Mobility size distribution of the particles at the beginning and end times of each filter sampling periods.

Similarly to the work by China, Mazzoleni et al. (2013), electronically bright and dark particles were observed in the samples when imaged under the scanning electron microscope at an accelerating voltage of $1 \mathrm{KV}$ and a beam current of $10 \mu \mathrm{A}$. Some example of electronically bright and dark spherical particles are shown in the SEM images in figure 3 (a \& b) and figure 4 (a \& b). Bright particles were stable under the electron beam (no significant change in shape or size was observed even after exposing them to the electron beam for $\sim 5 \mathrm{~min}$ ). In contrast, the dark particles were highly volatile and were damaged within $\sim 10-20 \mathrm{sec}$ of being exposed to the electron beam (figure $3(\mathrm{~g} \& \mathrm{~h})$ ). Lower volatility of bright paricles indicates that the bright particles were more aged in comparison to dark particles (Donahue, Robinson et al. 2012). Figure 3 (f) shows that the dark spherical particles accounted for $\sim 75-85 \%$ of the spherical particle population in all the three samples. These fractions are based on the classification of 162 and 179 spherical particles in samples B and C, respectively. As only $\sim 15 \%$ of the imaged particles in sample A were spherical particles, only 38 spherical particles were classified to obtain the relative abundance of bright and dark particles in this sample. 

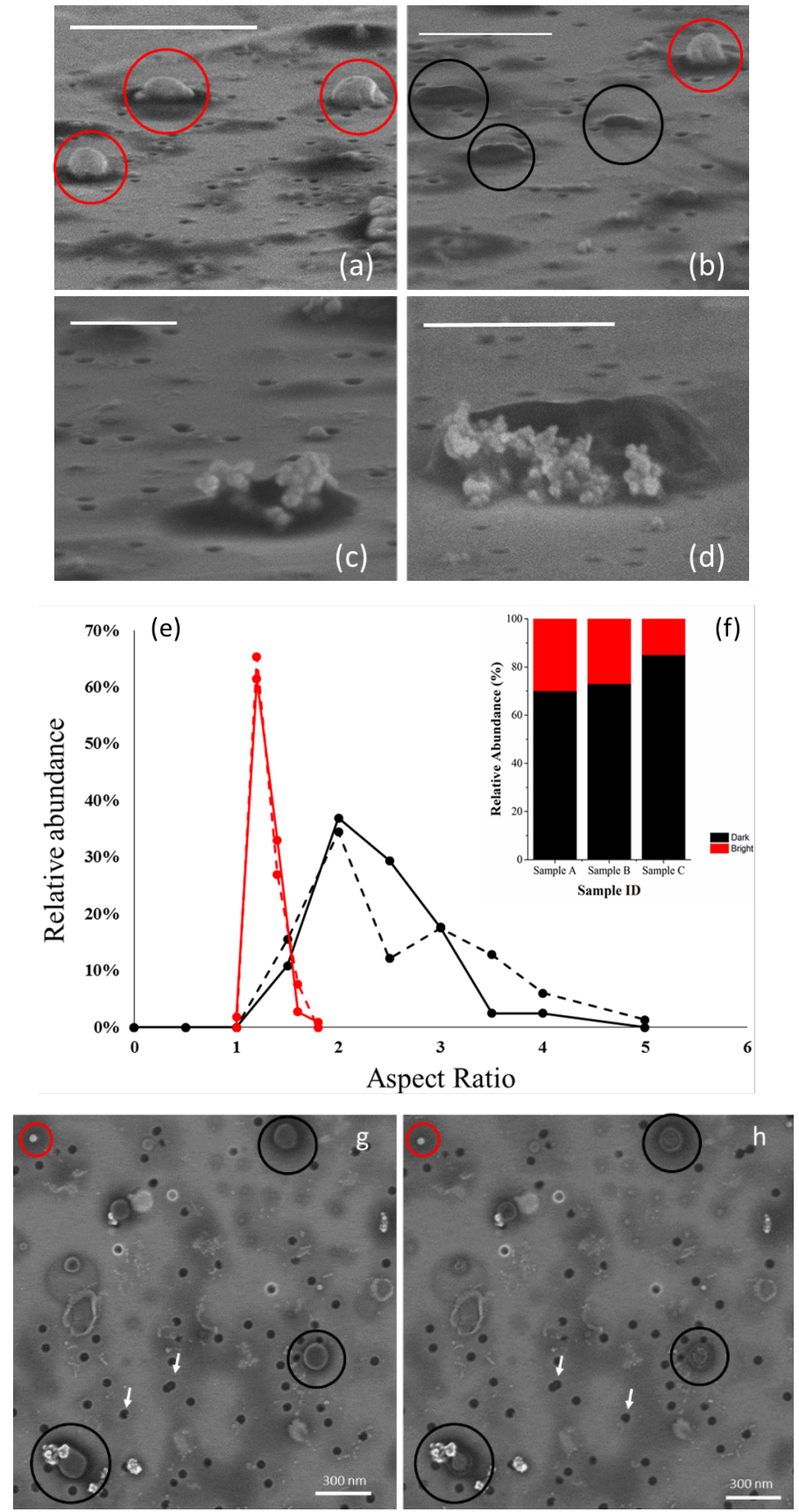

Figure 3-3 (a, b) SEM images obtained by tilting the sample at 75 degree showing bright and dark spherical particles (encircled). (c, d) Tilted SEM images of partially encapsulated soot particles. Each scale bar is $100 \mathrm{~nm}$. (e) Aspect ratio of bright and dark particles for samples B (solid line) and C (dashed line) measured from tilted (75 degree) SEM images. (f) Relative abundance of bright and dark spherical particles in the three samples. Spherical particles (g) before and (h) after 10-15s of electron beam exposure. (h) 
Shows the damaged dark particles (encircled in black) due to electron beam bombardment. Note that the bright particle (encircled in red) remains unchanged. Note that the dark circles pointed by white arrows are holes of the filter.

Figure 3 (e) compares the aspect ratio of the bright and dark spherical particles from sample B (\# particles analyzed: Bright: 117, Dark: 119) and C (\# particles analyzed: Bright: 26, Dark: 94) calculated from the images obtained by tilting the sample by 75 degrees. The total particle number concentration, when the sample $\mathrm{C}$ was collected dropped to $\sim 50 \%$ of the concentration during the period sample B was collected at (figure 2(a)); therefore, fewer particles were analyzed in sample C. We did not calculate the aspect ratio for sample A as a very low fraction of spherical particles were found on this sample. The aspect ratio of bright particles for both samples was distributed between 1 and 1.5 (figure 3(e)), indicating that these particles were nearly spherical and did not deform significantly upon their impaction on the substrate. The aspect ratio of dark particles spreads in the range from 1.5 to 3.5 for sample $\mathrm{B}$, while for sample $\mathrm{C}$ it spreads over the range from 1.5 to 5 , suggesting a larger deformation of dark particles during sample collection.

\subsubsection{Mixing state of soot}

\section{(a) Coated soot}

Due to the wind patterns discussed earlier in section 3.1, the soot collected at the T1 site during the sampling periods is expected to be $\sim 24$ hour aged (Fast, Gustafson Jr et al. 2012, Zaveri, Shaw et al. 2012). This age may have contributed to the higher fraction of C2 soot particles ( $70 \%$ in samples A and $\mathrm{C}$, and $\sim 40 \%$ in sample $\mathrm{B}$ ) in comparison to $\mathrm{C} 0$ and $\mathrm{C} 1$ soot particles $(\sim 18 \%$ in samples $\mathrm{A}, \sim 25 \%$ in sample and $\mathrm{C}$, and $\sim 16 \%$ in sample B) (figure 4 (c)). 5-10\% of heavily coated C3 soot particles was also observed in all three samples. These fractions are based on a total of 1362 soot particles classified from all the samples. 

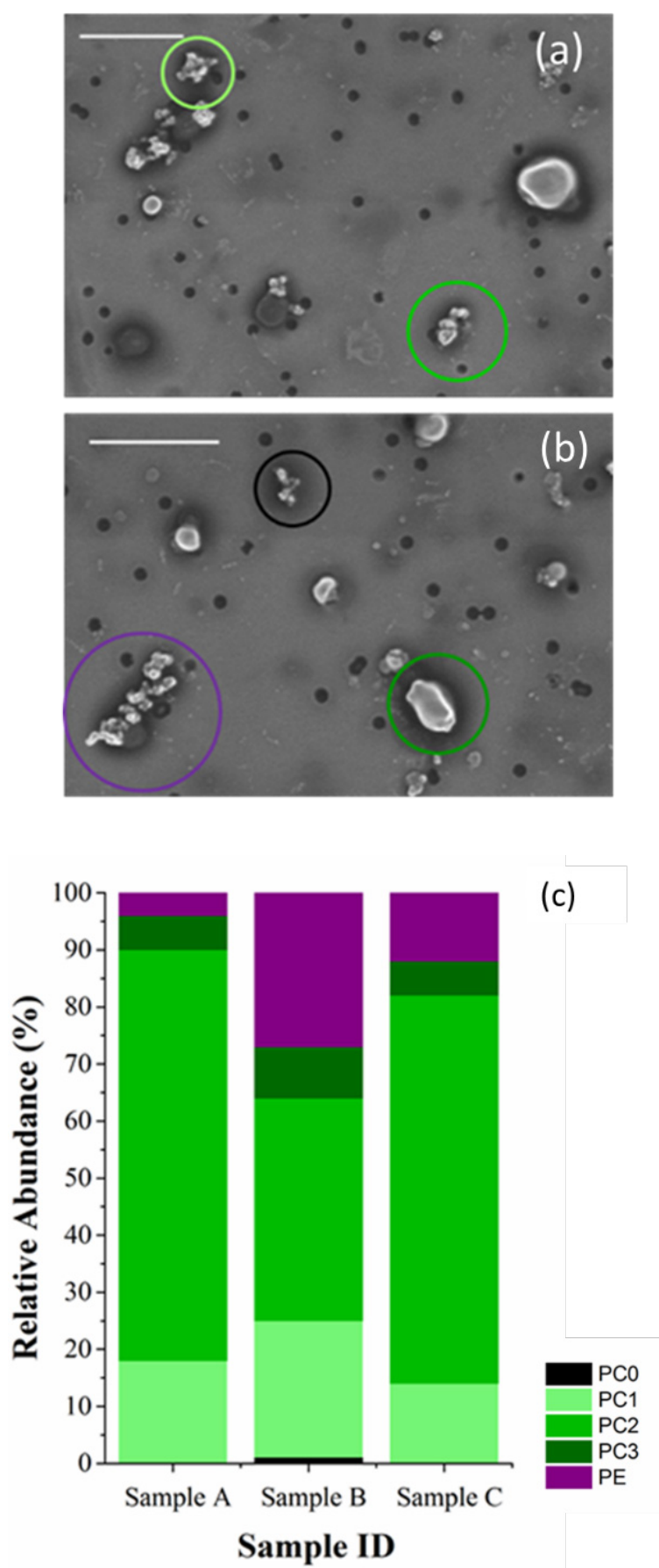


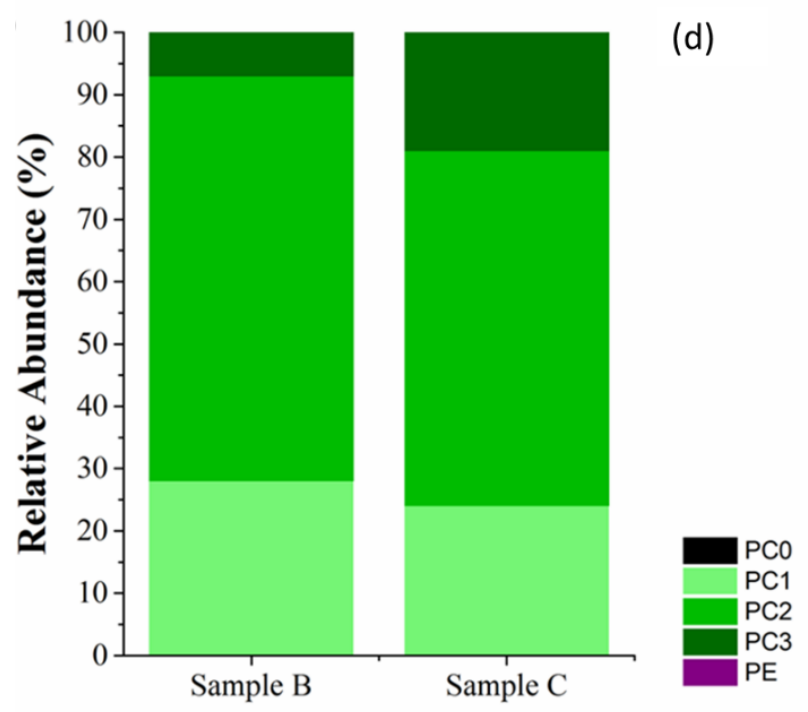

Sample ID

Figure 3-4 Classification of soot particles: $(a, b)$ top-view SEM images of various soot particles in different categories encircled by their respective colors used in the column plots in (c) and (d). (c) Relative abundance of different soot categories in each sample. (d) Categories of soot in partially encapsulated (PE) particles of sample B and C only (due to the low relative abundance of PE particles in sample A, it is not shown in (d)).

Distributions of the area equivalent diameter, roundness and convexity were obtained by analyzing $\sim 400$ particles from the coated soot categories $(\mathrm{C} 0, \mathrm{C} 1, \mathrm{C} 2$ and $\mathrm{C} 3$ combined together) and are shown in figure 5 (a) and (b).

\section{(b) Partially encapsulated particles}

Coagulation of soot with other co-existing aerosols (host) can result in the formation of partially encapsulated or surface-attached particles (Adachi and Buseck 2013, China, Mazzoleni et al. 2013). In figure 3 (c \& d) and figure 4 (b) we show some example of tilted and top view SEM images of partially encapsulated soot.

\section{Morphology of encapsulated soot}

We point out that the soot particles in the category PE can have different levels of coating as well and we therefore also analyze their degree of coating as reported in Figure 4 (d). We compare the relative abundance of $\mathrm{C} 0-\mathrm{C} 3$ soot in PE particles with the relative abundance of $\mathrm{C} 0-\mathrm{C} 3$ soot for samples $\mathrm{B}$ and $\mathrm{C}$, as shown in figure 4 (c). The fraction of 
C0-C3 soot in PE particles (figure 4(d)) follows the relative abundance of non-partially encapsulated $\mathrm{C} 0-\mathrm{C} 3$ soot in the atmosphere (figure 4(c)). For example, $\mathrm{C} 2$ soot, which is the most abundant mixed soot configuration is also the most abundant for the PE particles, followed by $\mathrm{C} 1$ and $\mathrm{C} 3$ soot particles. Top view images of partially encapsulated particles were analyzed to obtain the morphological parameters (area equivalent diameter, roundness and convexity) of the portion of soot outside the host. Soot attached to $116 \mathrm{PE}$ particles were analyzed and their morphological parameters were compared to the morphological parameters of non-PE coated soot (figure 5 (a) and (b)).

Similarity the fraction of $\mathrm{C} 0-\mathrm{C} 3$ soot and the distribution of morphological parameters in $\mathrm{PE}$ and non-PE coated soot suggest that no particular soot morphology is preferred in the formation of PE particles. Coagulation of soot with host particles most probably occurs as a result of their collision in the atmosphere, which in turn is governed by relative abundance of coagulating particles. 

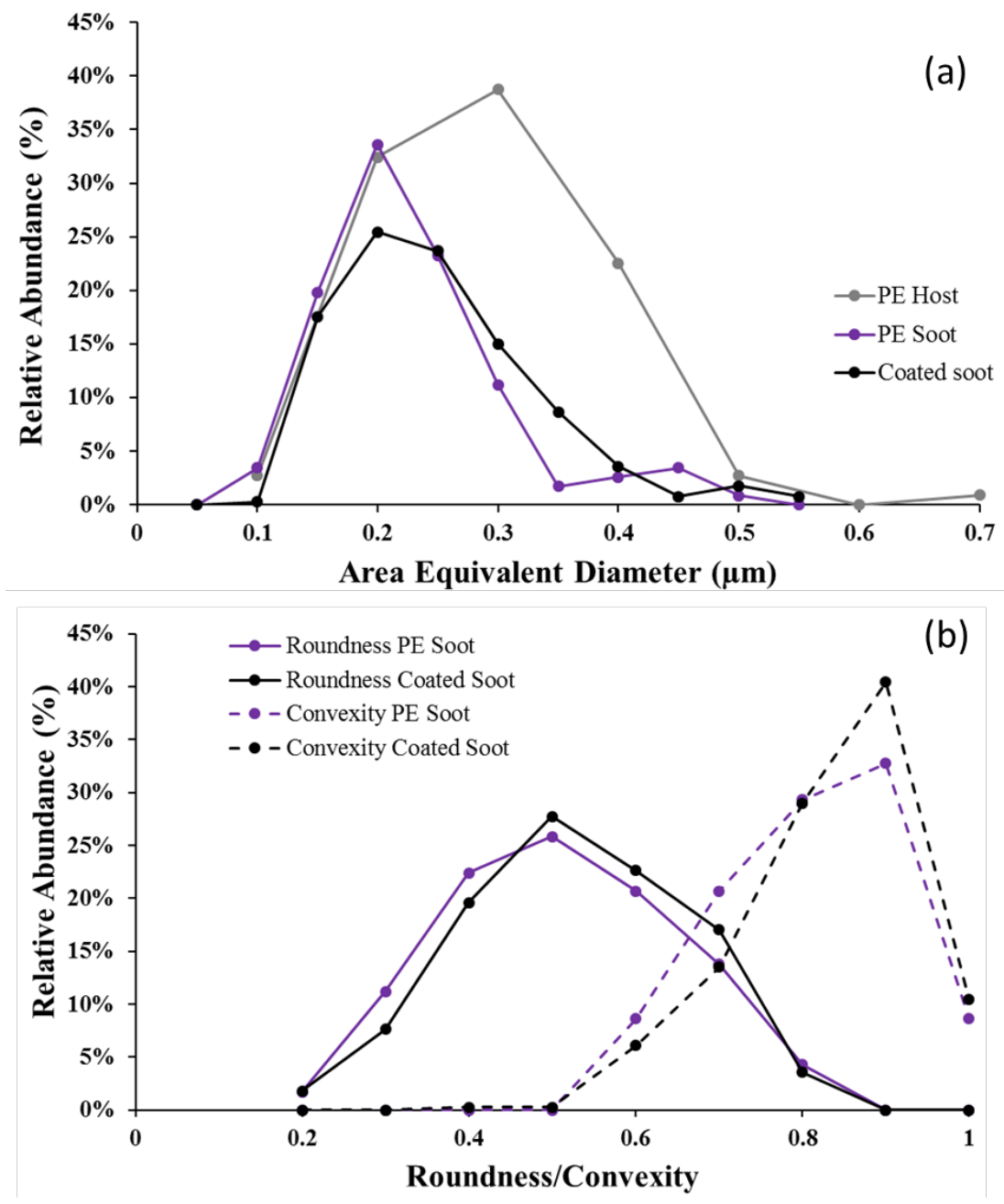

Figure 3-5 (a) Size distribution of PE soot and host compared to the size distribution of the coated soot ( $\mathrm{C} 0-\mathrm{C} 3)$ population categorized in figure 4. (b) Roundness and convexity of $\mathrm{PE}$ soot is compared to the coated soot $(\mathrm{C} 0-\mathrm{C} 3)$ population categorized in figure 4

\section{Host particles}

All the sampling periods discussed in this study were dominated by spherical, presumably biogenic SOA particles. Almost all the PE particles observed in the three samples investigated in this study had a spherical or nearly spherical host. We further categorized the partially encapsulated particles based on the relative electronic contrast (gray scale intensity) of their host and found that $\sim 90 \%$ of the PE soot particles were associated with electronically dark spherical or nearly spherical hosts. The size distribution of the host particles estimated from top view SEM images is shown in figure 5 (a). 


\subsection{Discussion}

\section{Viscosity of host and formation of partially encapsulated soot}

Based on the SEM analysis, we find that partially encapsulated soot particles tend to form more frequently with dark particles as compared to bright particles. In the top and tilted-view images, bright particles are characterized by very low volatility (under the electron beam) (figure 3(c)) and an aspect ratio close to 1 (close to a spherical shape) (figure 3(e)), denoting a vertical dimension (with respect to the plane of the filter) close to the horizontal dimension and therefore denoting minimal deformation at impaction or deposition on the substrate (figure $3(\mathrm{a} \& \mathrm{~b})$ ). On the other hand, dark particles exhibit higher aspect ratio meaning lower vertical dimension with respect to the horizontal dimension and therefore more oblate shape (figure 3 (b \& e)) due to the deformation at impaction or deposition (O'Brien, Neu et al. 2014). O'Brien, Neu et al. (2014) related the extent of deformation of the spherical particles to their viscosity or their phase state, where the high viscosity, solid or nearly solid spherical particles exhibit negligible deformation as compared to the deformation of less viscous, liquid- like particles. The higher aspect ratio (larger deformation) of dark particles in our study therefore indictes the lower viscosity of these particles in comparison to the bright particles $(\mathrm{AR} \approx 1-1.5)$.

During coagulation, when soot interacts with the spherical particles, their viscosity plays a major role in determining the resulting soot-SOA mixing state. Based on our analysis, we find that $90 \%$ of PE particles are formed with electronically dark particles having lower viscosity as compared to bright spherical particles. Due to the high viscosity of bright particles, soot colliding with bright particles, fails to stick to them. Collision of soot with very low viscosity particles possibly coats the soot with coating level depending upon the size of the host particle. Nearly $20 \%$ of dark particles in sample $\mathrm{C}$ having aspect ratio $>3.5$ (figure 3 (e)) may be considered as very low viscosity particles. Our analysis indicates that when the viscosity of the host particle is intermediate between the bright spherical particles $(\mathrm{AR} \sim 1)$ and dark spherical particles with high $\mathrm{AR}$, then the soot succeeds to partially sink into or stick on the surface of the host particle, and partially encapsulated are formed. 


\subsection{Conclusions}

In this study we discussed the evolution of the mixing state of soot in a biogenically influenced environment. Analysis of samples collected during CARES, revealed that in a biogenically influenced environment, observed soot particles were internally (coated or partially encapsulated) as well as externally mixed. In the external mixture, spherical particles dominated the particle population in all the samples. Based on previous studies, spherical particles observed in an external mixture with soot under SEM, were presumed to be homogeneously nucleated secondary organic aerosols (Virtanen, Joutsensaari et al. 2010, O'Brien, Neu et al. 2014). By imaging spherical particles at a tilt of 75 degrees, we observed that about $80 \%$ of the spherical dark particles, appeared to be deformed to oblate shapes at impaction; while the remaining $20 \%$ bright particles remained nearly spherical. The deformation of the particles reflects their viscosity or phase state. While the low viscosity particles deformed to non-spherical shapes during impaction/deposition, high viscosity particles remained unaffected.

About $90 \%$ of partially encapsulated soot particles had a low viscosity, dark, spherical particle as host; while highly viscous, nearly solid spherical particles and soot mostly remained externally mixed. Our key finding therefore, reveals that the variable viscosity of SOA particles, plays an important role in determining the mixing state of soot during coagulation. While the collision of soot with solid/nearly solid particles does not result in coagulation, collision of soot with a particle of lower viscosity results into the formation of surface attached/partially encapsulated soot, in which a part of the soot particle sticks to or partially penetrates into the SOA particle. While the coating of soot is often attributed to condensation of coating material on soot (Khalizov, Lin et al. 2013, Metcalf, Loza et al. 2013, Schnitzler, Dutt et al. 2014), our study also indicates that, coagulation of soot with extremely low viscosity, liquid-like particles might also result into its coating.

So far, relative humidity has been identified as a key player in determining viscosity of SOA (Renbaum-Wolff, Grayson et al. 2013). From our study, we provide evidences of the role that viscosity of SOA particles plays in determining the mixing state of soot. Therefore, our findings can be used in relating sources and environmental factors like 
relative humidity conditions with the expected soot mixing states in the given mixing scenario. Since the optical properties of soot are sensitive to the position of the soot in an internal mixture (Sedlacek, Lewis et al. 2012), categorizing internally mixed soot based on the position of soot in the particle and treating different categories separately in climate models is crucially important to improve the accuracy of radiative forcing estimates. 


\section{References}

1. Adachi, K. and P. Buseck (2008). "Internally mixed soot, sulfates, and organic matter in aerosol particles from Mexico City." Atmospheric Chemistry and Physics 8(21): 6469-6481.

2. Adachi, K. and P. R. Buseck (2013). "Changes of ns-soot mixing states and shapes in an urban area during CalNex." Journal of Geophysical Research: Atmospheres.

3. Adachi, K., Y. Zaizen, M. Kajino and Y. Igarashi (2014). "Mixing state of regionally transported soot particles and the coating effect on their size and shape at a mountain site in Japan." Journal of Geophysical Research: Atmospheres.

4. Bond, T. C. and R. W. Bergstrom (2006). "Light absorption by carbonaceous particles: An investigative review." Aerosol Science and Technology 40(1): 27-67.

5. Bond, T. C., S. J. Doherty, D. Fahey, P. Forster, T. Berntsen, B. DeAngelo, M. Flanner, S. Ghan, B. Kärcher and D. Koch (2013). "Bounding the role of black carbon in the climate system: A scientific assessment." Journal of Geophysical Research: Atmospheres 118(11): 5380-5552.

6. Buseck, P. R., K. Adachi, A. Gelencsér, É. Tompa and M. Pósfai (2014). "Ns-Soot: A Material-Based Term for Strongly Light-Absorbing Carbonaceous Particles." Aerosol Science and Technology 48(7).

7. China, S., C. Mazzoleni, K. Gorkowski, A. C. Aiken and M. K. Dubey (2013). "Morphology and mixing state of individual freshly emitted wildfire carbonaceous particles." Nature communications 4.

8. China, S., N. Salvadori and C. Mazzoleni (2014). "Effect of Traffic and Driving Characteristics on Morphology of Atmospheric Soot Particles at Freeway OnRamps." Environmental science \& technology 48(6): 3128-3135.

9. China, S., B. Scarnato, R. C. Owen, B. Zhang, M. T. Ampadu, S. Kumar, K. Dzepina, M. P. Dziobak, P. Fialho and J. A. Perlinger (2015). "Morphology and mixing state of aged soot particles at a remote marine free troposphere site: 
Implications for optical properties." Geophysical Research Letters 42(4): 12431250.

10. China, S., B. Scarnato, R. C. Owen, B. Zhang, M. T. Ampadu, S. Kumar, K. Dzepina, M. P. Dziobak, P. Fialho and J. A. Perlinger (2015). "Morphology and Mixing State of Aged Soot Particles at a Remote Marine Free Troposphere Site: Implications for Optical Properties." Geophysical Research Letters.

11. Donahue, N., J. Kroll, S. Pandis and A. Robinson (2012). "A two-dimensional volatility basis set-Part 2: Diagnostics of organic-aerosol evolution." Atmospheric Chemistry and Physics 12(2): 615-634.

12. Donahue, N. M., A. L. Robinson, E. R. Trump, I. Riipinen and J. H. Kroll (2012). Volatility and aging of atmospheric organic aerosol. Atmospheric and Aerosol Chemistry, Springer: 97-143.

13. Fast, J. D., W. Gustafson Jr, L. K. Berg, W. J. Shaw, M. Pekour, M. Shrivastava, J. C. Barnard, R. Ferrare, C. A. Hostetler and J. Hair (2012). "Transport and mixing patterns over Central California during the carbonaceous aerosol and radiative effects study (CARES)." Atmos. Chem. Phys 12(4): 1759-1783.

14. Kanakidou, M., J. Seinfeld, S. Pandis, I. Barnes, F. Dentener, M. Facchini, R. V. Dingenen, B. Ervens, A. Nenes and C. Nielsen (2005). "Organic aerosol and global climate modelling: a review." Atmospheric Chemistry and Physics 5(4): 10531123.

15. Khalizov, A. F., Y. Lin, C. Qiu, S. Guo, D. Collins and R. Zhang (2013). "Role of $\mathrm{OH}$-initiated oxidation of isoprene in aging of combustion soot." Environmental science \& technology 47(5): 2254-2263.

16. Koop, T., J. Bookhold, M. Shiraiwa and U. Pöschl (2011). "Glass transition and phase state of organic compounds: dependency on molecular properties and implications for secondary organic aerosols in the atmosphere." Physical Chemistry Chemical Physics 13(43): 19238-19255. 
17. Kuwata, M. and S. T. Martin (2012). "Phase of atmospheric secondary organic material affects its reactivity." Proceedings of the National Academy of Sciences 109(43): 17354-17359.

18. Metcalf, A. R., C. L. Loza, M. M. Coggon, J. S. Craven, H. H. Jonsson, R. C. Flagan and J. H. Seinfeld (2013). "Secondary organic aerosol coating formation and evaporation: chamber studies using black carbon seed aerosol and the singleparticle soot photometer." Aerosol Science and Technology 47(3): 326-347.

19. Moffet, R. C., T. Rödel, S. T. Kelly, X.-Y. Yu, G. Carroll, J. Fast, R. A. Zaveri, A. Laskin and M. K. Gilles (2013). "Spectro-microscopic measurements of carbonaceous aerosol aging in Central California." Atmospheric Chemistry and Physics 13(20): 10445-10459.

20. Myhre, G., D. Shindell, F. Bréon, W. Collins, J. Fuglestvedt, J. Huang, D. Koch, J. Lamarque, D. Lee and B. Mendoza (2013). "Anthropogenic and natural radiative forcing, Chapter 8 in Climate Change 2013: The Physical Science Basis. Contribution of Working Group I to the Fifth Assessment Report of the Intergovernmental Panel on Climate Change, edited by Stocker, TF, D. Qin, G." K. Plattner, M. Tignor, SK Allen, J. Boschung, A. Nauels, Y. Xia, V. Bex and PM Midgley, Cambridge University Press, Cambridge, UK and New York, NY.

21. O'Brien, R. E., A. Neu, S. A. Epstein, A. C. MacMillan, B. Wang, S. T. Kelly, S. A. Nizkorodov, A. Laskin, R. C. Moffet and M. K. Gilles (2014). "Physical properties of ambient and laboratory-generated secondary organic aerosol." Geophysical Research Letters 41(12): 4347-4353.

22. Renbaum-Wolff, L., J. W. Grayson, A. P. Bateman, M. Kuwata, M. Sellier, B. J. Murray, J. E. Shilling, S. T. Martin and A. K. Bertram (2013). "Viscosity of $\alpha$ pinene secondary organic material and implications for particle growth and reactivity." Proceedings of the National Academy of Sciences 110(20): 8014-8019. 
23. Riemer, N., M. West, R. Zaveri and R. Easter (2010). "Estimating black carbon aging time-scales with a particle-resolved aerosol model." Journal of Aerosol Science 41(1): 143-158.

24. Riemer, N., M. West, R. A. Zaveri and R. C. Easter (2009). "Simulating the evolution of soot mixing state with a particle-resolved aerosol model." Journal of Geophysical Research: Atmospheres (1984-2012) 114(D9).

25. Saukko, E., A. Lambe, P. Massoli, T. Koop, J. Wright, D. Croasdale, D. Pedernera, T. Onasch, A. Laaksonen and P. Davidovits (2012). "Humidity-dependent phase state of SOA particles from biogenic and anthropogenic precursors." Atmospheric Chemistry and Physics 12(16): 7517-7529.

26. Scarnato, B. V., S. China, K. Nielsen and C. Mazzoleni (2015). "Perturbations of the optical properties of mineral dust particles by mixing with black carbon: a numerical simulation study." Atmos. Chem. Phys. 15(12): 6913-6928.

27. Schnitzler, E. G., A. Dutt, A. M. Charbonneau, J. S. Olfert and W. Jäger (2014). "Soot Aggregate Restructuring Due to Coatings of Secondary Organic Aerosol Derived from Aromatic Precursors." Environmental science \& technology 48(24): 14309-14316.

28. Sedlacek, A. J., E. R. Lewis, L. Kleinman, J. Xu and Q. Zhang (2012). "Determination of and evidence for non-core-shell structure of particles containing black carbon using the Single-Particle Soot Photometer (SP2)." Geophysical Research Letters 39(6).

29. Setyan, A., Q. Zhang, M. Merkel, W. B. Knighton, Y. Sun, C. Song, J. E. Shilling, T. B. Onasch, S. C. Herndon and D. R. Worsnop (2012). "Characterization of submicron particles influenced by mixed biogenic and anthropogenic emissions using high-resolution aerosol mass spectrometry: results from CARES." Atmospheric Chemistry and Physics 12(17): 8131-8156.

30. Sorensen, C. and G. Feke (1996). "The morphology of macroscopic soot." Aerosol Science and Technology 25(3): 328-337. 
31. Vaden, T. D., D. Imre, J. Beránek, M. Shrivastava and A. Zelenyuk (2011). "Evaporation kinetics and phase of laboratory and ambient secondary organic aerosol." Proceedings of the National Academy of Sciences 108(6): 2190-2195.

32. Vaden, T. D., C. Song, R. A. Zaveri, D. Imre and A. Zelenyuk (2010). "Morphology of mixed primary and secondary organic particles and the adsorption of spectator organic gases during aerosol formation." Proceedings of the National Academy of Sciences 107(15): 6658-6663.

33. Virtanen, A., J. Joutsensaari, T. Koop, J. Kannosto, P. Yli-Pirilä, J. Leskinen, J. M. Mäkelä, J. K. Holopainen, U. Pöschl and M. Kulmala (2010). "An amorphous solid state of biogenic secondary organic aerosol particles." Nature 467(7317): 824-827.

34. Virtanen, A., J. Kannosto, H. Kuuluvainen, A. Arffman, J. Joutsensaari, E. Saukko, L. Hao, P. Yli-Pirilä, P. Tiitta and J. Holopainen (2011). "Bounce behavior of freshly nucleated biogenic secondary organic aerosol particles." Atmospheric Chemistry and Physics 11(16): 8759-8766.

35. Zaveri, R., W. Shaw, D. Cziczo, B. Schmid, R. Ferrare, M. Alexander, M. Alexandrov, R. Alvarez, W. Arnott and D. Atkinson (2012). "Overview of the 2010 Carbonaceous Aerosols and Radiative Effects Study(CARES)." Atmospheric Chemistry and Physics 12(16): 7647-7687.

36. Zhang, Q., J. Jimenez, M. Canagaratna, J. Allan, H. Coe, I. Ulbrich, M. Alfarra, A. Takami, A. Middlebrook and Y. Sun (2007). "Ubiquity and dominance of oxygenated species in organic aerosols in anthropogenically-influenced Northern Hemisphere midlatitudes." Geophysical Research Letters 34(13). 


\section{Secondary Organic Aerosol Processing of Diesel Soot and Effects on Condensational Rate in Different Relative Humidity Conditions ${ }^{4}$}

\subsection{Abstract}

Secondary organic aerosol (SOA) are formed from the oxidation of volatile organic compounds emitted from biogenic and anthropogenic sources. Soot particles emitted during combustion processes can be coated by condensation of secondary organic material. However, previous studies established that the viscosity of SOA, is affected by relative humidity. Here we discuss the effects of relative humidity on the condensation and growth of $\alpha$-pinene SOA on diesel soot in controlled laboratory conditions during the Soot Aerosol Aging Study (SAAS).

Soot particles were produced with a Diesel generator and size-selected with a differential mobility analyzer before being injected into a reaction chamber. Experiments were conducted under dry $(\mathrm{RH}<2 \%)$ and humid conditions $(\mathrm{RH} \sim 80 \%)$ by condensing SOA generated from $\mathrm{OH}$-initiated photochemical oxidation of $\alpha$-pinene on the soot particle seeds. In dry conditions soot particles grew up to twice the mobility diameter of nascent soot, depending upon the seed particle number concentration; whereas in humid conditions, a decrease in mobility diameter was observed at the beginning of the SOA condensation and only a modest growth in mobility diameter was observed later on, even when most of the $\alpha$-pinene was entirely consumed. This study suggests that the viscosity of the material forming SOA and the morphology of the seed soot particles play a crucial role in the growth of SOA on soot. Mixing configurations produced in different relative humidity conditions result in particle morphologies often significantly different from spherical core-shells used in Mie calculations, impacting the optical properties of SOA mixed soot.

\footnotetext{
${ }^{4}$ Based on the manuscript in preparation for Environmental Science and Technoogy (to be submitted in spring 2016)
} 


\subsection{Introduction}

Till date, studies on Earth's radiative balance have suggested that atmospheric Black Carbon (BC) is potentially the second largest contributor to the positive radiative forcing (Stocker, Qin et al. 2013). This is because BC is a strong absorber of solar radiation in the ultraviolet, visible and near infrared spectral regions (Jacobson 2001, Ramanathan and Carmichael 2008). Nanosphere soot (Buseck, Adachi et al. 2014), often just called soot, is considered a surrogate for black carbon and the terms are often approximately used interchangeably. Soot is emitted into the atmosphere as a result of incomplete combustion in natural and anthropogenic processes. During an incomplete combustion process, soot is generally accompanied by the emission of other primary organic aerosols and volatile organic compounds. Fresh soot emitted into the atmosphere typically has a fractal-like structure in which primary spherical particles, termed as monomers, are arranged into branched, chain-like aggregates (Sorensen 2001). In the atmosphere, soot interacts with water and other aerosols such as organics, sulfates, and nitrates, and transforms its physical and chemical properties (Riemer, Vogel et al. 2004, Moffet and Prather 2009, China, Scarnato et al. 2015). This process is often termed as "ageing", which governs the lifetime and loading of soot in the atmosphere and its radiative forcing (Van Poppel, Friedrich et al. 2005).

Semivolatile organic compounds are formed in the atmosphere as a result of photochemical oxidation of volatile organic compounds (Kanakidou, Seinfeld et al. 2005, Donahue, Kroll et al. 2012, Ehn, Thornton et al. 2014), emitted from biogenic and anthropogenic sources. These semivolatile organic compounds condense on seed aerosol particles and form particle phase secondary organic material (SOM). Several studies have been conducted to understand the condensational growth of SOA on seed aerosol particles (Jimenez, Canagaratna et al. 2009, Ehn, Thornton et al. 2014, Kristensen, Cui et al. 2014). Ehn, Thornton et al. (2014) studied the SOA mass formation from $\alpha$-pinene oxidation in a series of chamber studies and found that the condensation of extremely low volatility organic compounds on the surface of existing aerosols accounts for a significant SOA mass yield. Based on their modeling and experimental results, they established that an increase 
in seed particle surface area serving as condensational sink corresponds to an increase in mass of SOA formed on these seed particles due to the condensation of extremely low volatility organic compounds.

The condensation of semivolatile organic compounds on soot is an important pathway for soot processing in the atmosphere. This process results into complex soot mixing states and morphologies (Adachi and Buseck 2008, Sedlacek, Lewis et al. 2012, Adachi and Buseck 2013, China, Mazzoleni et al. 2013). Several field studies conducted to investigate the mixing states of soot in different atmospheric conditions, have shown that soot is often mixed with sulfates and SOA that coats the soot cores during the ageing process (Schwarz, Spackman et al. 2008, Moffet and Prather 2009, Cahill, Suski et al. 2012, Adachi and Buseck 2013, China, Mazzoleni et al. 2013, China, Salvadori et al. 2014). Previous studies have also revealed that condensation of organic and sulfates on the surface of soot particles, transforms it from hydrophobic to hydrophilic, making the mixed particle an active cloud condensation nuclei (Zhang, Khalizov et al. 2008). This reduces the atmospheric lifetime of soot due to wet scavenging (Saathoff, Naumann et al. 2003, Van Poppel, Friedrich et al. 2005, Khalizov, Lin et al. 2013). In addition, the soot restructuring during the aging processes and its mixing with other co-existing aerosols also influence its optical properties (Jacobson 2001, Cross, Onasch et al. 2010, Cappa, Onasch et al. 2012, Lack, Langridge et al. 2012).

The study of the growth of SOA coating holds its significance especially in quantifying the enhancement of light absorption due to the so called "lensing effect" in mixed soot particles with core-shell morphology (Jacobson 2001, Cappa, Onasch et al. 2012), and in better understanding the aerosol-cloud interactions (Metcalf, Loza et al. 2013). Laboratory studies, executed under controlled conditions, are an important step in understanding the complicated observations obtained during ambient sampling. A limited set of laboratory experiments have been designed to specifically study the morphology and optical properties of soot seeds due to the growth of SOA coatings (Saathoff, Naumann et al. 2003, Schnaiter, Horvath et al. 2003, Schnaiter, Linke et al. 2005, Cross, Onasch et al. 2010, Metcalf, Loza et al. 2013). Some other studies aimed at understanding the interaction of 
aged soot with water vapor at high RH and the quantification of its $\mathrm{CCN}$ activity (Zhang, Khalizov et al. 2008, Khalizov, Lin et al. 2013); however, the effect of relative humidity on the growth dynamics of SOA on soot still remains largely unexplored.

A main goal of our study was to investigate the SOA growth on soot seeds in dry and humid conditions. Here we discuss the interplay between soot morphology, SOA formation and relative humidity with a dedicated set of experiments conducted during the Soot Aerosol Ageing Study (SAAS). SAAS was a chamber study conducted at the Pacific Northwest National Laboratory in November 2013 and January 2014, as a follow-up to the Carbonaceous Aerosols Radiative Effects Study (CARES). CARES was conducted in June 2010 in the Sacramento (CA) area, aiming at the study of mixing of urban plumes from Sacramento with biogenic emissions from the forests of the Sierra Nevada (Zaveri, Shaw et al. 2012). The aim of SAAS was to understand how soot ages upon mixing with biogenic

emissions, in an attempt to simulate conditions encountered during CARES. $\alpha$-pinene is one of the dominant constituent of monoterpene emissions in forested areas in the United States (Lerdau, Dilts et al. 1994, Geron, Rasmussen et al. 2000), while diesel sources dominate the emissions of soot in the Sacramento area. Therefore, during SAAS we used a Diesel engine to generate soot and $\alpha$-pinene for the generation of SOA. We deployed several instruments to monitor the physical, optical, and chemical properties of soot and SOA-mixed soot. In addition, aerosol samples were collected on different substrates for offline electron microscopy that is a powerful tool for the investigation of soot mixing states (Adachi and Buseck 2008, Adachi and Buseck 2013, China, Mazzoleni et al. 2013). Here we discuss the different soot-SOA mixing states encountered at different $\mathrm{RH}$ conditions, with implications on the mixed aerosol optical properties that directly affects the radiative forcing of soot.

\subsection{Experimental section}

\subsubsection{Soot and SOA generation}

During SAAS, soot was generated from a diesel engine and was first passed through a charcoal denuder to remove volatile organic compounds and $\mathrm{NO}_{\mathrm{x}}$ co-generated during the combustion process in the engine. In this manuscript, we discuss five SOA condensation 
experiments, three of them conducted at $\mathrm{RH}<2 \%$ (dry conditions) and two conducted at $\mathrm{RH} \approx 80 \%$ (humid conditions) (Table 1).

In each of these experiments, soot particles were size selected based on their mobility diameter by using a differential mobility analyzed (DMA, TSI model 3081) to obtain a narrow mobility size distribution. The mode mobility diameter of size selected soot for experiments $1-4$ was $\approx 120 \mathrm{~nm}$, while for experiment 5 , it was $180 \mathrm{~nm}$. The size distribution of nascent soot for experiments 1 to 5 are shown in supplementary Figure S1. Mobilityselected soot was injected into the PNNL environmental chamber. Once the desired particle number concentrations $(\approx 10,000 \# / c c)$ were achieved, soot injection was stopped. Thereafter, SOA was generated in the chamber by photochemical oxidation of $\alpha$-pinene in presence of $\mathrm{OH}$ radicals. The SOA precursor $\alpha$-pinene $(2 \mu \mathrm{L})$ was injected with dry air flowing into the chamber at a rate of 2 LPM. The $\alpha$-pinene injection was followed by injection of hydrogen peroxide, $\mathrm{H}_{2} \mathrm{O}_{2}$ for $\approx 1 \mathrm{hr}$ to facilitate the $\mathrm{OH}$-initiated oxidation of $\alpha$-pinene. Upon completion of $\mathrm{H}_{2} \mathrm{O}_{2}$ injection, UV lights were turned on. The formation of SOA on the soot seeds initiated at this point as a result of the photochemistry 
Table 4-1: Mean single particle morphological parameters of samples from all the condensation experiments.

\begin{tabular}{|c|c|c|c|c|c|c|c|c|c|c|}
\hline Expt no. & RH (\%) & $\begin{array}{l}\mathrm{NS} \mathrm{D}_{\mathrm{m}} \\
(\mathrm{nm})\end{array}$ & $\begin{array}{l}\text { Particle } \\
\text { conc*. } \\
(\# / c c)\end{array}$ & $\begin{array}{l}\text { Seed surface } \\
\text { area* }\left(\mathrm{nm}^{2} / \mathrm{cc}\right)\end{array}$ & $\begin{array}{l}\text { Final } \\
\text { GFD }_{m}\end{array}$ & $\begin{array}{l}\text { Sampling } \\
\text { phase }\end{array}$ & $\mathrm{n}$ & $\mathrm{D}_{\mathrm{Aeq}}(\mathrm{nm})$ & $\mathrm{CV}$ & $\mathrm{RN}$ \\
\hline \multirow{3}{*}{1} & \multirow{3}{*}{$<2 \%$} & \multirow{3}{*}{120} & \multirow{3}{*}{1805} & \multirow{3}{*}{$1.37 \mathrm{E}+08$} & \multirow{3}{*}{2.2} & 1 & 200 & $153(45)$ & $0.71(0.10)$ & $0.41(0.12)$ \\
\hline & & & & & & 2 & 200 & $136(41)$ & $0.77(0.07)$ & $0.46(0.11)$ \\
\hline & & & & & & 3 & 200 & $163(50)$ & $0.82(0.06)$ & $0.53(0.11)$ \\
\hline \multirow{3}{*}{2} & \multirow{3}{*}{$\approx 80 \%$} & \multirow{3}{*}{120} & \multirow{3}{*}{8913} & \multirow{3}{*}{$6.64 \mathrm{E}+08$} & \multirow{3}{*}{1.13} & 1 & 200 & $144(62)$ & $0.73(0.11)$ & $0.41(0.12)$ \\
\hline & & & & & & 2 & 200 & $136(49)$ & $0.81(0.08)$ & $0.50(0.11)$ \\
\hline & & & & & & 3 & 200 & $128(49)$ & $0.83(0.07)$ & $0.53(0.12)$ \\
\hline \multirow{3}{*}{3} & \multirow{3}{*}{$<2 \%$} & \multirow{3}{*}{120} & \multirow{3}{*}{8256} & \multirow{3}{*}{$5.53 \mathrm{E}+08$} & \multirow{3}{*}{1.6} & 1 & 100 & $158(36)$ & $0.71(0.09)$ & $0.40(0.09)$ \\
\hline & & & & & & 2 & 100 & $136(32)$ & $0.77(0.08)$ & $0.47(0.10)$ \\
\hline & & & & & & 3 & 100 & $164(38)$ & $0.82(0.06)$ & $0.54(0.07)$ \\
\hline \multirow{3}{*}{4} & \multirow{3}{*}{$\approx 80 \%$} & \multirow{3}{*}{120} & \multirow{3}{*}{8378} & \multirow{3}{*}{$6.63 \mathrm{E}+08$} & \multirow{3}{*}{1} & 1 & 100 & $139(58)$ & $0.73(0.10)$ & $0.43(0.13)$ \\
\hline & & & & & & 2 & 100 & $168(58)$ & $0.77(0.10)$ & $0.48(0.14)$ \\
\hline & & & & & & 3 & 100 & $156(37)$ & $0.81(0.09)$ & $0.5(0.12)$ \\
\hline \multirow{3}{*}{5} & \multirow{3}{*}{$2 \%$} & \multirow{3}{*}{180} & \multirow{3}{*}{3500} & \multirow{3}{*}{$4.66 \mathrm{E}+08$} & \multirow{3}{*}{1.17} & 1 & 100 & $167(75)$ & $0.73(0.13)$ & $0.41(0.14)$ \\
\hline & & & & & & 2 & 100 & $166(51)$ & $0.72(0.1)$ & $0.41(0.14)$ \\
\hline & & & & & & 3 & 100 & $159(53)$ & $0.82(0.08)$ & $0.52(0.12)$ \\
\hline
\end{tabular}

* At the beginning of the SOA generation, i.e. when the UV lights were turned on. Numbers in parenthesis indicate the standard deviation. For all the first four experiments, the mode mobility diameter of nascent soot was $120 \mathrm{~nm}$, while it was $180 \mathrm{~nm}$ for the fifth experiment. NS= Nascent soot, $\mathrm{n}=$ number of particles analyzed, $\mathrm{CV}=$ convexity, $\mathrm{RN}=$ Roundness 


\subsubsection{Particle mobility and mass measurements}

Various instruments including a scanning mobility particle sizer (SMPS), an Aerosol Mass Spectrometer (AMS), a Proton-Transfer-Reaction Mass Spectrometer (PTR-MS), and a Single Particle Laser Ablation Time-of-Flight mass spectrometer (SPLAT II) were used to measure the physical and chemical properties of soot. The SMPS sampled the aerosol continuously to monitor the size distribution and the total particle concentration during the entire experiment. However, the AMS, PTR-MS, SPLAT II and the sample collectors were operated only for short intervals at three crucial phases of the experiment (vertical lines in Figure 2) to avoid a rapid decay of the particle concentration in the chamber: Phase 1- when the chamber was filled with nascent soot; Phase 2- within 30-40 minutes from the beginning of photochemical oxidation of $\alpha$-pinene; and Phase 3- when SOA formation stabilized, i.e. when nearly all the $\alpha$-pinene was consumed due to photochemical oxidation.

The SMPS measurements for the particle size distributions in dry (experiment 1: $\mathrm{RH} \sim 2 \%$ ) and humid (experiment 2 : $\mathrm{RH} \sim 80 \%$ ) conditions for the different experimental phases during SAAS are shown in supplementary figure S2, a and b, respectively. We used the mobility size distribution from SMPS and the vacuum aerodynamic size distribution and SOA mass fraction from SPLAT-II to calculate the growth factors of SOA on soot for the mobility diameter, the vacuum aerodynamic diameter, and the mass $\left(\mathrm{GFD}_{\mathrm{m}}, \mathrm{GFD}_{\mathrm{va}}\right.$ and GFM). $\mathrm{GFD}_{\mathrm{m}}$ is given by the ratio of the mode mobility diameter of the coated soot at time $t\left(D_{t}\right)$ to the mode mobility diameter of the nascent soot $\left(D_{0}\right)$. (Equation $\left.(4)\right)($ Khalizov, Lin et al. 2013).

$$
G F D_{m}=\frac{D_{t}}{D_{0}}
$$

Similarly the $G D_{\text {va }}$ was calculated using the mode vacuum aerodynamic diameter. Finally, the mass growth factor (GFM), defined by the ratio of mass of the soot particle at time $t$ and mass of fresh soot particle (Zhang, Khalizov et al. 2008), was calculated as:

$$
G F M=\frac{m_{t}}{m_{0}}
$$


The GFM can also be expressed in terms of the SOA mass fraction, $f_{S O A}=m_{S O A}$ / $m_{S O A}+m_{\text {Soot }}$ as:

$$
G F M=\frac{1}{1-f_{S O A}(t)}
$$

\subsubsection{Particle morphology}

Aerosol samples were collected on lacey carbon grids for Transmission Electron Microscopy (TEM) and on nuclepore polycarbonate membranes for Scanning Electron Microscopy (SEM) to investigate the evolution of particle morphology. A four-stage impactor (MPS-4G1) was used to collect aerosol on the substrates in the third and fourth stages with $50 \%$ cut off aerodynamic diameters of $150 \mathrm{~nm}$ and $50 \mathrm{~nm}$, respectively. A custom made sampler was used to collect particles on the nuclepore filters. Samples were collected during the three phases of the experiment discussed in section 2.2, from the dry and humid experiments. Individual particles were imaged using a Field Emission SEM (Hitachi S-4700) and a TEM (JEOL JEM-2010). The 2-D projected images were processed and analyzed using the freely available ImageJ 1.48 software according to the approach discussed by China, Salvadori et al. (2014) to obtain several parameters and quantifying the shape and size of the particles. The area equivalent diameter $D_{A e q}$ obtained from the particle projected area, is a measure of the 2-D particle size. We calculated $D_{A e q}$ as:

$$
D_{A e q}=\sqrt{\frac{4}{\pi} A_{p}}
$$

Where $A_{p}$ is the projected area of the particle. Convexity (also known as solidity) and roundness describe the particle's degree of compaction and overall shape. Roundness is given by:

$$
\text { Roundness }=\frac{4 A_{p}}{\pi L_{\max }^{2}}
$$

Where $L_{\max }$ is the maximum length of the particle. Convexity is calculated by taking the ratio of the projected area $\left(A_{p}\right)$ of the particle to the area of the smallest convex hull 
polygon $\left(A_{c}\right)$ fitted onto the 2D image of the particle (China, Scarnato et al. 2015) (Figure $1)$.

$$
\text { Convexity }=\frac{A_{p}}{A_{c}}
$$

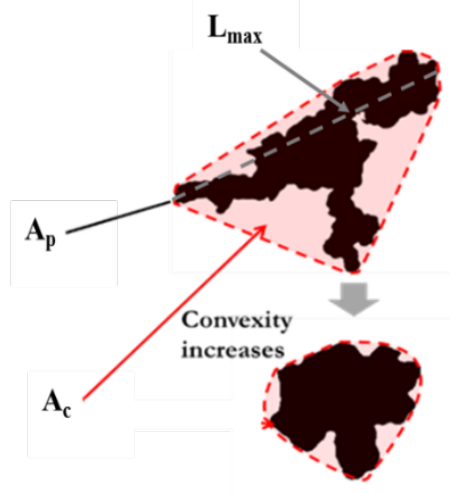

Figure 4-1 Morphological parameters: Ap: projected area of the particle, Ac: Area of convex hull polygon, Lmax: maximum length. The convexity of the upper particle is 0.56 and that of the lower particle is 0.9

\subsection{Results}

In this section we mainly discuss the results from experiment 1 and 2; results from experiments 3,4 and 5 (Table 1) are utilized to assess the reproducibility of the observations from the first two experiments.

\subsubsection{Growth of SOA mass on soot seeds}

Figure 2 shows the time evolution of the concentration of $\alpha$-pinene in the chamber during experiments 1 and 2 as observed by the PTR-MS. The initial concentration of $\alpha$ pinene in the two experiments was comparable. When the UV lights were turned on (at time $=0$ ), the decay in $\alpha$-pinene concentration due to photochemical oxidation was followed by an increase in SOA mass as observed by the AMS. In high RH (humid) conditions the SOA mass growth rate was observed to be slower as compared to that in low RH (dry) conditions. 


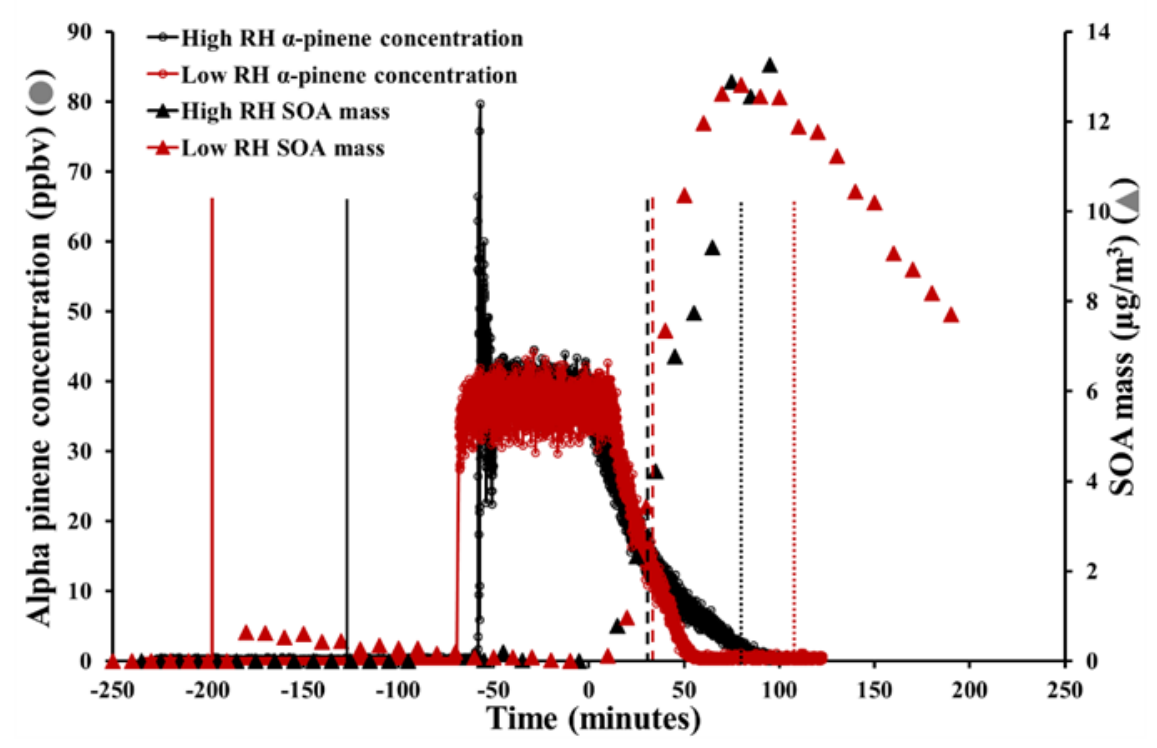

Figure 4-2 Time series of $\alpha$ - pinene concentration (circles) and of SOA mass concentrations (triangles) from experiments 1 and 2. In red are the data for the low RH experiment, and in black the data for the high $\mathrm{RH}$ experiment. Time $\mathrm{t}=0$ indicates when UV lights were turned on and the photochemical oxidation of $\alpha$-pinene started. Vertical lines indicate when samples were collected for electron microscopy, with sampling times of 15-60 sec. Solid lines indicate nascent soot (phase 1), dashed lines indicate samples collected within 30-40 minutes from the beginning of the SOA formation (phase 2), and dotted lines indicate samples collected when the SOA concentration was stabilized, i.e. when all $\alpha$-pinene was consumed (phase 3$)$ ).

\subsubsection{Evolution of particle size, mass and morphology in dry conditions}

Figure 3 (panels a, b \& c) depicts the GFM, GFD va and GFD ${ }_{\mathrm{m}}$ of soot as the growth of SOA proceeded (Figure 2) in dry (experiment 1, red curve) and humid (experiment 2, black curve) conditions. In this section we present the results obtained during the experiment in dry conditions, while the results of the experiment in humid condition will be presented in section 3.3 . 

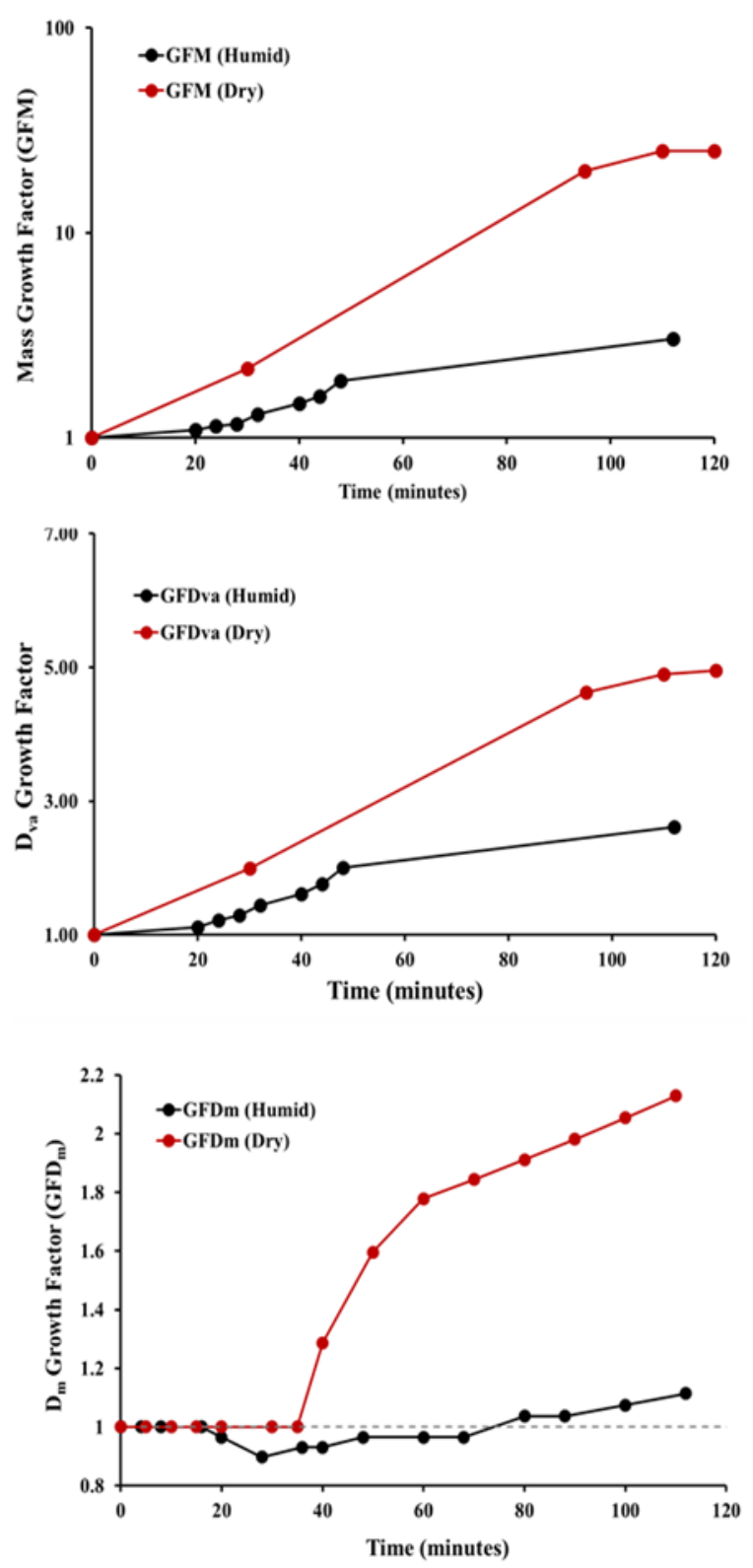

Figure 4-3 (a) Mass growth factor (GFM) ( log scale) (b) vacuum aerodynamic diameter growth factor (GFDva) ( linear scale) and (c) mobility diameter growth factor (GFDm) (linear scale) for the soot-SOA internally mixed particles in humid and dry experiments. The horizontal axes represent the time elapsed since the SOA generation began ( $\mathrm{t}=0$ when the UV lights were turned on), in minutes. The grey dashed line in the $\mathrm{GFD}_{\mathrm{m}}$ plot represents a diameter growth factor of 1 (nascent soot at $\mathrm{t}=0$ ). 
In dry conditions, the $\mathrm{GFD}_{\mathrm{va}}$ and GFM showed a continuous increase due to SOA condensation. An increase in particle mobility diameter was also observed approximately 30-40 min after the beginning of the SOA generation. By the time the $\alpha$-pinene was mostly consumed, the particle vacuum aerodynamic diameter increased up to five times and the mobility diameter up to two times that of fresh soot $\left(\mathrm{GFD}_{\mathrm{va}} \approx 5.0, \mathrm{GFD}_{\mathrm{m}} \approx 2.1\right)$, while the mass grew by about 25 times $(\mathrm{GFM} \approx 25)$. The lower $\mathrm{GFD}_{\mathrm{m}}$ in experiment 3 (Table 1$)$ may be attributed to the higher concentration of seed soot particles available for the condensation of SOA at the beginning of the SOA generation. Even lower growth in experiment 5 may additionally be attributed to the larger size of individual soot particles, which may require larger amounts of SOA to condense on them in order to see a significant change in the particle mobility diameter. In figure 4 , open circles represent the $D_{\text {Aeq }}$ number distribution of particles determined from the SEM analysis for the three phases of experiment 1 .

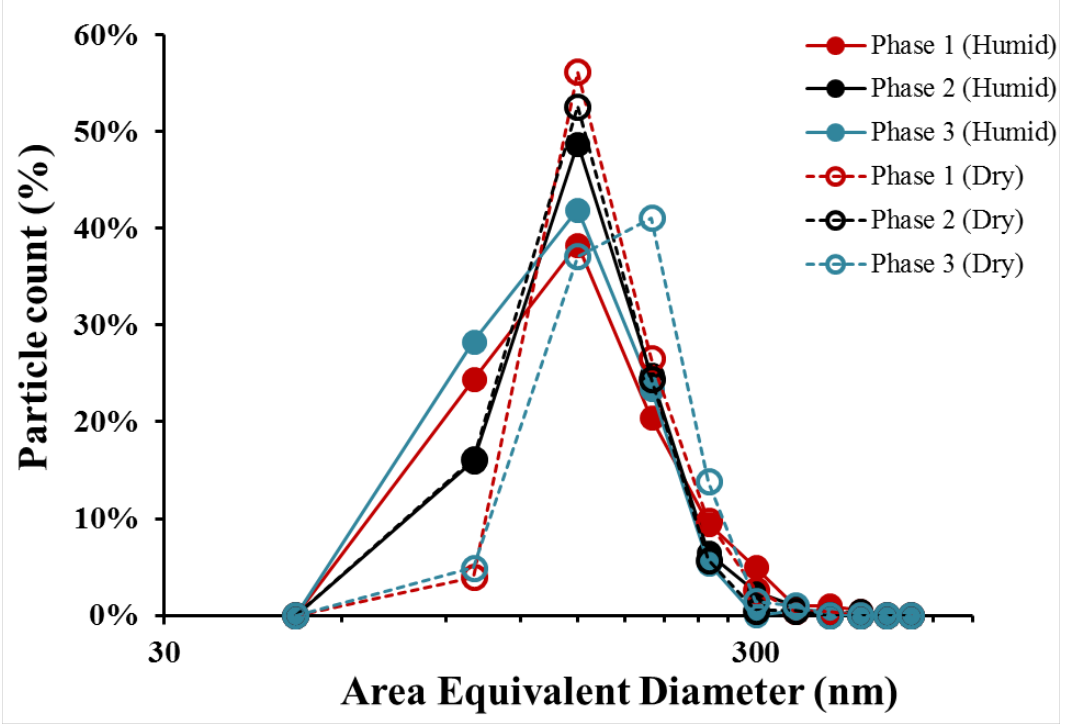

Figure 4-4 (a) Area equivalent diameter number distribution for phase 1, 2 and 3 from high (solid lines) and low (dashed lines) relative humidity conditions. Particle growth is evident in dry conditions by the shift in mode diameter from $D_{A e q} \approx 150 \mathrm{~nm}$ in phase 1 to $D_{A e q} \approx 200 \mathrm{~nm}$ in phase 3 . 
The soot particles grew from a mode $D_{\text {Aeq }} \approx 150 \mathrm{~nm}$ for nascent soot to a mode $D_{\text {Aeq }} \approx$ $200 \mathrm{~nm}$ in phase 3. The convexity (figure 5(a)) and roundness (figure 5(b)) of these particles gradually increased from phase 1 to phase 3 . This increase may be attributed to filling of gaps between soot branches with condensed SOA. In Figure 6(b) we show examples of TEM images from experiment 1 of particles from phase 1, phase 2 and phase 3 , indicated by letters (i), (ii), (iii), respectively. The average values of the respective morphological parameters are listed in Table 1, along with their corresponding standard deviations in parenthesis.

\subsubsection{Evolution of particle size, mass and morphology in humid conditions}

In humid conditions, the rise in GFM and $\mathrm{GFD}_{\mathrm{va}}$ by $8-10 \%$ within $30 \mathrm{~min}$ of the beginning of SOA generation in experiment 2 (figure $3(\mathrm{a} \& \mathrm{~b})$ ), indicates initial SOA uptake by soot. After this initial SOA uptake, the mobility diameter growth factor actually decreased to values less than 1 (figure 3(b)) indicating a substantial compaction of the soot particles. The rapid increase in convexity (figure 5(a)) and roundness (figure 5(b)) of these particles is also mostly attributed to soot compaction due to condensed SOA. Only after $\sim 65$ minutes, the $\mathrm{GFD}_{\mathrm{m}}$ slowly increased above unity. The final growth $\left(\mathrm{GFD}_{\mathrm{va}} \approx 2.6\right.$, $\mathrm{GFD}_{\mathrm{m}} \approx 1.11$, and $\mathrm{GFM} \approx 3$, with no noticeable change in mode $\left.D_{A e q}\right)$ in humid conditions was small as compared to dry conditions. The low mass growth factor (figure 3(a)) at high $\mathrm{RH}$ in experiment 2, suggests that soot particles were much less prone to uptake SOA in these conditions. TEM images in figure 6(a) (i), (ii), (iii) represent the particles from phase 1 , phase 2 and phase 3 of the experiment, respectively. Note that the particle in figure 6(a) (ii) from phase 2 of the experiment 2 (humid) appears to be more compact and with less SOA coating (generally seen as a smooth layer over the monomers making them barely distinguishable from each other) than the particle in figure 6(b) (ii) from phase 2 of experiment 1 (dry). 

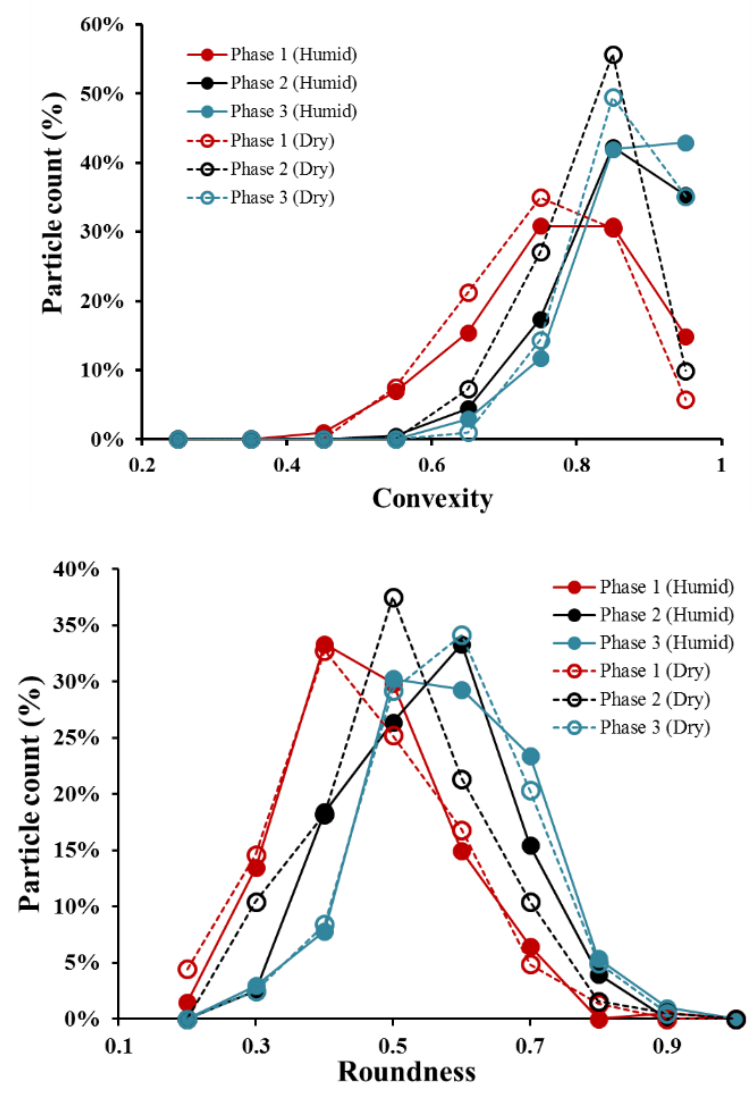

Figure 4-5 (a) convexity and (b) roundness of nascent soot particles from phase 1, 2 and 3 for dry (dashed lines) and humid experiments (solid lines). In humid conditions, the distributions of convexity and roundness of phase 2 particles (filled black circles) approach the distributions of phase 3 particles from the dry experiment (open blue circles), indicating a rapid soot compaction. 

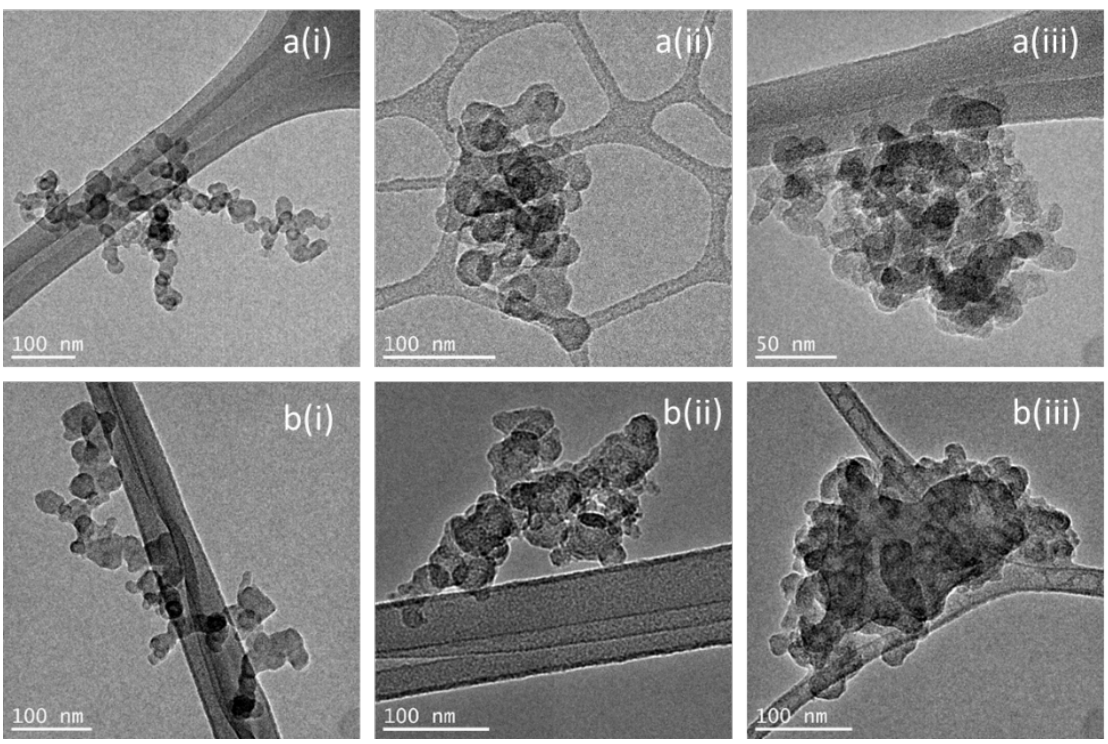

Figure 4-6 TEM images of sample particles for (i) phase 1, (ii) phase 2 and (iii) phase 3 for (a) Experiment 2 (humid) and (b) Experiment 1 (dry).

\subsection{Discussion}

\subsubsection{SOA growth and seed surface area}

In an experimental and modeling study, Ehn, Thornton et al. (2014) established that the partitioning of SOA to particle phase was dependent upon the surface area of seed available for condensation. We calculated the approximate values of total soot seed surface area $\left(\mathrm{nm}^{2} / \mathrm{cc}\right)$ available for condensation of organics upon the beginning of SOA generation by integrating the seed surface area calculated for each mobility diameter $\left(D_{m}\right)$ using the equation:

$$
\text { Seed Surface Area }=4 \pi\left(\frac{D_{m}}{2}\right)^{2} N
$$

Where, $N(\# / \mathrm{cc})$ is the particle number concentration corresponding to the $D_{m}$

The maximum growth of SOA on individual particles in experiment 1 may partially be attributed to the minimum seed surface area available for condensation in this experiment. However, experiments 2, 3 and 4 have comparable seed surface upon the beginning of SOA generation, yet the higher SOA growth was observed on particles in dry conditions as 
compared to those in humid conditions. In section 4.2 we discuss some possible explanations for the observed discrepancies.

\subsubsection{Slow growth of SOA in humid conditions}

Cocker III, Clegg et al. (2001) observed no significant dependence of SOA mass yield (formed on AS seed from oxidation of $\alpha$-pinene with ozone) on relative humidity. Seinfeld, Erdakos et al. (2001), modeled the effect of relative humidity on the yield of condensed SOA mass and predicted an increase in the SOA mass at higher relative humidity. They attributed this increase to the degree of oxidation and hydrophilicity of the oxidation products in humid conditions. Therefore, a stronger increase was predicted in the case of SOA from cyclohexene precursor, while in the case of $\alpha$-pinene/ozone system, the predicted SOA yield at high RH was comparable to that at low RH. Seinfeld, Erdakos et al. (2001) validated their predictions by discussing the results in the context of the laboratory study by Cocker III, Clegg et al. (2001) and Edney, Driscoll et al. (2000). In a recent study, Kristensen, Cui et al. (2014) confirmed the lack of dependence of SOA mass

yield (condensed on ammonium sulfate seeds) on relative humidity in $\alpha$-pinene/ozone and $\alpha$-pinene/OH-initiated photo-oxidation systems. Even though the SOA mass yield may not be effected by relative humidity, it has been established by Renbaum-Wolff, Grayson et al. (2013) that relative humidity plays a significant role in determining the viscosity of secondary organic material ( $\mathrm{SOM}$ ) constituting the $\mathrm{SOA}$; i.e., for $\mathrm{RH} \geq 80 \%$, the viscosity of SOM corresponds to that of a liquid while at $\mathrm{RH} \leq 30 \%$, it corresponds to that of a solid. The low viscosity of SOM observed in humid conditions is due to the uptake of water as a result of the hygroscopic nature of SOM. Similarly, the enhanced uptake of water by soot coated with SOM formed from different organic precursors has been reported in several previous studies (Virkkula, Van Dingenen et al. 1999, Saathoff, Naumann et al. 2003, Tritscher, Jurányi et al. 2011). Based on these studies, we expect the viscosity of SOM in our humid experiment to be much lower than that of SOM in the dry experiment. The condensation of SOM on soot preferentially fills empty pores due to the inverse Kelvin effect (Weingartner, Burtscher et al. 1997, Popovicheva, Persiantseva et al. 2008). In humid conditions, the low viscosity SOM condensed in the pores of soot, exerts capillary forces that restructure the soot aggregate to a more compact shape. This effect has been 
observed in several previous studies (Miljevic, Surawski et al. 2012, Ma, Zangmeister et al. 2013).

Coelho, Bekki et al. (2000) developed a theoretical framework for calculating the uptake rates of gases on fractal particles. Bekki, David et al. (2000) extended this framework to the uptake of any chemical species on atmospheric soot fractals. According to this framework, for the reactive uptake of a chemical species on a fractal aggregate, the uptake flux, $J_{\text {fractal }}$ is proportional to its surface area $\left(\mathrm{S}_{\text {fractal }}\right)$, and is given by:

$$
J_{\text {fractal }}=K_{s} S_{\text {fractal }} C_{\infty}
$$

Where, $\mathrm{K}_{\mathrm{s}}$ is the surface reaction rate constant and $\mathrm{C}_{\infty}$ is the concentration of chemical species far from the aggregate.

The surface area of the fractal with $\mathrm{N}$ monomers is given by:

$$
S_{\text {fractal }}=F S_{0} N
$$

Where, $\mathrm{s}_{0}$ is the surface are of the monomers and $\mathrm{F}$, the fraction of free surface area of the aggregate (i.e. the surface in contact with the air), is inversely proportional to the compacity of the aggregate $\zeta$,

$$
F \zeta=\text { Constant }
$$

For example, for fractal aggregate with cubic monomers (assumption made for numerical simplicity), the value of proportionality constant has been estimated to be $\sim 2.4$ (Bekki, David et al. 2000). $\zeta$ corresponds to the structure coefficient or the prefactor, $k_{0}$ is the prefactor, in the aggregate with spherical monomers (e.g. soot) and is related to fractal dimension $D_{F}$ by:

$$
\zeta \sim k_{0} 2^{D_{F}}
$$

Several studies have previously established that when soot is compacted, its fractal dimension increases (Liu, Mishchenko et al. 2008, China, Mazzoleni et al. 2013). Freshly emitted soot particles have fractal dimension ranging from 1.50 to 1.80 while the fractal dimension of aged, compacted particles has been estimated to be as high as 2.75 (Bekki, David et al. 2000, China, Scarnato et al. 2015). Based on the morphological analysis that 
we performed on the nascent soot samples collected during this study, we estimated the fractal dimension of these particles to be $\sim 1.53$, with a prefactor, $\mathrm{k}_{0}=3.44$. We used $\mathrm{k}_{0}=3.44$ from our analysis and $\mathrm{k}_{0}=1.60$, suggested by Liu, Mishchenko et al. (2008) to estimate the change in the fraction of free surface area of these particles as they compact from $\mathrm{D}_{\mathrm{F}}=1.50$ to 2.75 (Figure 7). For fractal with cubic monomers (proportionality constant $\sim 2.4$ ) and assuming that the number of monomers $\mathrm{N}$ in the aggregate remains constant while the soot compacts, the decrease in surface area of the fractal as the fractal dimension increases from 1.5 to 2.75 was estimated to be $\sim 58 \%$ (equation 9 ), this value is independent of the value proportionality constant, therefore it can be assumed to be valid for other fractal aggregates, irrespective of their monomer shapes. This decrease in fractal surface area therefore may result in reducing the uptake by the aggregate by the same proportion (equation 8).

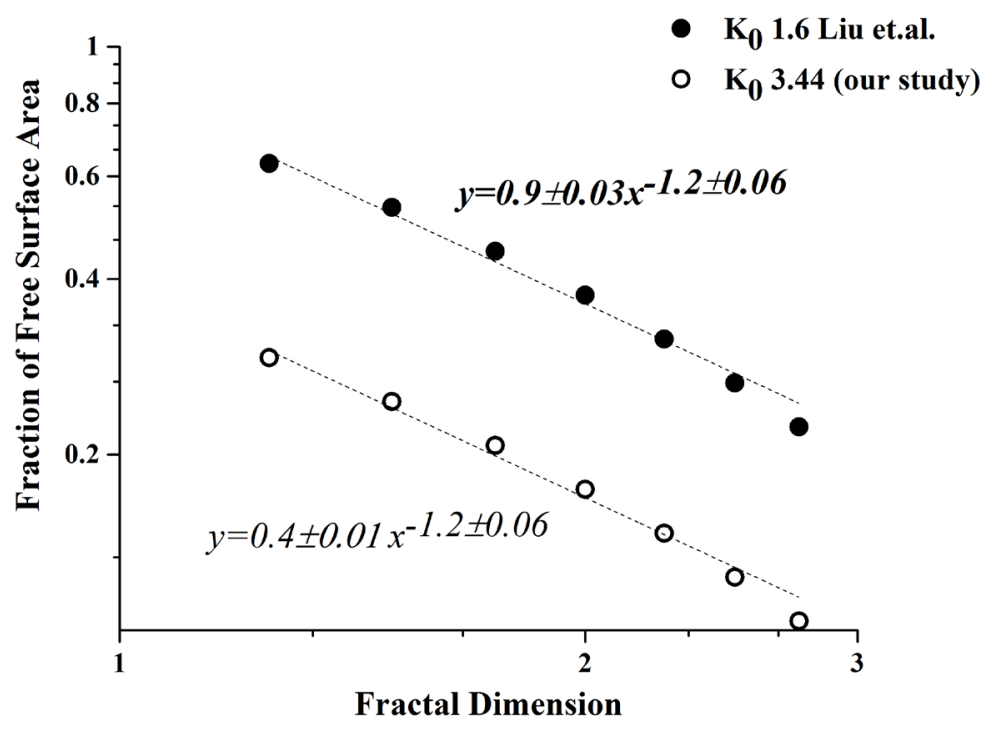

Figure 4-7 Fraction of free surface area vs. fractal dimension for different values of the prefactor.

Additionally, compact soot particles have a more convex surface with respect to nascent soot as quantified by the increase in particle convexity and roundness from phase 1 to phase 2 (figure $5(\mathrm{a} \& \mathrm{~b})$ ) and visually evidenced by the TEM images in figure 6(a (i)(iii)). Using the Kelvin equation, Crouzet and Marlow (1995) revealed that the mean curvature of the surface plays a remarkable role in the process of condensation. 
Condensation can occur at sub-saturated conditions in the case of negative curvature or concave surface (soot pores or the area between soot branches) due to the depression of equilibrium vapor pressure over such surfaces. On the contrary, in the case of compacted particles with positive mean curvature or convex surface, condensation can occur only under supersaturated conditions. We hypothesize that the organic vapors in the vicinity of compact soot particles experience a more convex surface (positive mean curvature) than for non-compact soot. Therefore, the elevated equilibrium vapor pressure over the compact soot particles slows further the condensation of SOM. However, some of the voids deeper into the compacted fractals may still be accessible by low viscosity SOM formed in humid conditions. SOM thereby manages to infiltrate into these deeper pores, leaving surface pores available for further condensation of organics. This may result in the slow, yet continuous, growth in particle mass seen in figure 3(a). Since most of the SOM mass may infiltrate into the pores inside the particle, only a modest growth in mobility diameter was observed. In agreement with this hypothesis, the TEM images show more SOM coating for the less compact soot particles in dry conditions (Figure 6(b(iii)) compared to the compact soot found in humid conditions (Figure 6(a(iii)).

\subsection{Conclusions}

In this paper we discussed the effect of relative humidity on the condensational growth of $\alpha$-pinene SOA on soot particles. The results of this study indicate that both the viscosity of SOM, the free surface area of the seed soot particles play a substantial role in determining the condensational growth of SOA on soot particles and the resulting morphology of SOA mixed soot particles.

These findings are relevant to environments where urban emissions interact with biogenic emissions and the diurnal variations in relative humidity are significant. For example, the central valley of California, studied during CARES (Zaveri, Shaw et al. 2012), where urban plume from Sacramento city is mixed with biogenic emissions from pines dominating the forests of Sierra Nevada. Furthermore, the relative humidity at the central valley of California during summer time varies from $\approx 80 \%$ to $\approx 20 \%$. Based on 
this study we conclude that the morphology soot mixed with the biogenic SOA may be significantly affected by the existing relative humidity conditions and conversely this might affect the SOA growth yield on the soot seeds.

Schnitzler, Dutt et al. (2014) found that in case of the condensation of anthropogenic SOA on soot at $15 \%$ relative humidity, restructuring begins only when a threshold SOA mass, mass growth factor $\sim 2$ is reached. The fully restructured soot particles in their study were not spherical. In contrast to this, our study indicates that relatively lower amount (mass growth factor $\sim 1.13$ ) of biogenic SOA condensed on soot can lead to fast and higher degree of soot restructuring in humid conditions, resulting into almost spherical particles.

Moreover, in humid conditions $(\mathrm{RH} \approx 80 \%)$, the viscosity of SOM may be similar to that of a liquid; its condensation on soot results in soot restructuring, slowing further SOM uptake by soot particles. The low viscosity SOM can infiltrate deeper into the particle pores increasing its mass, but not significantly affecting its size. This effect may result in soot particles that are more "homogenously" mixed with SOM. However, in dry conditions (RH $<2 \%$ ), when the particles grew up to 2 times the initial soot mobility diameter, most of the SOA condensation occurred in the external soot pores and branches. These processes may have a significant impact on the optical properties of soot particles mixed with SOA at different $\mathrm{RH}$, which need to be further investigated and quantified. Furthermore, from this study we understand that neither of the two mixing scenarios discussed above can be best represented by a core-shell model, therefore accounting for the effect of humidity on soot morphology and mixing state may be required in optical models. 


\section{References}

1. Adachi, K. and P. Buseck (2008). "Internally mixed soot, sulfates, and organic matter in aerosol particles from Mexico City." Atmospheric Chemistry and Physics 8(21): 6469-6481.

2. Adachi, K. and P. R. Buseck (2013). "Changes of ns-soot mixing states and shapes in an urban area during CalNex." Journal of Geophysical Research: Atmospheres.

3. Bekki, S., C. David, K. Law, D. M. Smith, D. Coelho, J. F. Thovert and P. M. Adler (2000). "Uptake on fractal particles: 2. Applications." Journal of Geophysical Research: Atmospheres (1984-2012) 105(D3): 3917-3928.

4. Buseck, P. R., K. Adachi, A. Gelencsér, É. Tompa and M. Pósfai (2014). "Ns-Soot: A Material-Based Term for Strongly Light-Absorbing Carbonaceous Particles." Aerosol Science and Technology 48(7).

5. Cahill, J., K. Suski, J. Seinfeld, R. Zaveri and K. Prather (2012). "The mixing state of carbonaceous aerosol particles in northern and southern California measured during CARES and CalNex 2010." Atmospheric Chemistry and Physics 12(22): 10989-11002.

6. Cappa, C. D., T. B. Onasch, P. Massoli, D. R. Worsnop, T. S. Bates, E. S. Cross, P. Davidovits, J. Hakala, K. L. Hayden and B. T. Jobson (2012). "Radiative absorption enhancements due to the mixing state of atmospheric black carbon." Science 337(6098): 1078-1081.

7. China, S., C. Mazzoleni, K. Gorkowski, A. C. Aiken and M. K. Dubey (2013). "Morphology and mixing state of individual freshly emitted wildfire carbonaceous particles." Nature Communications 4.

8. China, S., N. Salvadori and C. Mazzoleni (2014). "Effect of Traffic and Driving Characteristics on Morphology of Atmospheric Soot Particles at Freeway OnRamps." Environmental Science \& Technology 48(6): 3128-3135. 
9. China, S., B. Scarnato, R. C. Owen, B. Zhang, M. T. Ampadu, S. Kumar, K. Dzepina, M. P. Dziobak, P. Fialho and J. A. Perlinger (2015). "Morphology and Mixing State of Aged Soot Particles at a Remote Marine Free Troposphere Site: Implications for Optical Properties." Geophysical Research Letters.

10. Cocker III, D. R., S. L. Clegg, R. C. Flagan and J. H. Seinfeld (2001). "The effect of water on gas-particle partitioning of secondary organic aerosol. Part I: $\alpha$ pinene/ozone system." Atmospheric Environment 35(35): 6049-6072.

11. Coelho, D., S. Bekki, J. F. Thovert and P. M. Adler (2000). "Uptake on fractal particles: 1. Theoretical framework." Journal of Geophysical Research: Atmospheres (1984-2012) 105(D3): 3905-3916.

12. Cross, E. S., T. B. Onasch, A. Ahern, W. Wrobel, J. G. Slowik, J. Olfert, D. A. Lack, P. Massoli, C. D. Cappa and J. P. Schwarz (2010). "Soot particle studiesinstrument inter-comparison-project overview." Aerosol Science and Technology 44(8): 592-611.

13. Crouzet, Y. and W. H. Marlow (1995). "Calculations of the equilibrium vapor pressure of water over adhering 50-200-nm spheres." Aerosol Science and Technology 22(1): 43-59.

14. Donahue, N., J. Kroll, S. Pandis and A. Robinson (2012). "A two-dimensional volatility basis set-Part 2: Diagnostics of organic-aerosol evolution." Atmospheric Chemistry and Physics 12(2): 615-634.

15. Edney, E., D. Driscoll, R. Speer, W. Weathers, T. Kleindienst, W. Li and D. Smith (2000). "Impact of aerosol liquid water on secondary organic aerosol yields of irradiated toluene/propylene/ $\mathrm{NO} x /(\mathrm{NH} 4) 2 \mathrm{SO}$ 4/air mixtures." Atmospheric Environment 34(23): 3907-3919.

16. Ehn, M., J. A. Thornton, E. Kleist, M. Sipilä, H. Junninen, I. Pullinen, M. Springer, F. Rubach, R. Tillmann and B. Lee (2014). "A large source of low-volatility secondary organic aerosol." Nature 506(7489): 476-479. 
17. Geron, C., R. Rasmussen, R. R Arnts and A. Guenther (2000). "A review and synthesis of monoterpene speciation from forests in the United States." Atmospheric Environment 34(11): 1761-1781.

18. Jacobson, M. Z. (2001). "Strong radiative heating due to the mixing state of black carbon in atmospheric aerosols." Nature 409(6821): 695-697.

19. Jimenez, J., M. Canagaratna, N. Donahue, A. Prevot, Q. Zhang, J. Kroll, P. DeCarlo, J. Allan, H. Coe and N. Ng (2009). "Evolution of organic aerosols in the atmosphere." Science 326(5959): 1525-1529.

20. Kanakidou, M., J. Seinfeld, S. Pandis, I. Barnes, F. Dentener, M. Facchini, R. V. Dingenen, B. Ervens, A. Nenes and C. Nielsen (2005). "Organic aerosol and global climate modelling: a review." Atmospheric Chemistry and Physics 5(4): 10531123.

21. Khalizov, A. F., Y. Lin, C. Qiu, S. Guo, D. Collins and R. Zhang (2013). "Role of OH-initiated oxidation of isoprene in aging of combustion soot." Environmental Science \& Technology 47(5): 2254-2263.

22. Kristensen, K., T. Cui, H. Zhang, A. Gold, M. Glasius and J. Surratt (2014). "Dimers in $\alpha$-pinene secondary organic aerosol: effect of hydroxyl radical, ozone, relative humidity and aerosol acidity." Atmospheric Chemistry and Physics 14(8): 4201-4218.

23. Lack, D. A., J. M. Langridge, R. Bahreini, C. D. Cappa, A. M. Middlebrook and J. P. Schwarz (2012). "Brown carbon and internal mixing in biomass burning particles." Proceedings of the National Academy of Sciences 109(37): 1480214807.

24. Lerdau, M., S. B. Dilts, H. Westberg, B. K. Lamb and E. J. Allwine (1994). "Monoterpene emission from ponderosa pine." Journal of Geophysical Research: Atmospheres (1984-2012) 99(D8): 16609-16615. 
25. Liu, L., M. I. Mishchenko and W. P. Arnott (2008). "A study of radiative properties of fractal soot aggregates using the superposition T-matrix method." Journal of Quantitative Spectroscopy and Radiative Transfer 109(15): 2656-2663.

26. Ma, X., C. D. Zangmeister, J. Gigault, G. W. Mulholland and M. R. Zachariah (2013). "Soot aggregate restructuring during water processing." Journal of Aerosol Science 66(0): 209-219.

27. Metcalf, A. R., C. L. Loza, M. M. Coggon, J. S. Craven, H. H. Jonsson, R. C. Flagan and J. H. Seinfeld (2013). "Secondary organic aerosol coating formation and evaporation: chamber studies using black carbon seed aerosol and the singleparticle soot photometer." Aerosol Science and Technology 47(3): 326-347.

28. Miljevic, B., N. C. Surawski, T. Bostrom and Z. D. Ristovski (2012). "Restructuring of carbonaceous particles upon exposure to organic and water vapours." Journal of Aerosol Science 47: 48-57.

29. Moffet, R. C. and K. A. Prather (2009). "In-situ measurements of the mixing state and optical properties of soot with implications for radiative forcing estimates." Proceedings of the National Academy of Sciences 106(29): 11872-11877.

30. Popovicheva, O., N. M. Persiantseva, N. K. Shonija, P. DeMott, K. Koehler, M. Petters, S. Kreidenweis, V. Tishkova, B. Demirdjian and J. Suzanne (2008). "Water interaction with hydrophobic and hydrophilic soot particles." Physical Chemistry Chemical Physics 10(17): 2332-2344.

31. Ramanathan, V. and G. Carmichael (2008). "Global and regional climate changes due to black carbon." Nature Geoscience 1(4): 221-227.

32. Renbaum-Wolff, L., J. W. Grayson, A. P. Bateman, M. Kuwata, M. Sellier, B. J. Murray, J. E. Shilling, S. T. Martin and A. K. Bertram (2013). "Viscosity of $\alpha$ pinene secondary organic material and implications for particle growth and reactivity." Proceedings of the National Academy of Sciences 110(20): 8014-8019. 
33. Riemer, N., H. Vogel and B. Vogel (2004). "Soot aging time scales in polluted regions during day and night." Atmospheric Chemistry and Physics 4(7): 18851893.

34. Saathoff, H., K.-H. Naumann, M. Schnaiter, W. Schöck, O. Möhler, U. Schurath, E. Weingartner, M. Gysel and U. Baltensperger (2003). "Coating of soot and (NH 4) $2 \mathrm{SO} 4$ particles by ozonolysis products of $\alpha$-pinene." Journal of Aerosol Science 34(10): 1297-1321.

35. Schnaiter, M., H. Horvath, O. Möhler, K. H. Naumann, H. Saathoff and O. W. Schöck (2003). "UV-VIS-NIR spectral optical properties of soot and sootcontaining aerosols." Journal of Aerosol Science 34(10): 1421-1444.

36. Schnaiter, M., C. Linke, O. Möhler, K. H. Naumann, H. Saathoff, R. Wagner, U. Schurath and B. Wehner (2005). "Absorption amplification of black carbon internally mixed with secondary organic aerosol." Journal of Geophysical Research: Atmospheres (1984-2012) 110(D19).

37. Schnitzler, E. G., A. Dutt, A. M. Charbonneau, J. S. Olfert and W. Jäger (2014). "Soot Aggregate Restructuring Due to Coatings of Secondary Organic Aerosol Derived from Aromatic Precursors." Environmental science \& technology 48(24): 14309-14316.

38. Schwarz, J., J. Spackman, D. Fahey, R. Gao, U. Lohmann, P. Stier, L. Watts, D. Thomson, D. Lack and L. Pfister (2008). "Coatings and their enhancement of black carbon light absorption in the tropical atmosphere." Journal of Geophysical Research: Atmospheres (1984-2012) 113(D3).

39. Sedlacek, A. J., E. R. Lewis, L. Kleinman, J. Xu and Q. Zhang (2012). "Determination of and evidence for non-core-shell structure of particles containing black carbon using the Single-Particle Soot Photometer (SP2)." Geophysical Research Letters 39(6).

40. Seinfeld, J. H., G. B. Erdakos, W. E. Asher and J. F. Pankow (2001). "Modeling the formation of secondary organic aerosol (SOA). 2. The predicted effects of 
relative humidity on aerosol formation in the $\alpha$-pinene-, $\beta$-pinene-, sabinene-, $\Delta 3$ carene-, and cyclohexene-ozone systems." Environmental Science \& Technology 35(9): 1806-1817.

41. Sorensen, C. (2001). "Light scattering by fractal aggregates: a review." Aerosol Science \& Technology 35(2): 648-687.

42. Stocker, T. F., D. Qin, G.-K. Plattner, M. Tignor, S. K. Allen, J. Boschung, A. Nauels, Y. Xia, V. Bex and P. M. Midgley (2013). Climate Change 2013. The Physical Science Basis. Working Group I Contribution to the Fifth Assessment Report of the Intergovernmental Panel on Climate Change-Abstract for decisionmakers, Groupe d'experts intergouvernemental sur l'evolution du climat/Intergovernmental Panel on Climate Change-IPCC, C/O World Meteorological Organization, 7bis Avenue de la Paix, CP 2300 CH-1211 Geneva 2 (Switzerland).

43. Tritscher, T., Z. Jurányi, M. Martin, R. Chirico, M. Gysel, M. F. Heringa, P. F. DeCarlo, B. Sierau, A. S. Prévôt and E. Weingartner (2011). "Changes of hygroscopicity and morphology during ageing of diesel soot." Environmental Research Letters 6(3): 034026.

44. Van Poppel, L. H., H. Friedrich, J. Spinsby, S. H. Chung, J. H. Seinfeld and P. R. Buseck (2005). "Electron tomography of nanoparticle clusters: Implications for atmospheric lifetimes and radiative forcing of soot." Geophysical Research Letters $32(24)$.

45. Virkkula, A., R. Van Dingenen, F. Raes and J. Hjorth (1999). "Hygroscopic properties of aerosol formed by oxidation of limonene, $\alpha$-pinene, and $\beta$-pinene." Journal of Geophysical Research: Atmospheres (1984-2012) 104(D3): 3569-3579.

46. Weingartner, E., H. Burtscher and U. Baltensperger (1997). "Hygroscopic properties of carbon and diesel soot particles." Atmospheric Environment 31(15): 2311-2327. 
47. Zaveri, R., W. Shaw, D. Cziczo, B. Schmid, R. Ferrare, M. Alexander, M. Alexandrov, R. Alvarez, W. Arnott and D. Atkinson (2012). "Overview of the 2010 Carbonaceous Aerosols and Radiative Effects Study(CARES)." Atmospheric Chemistry and Physics 12(16): 7647-7687.

48. Zhang, R., A. F. Khalizov, J. Pagels, D. Zhang, H. Xue and P. H. McMurry (2008). "Variability in morphology, hygroscopicity, and optical properties of soot aerosols during atmospheric processing." Proceedings of the National Academy of Sciences 105(30): 10291-10296. 


\section{Research Implications \& Future Directions}

Black carbon/soot affects the Earth's radiation budget by warming the atmosphere due to its ability to absorb solar radiation. However, there are large uncertainties associated with the radiative forcing estimates due to black carbon in the atmosphere. A part of these uncertainties arise from the lack of good understanding of soot processing in the atmosphere, due to the limitations of instruments measuring optical properties and models used in the estimation of the radiative forcing (Bond, Doherty et al. 2013, Myhre, Shindell et al. 2013).

The research discussed in this dissertation makes a few footsteps in the direction of understanding some of the lesser known science about the properties and behavior of carbonaceous aerosols in the atmosphere and the implications to climate change. We focused on understanding the evolution of the morphology and mixing state of ambient and laboratory generated carbonaceous aerosols exploiting the resolution and imaging capabilities of electron microscopy. We also developed a novel photoacoustic nephelometer spectrometer to measure the optical properties of aerosols; contributing to the advancement of instrumentation for future research. This instrument has multiwavelength measurement capabilities and overcomes some of the limitations of traditionally used filter-based instruments like the aethalometer and Particle Soot Absorption Photometer.

Absorption measurements from filter-based methods include artifacts due to multiple scattering from the substrate and possibly due to changes in particle morphology when they are deposited on the filter. On the contrary, photoacoustic instruments measure aerosol absorption while the particles are suspended in air. Commercially available photoacoustic instruments however, are limited by the number of operating wavelengths. In chapter 2 we discussed the development of a novel multi-wavelength photoacoustic nephelometer spectrometer instrument, which is capable of measuring over almost the entire visible spectrum (from $\sim 400 \mathrm{~nm}$ to $\sim 700 \mathrm{~nm}$ ). The instrument combines a photoacoustic spectrometer with a nephelometer and is therefore capable of measuring aerosol absorption and scattering simultaneously. We used the new photoacoustic nephelometer spectrometer 
to study the optical properties of $\mathrm{NO}_{2}$ gas, kerosene soot and salt aerosol. This work laid the foundation for the development of future field deployable broad spectrum instruments and our approach was successfully employed also by scientists at NIST who applied the technique to study the optical properties of soot, brown carbon as well as some gaseous species (Radney and Zangmeister 2015). The minimum detection limit of the current version of the instrument limits its use to laboratory or ambient studies in high to medium aerosol concentrations. Improvement of the minimum detection limit of the instrument to measure low pollution levels in the future will make this approach useful for monitoring purposes, including potentially at remote sites. In addition, the supercontinuum laser used in our instrument has a continuous spectrum from $400 \mathrm{~nm}$ to $2200 \mathrm{~nm}$. Therefore in future, the complete spectrum of the laser may be exploited to extend the spectral range of the photoacoustic instrument to cover the entire solar spectrum.

The role of the mixing state of soot on its optical properties has been intensely debated in atmospheric science for over a decade (Jacobson 2001, Cappa, Onasch et al. 2012, Liu, Aiken et al. 2015). The optical properties of soot are sensitive to its morphology and mixing state (which in turn depends upon material soot is mixed with), the process through which soot undergoes mixing and the environmental conditions during mixing. Therefore, Liu, Aiken et al. (2015) suggested a detailed assessment of region and source specific soot mixing state to elucidate the role of soot in influencing climate change.

In chapter 3, we focused on the mixing of soot (transported from urban site) with biogenic secondary organic aerosol in a forested environment. Based on the scanning electron microscopy (SEM) analysis of samples collected from a forested site during Carbonaceous Aerosols and Radiative Effects Study, we observed two major categories of mixed soot, namely, coated soot and partially encapsulated soot. Employing SEM analysis, we established that the viscosity of SOA particles determines the mixing state of particles resulting from the coagulation of soot with SOA. While soot and highly viscous, nearly solid, SOA are most likely to remain externally mixed, coagulation of soot with low viscosity SOA possibly result in coated soot. SOA particles with intermediate viscosity were involved in the formation of partially encapsulated particles. So far, relative humidity 
has been identified as a key player in determining viscosity of SOA (Renbaum-Wolff, Grayson et al. 2013), therefore, our study provides an indirect link between the environmental factors like relative humidity and the mixing states of soot.

Quantifying and understanding the formation of the partially encapsulated particles in a given mixing scenario is particularly important because of their possible role in the discrepancies between laboratory and theoretical calculation and field measurements of absorption enhancement (Cappa, Onasch et al. 2012, Adachi and Buseck 2013). These particles are treated as conventional core-shell structure in global climate models like coated soot, while in reality, in partially encapsulated particles, soot is positioned near to the surface of, or is partially encapsulated within, the host particle. In the events like biomass burning, where $\sim 60 \%$ of the particles have been identified as particles with soot near to the surface of the host (Sedlacek, Lewis et al. 2012), discrepancies in estimated radiative forcing may be largely driven by their treatment as core-shell structures.

During CARES (chapter 3), condensation of vapor phase organic material on soot was an important pathway for soot-SOA mixing. Therefore in a follow-up laboratory study (SAAS), the condensational growth of SOA on soot was investigated in a dedicated set of experiments, conducted under controlled conditions. In chapter 4 of this dissertation we compare the condensation of SOA on soot in dry $(<2 \% \mathrm{RH})$ and humid conditions $(\approx 80 \%$ $\mathrm{RH}$ ). Interestingly, in humid conditions we observed a relatively lower amount of SOA condensed on soot as compared to that condensed in dry conditions. In humid conditions, as soon as the condensation of SOA on soot began, we observed the compaction of soot particles. Depending upon the degree of compaction, the fraction of free surface area of soot available for condensation reduced by up to $50 \%$, leading to a reduced SOA growth rate on the compacted particles.

Differences in the evolution of the soot morphology and mixing state at different $\mathrm{RH}$ may have a significant and contrasting impact on the optical properties of soot particles. Therefore, in future studies, the optical properties of soot mixed with SOA in different relative humidity conditions should be further investigated. During SAAS, several instruments were deployed for measuring aerosol optical properties. The data from these 
instruments can be used to correlate the evolution of soot morphology and mixing state in the two RH conditions with measured optical properties.

Based on the findings from chapter 3 and 4, we conclude that the morphology of soot mixed with biogenic SOA by condensation or coagulation may be significantly affected by environmental factors like relative humidity. Therefore, the effect of relative humidity on soot morphology and mixing state should be accounted for in global climate models. Our findings are relevant to environments where urban emissions interact with biogenic emissions and the diurnal variations in relative humidity are significant. For example, the central valley of California, studied during CARES (Zaveri, Shaw et al. 2012), where urban plume from Sacramento city is mixed with biogenic emissions from pines dominating the forests of Sierra Nevada and the relative humidity during summer time varies diurnally from $\approx 80 \%$ to $\approx 20 \%$. Additionally, based on our findings, we also emphasize that all the soot mixing state and morphologies cannot be always represented by simplified morphological structures such as the spherically symmetric core-shell model used in the climate models to estimate the mixed soot optical properties.

In future research, we suggest the investigation of the optical properties of soot particles with observed morphology and mixing state in different environmental conditions. This can be accomplished by using our findings for more realistic definition of soot structure and highly detailed optical properties models like Discrete Dipole Approximation (DDA). Real atmosphere observations of particle morphology and mixing state using electron microscopy combined with single particle optical properties simulations using DDA will be helpful in improving the accuracy of radiative forcing estimates. 


\section{References}

1. Adachi, K. and P. R. Buseck (2013). "Changes of ns-soot mixing states and shapes in an urban area during CalNex." Journal of Geophysical Research: Atmospheres.

2. Bond, T. C., S. J. Doherty, D. Fahey, P. Forster, T. Berntsen, B. DeAngelo, M. Flanner, S. Ghan, B. Kärcher and D. Koch (2013). "Bounding the role of black carbon in the climate system: A scientific assessment." Journal of Geophysical Research: Atmospheres 118(11): 5380-5552.

3. Cappa, C. D., T. B. Onasch, P. Massoli, D. R. Worsnop, T. S. Bates, E. S. Cross, P. Davidovits, J. Hakala, K. L. Hayden and B. T. Jobson (2012). "Radiative absorption enhancements due to the mixing state of atmospheric black carbon." Science 337(6098): 1078-1081.

4. Jacobson, M. Z. (2001). "Strong radiative heating due to the mixing state of black carbon in atmospheric aerosols." Nature 409(6821): 695-697.

5. Liu, S., A. C. Aiken, K. Gorkowski, M. K. Dubey, C. D. Cappa, L. R. Williams, S. C. Herndon, P. Massoli, E. C. Fortner, P. S. Chhabra, W. A. Brooks, T. B. Onasch, J. T. Jayne, D. R. Worsnop, S. China, N. Sharma, C. Mazzoleni, L. Xu, N. L. Ng, D. Liu, J. D. Allan, J. D. Lee, Z. L. Fleming, C. Mohr, P. Zotter, S. Szidat and A. S. H. Prevot (2015). "Enhanced light absorption by mixed source black and brown carbon particles in UK winter." Nat Commun 6.

6. Myhre, G., D. Shindell, F. Bréon, W. Collins, J. Fuglestvedt, J. Huang, D. Koch, J. Lamarque, D. Lee and B. Mendoza (2013). "Anthropogenic and natural radiative forcing, Chapter 8 in Climate Change 2013: The Physical Science Basis. Contribution of Working Group I to the Fifth Assessment Report of the Intergovernmental Panel on Climate Change, edited by Stocker, TF, D. Qin, G." K. Plattner, M. Tignor, SK Allen, J. Boschung, A. Nauels, Y. Xia, V. Bex and PM Midgley, Cambridge University Press, Cambridge, UK and New York, NY. 
7. Radney, J. G. and C. D. Zangmeister (2015). "Measurement of Gas and Aerosol Phase Absorption Spectra across the Visible and Near-IR Using Supercontinuum Photoacoustic Spectroscopy." Analytical chemistry 87(14): 7356-7363.

8. Renbaum-Wolff, L., J. W. Grayson, A. P. Bateman, M. Kuwata, M. Sellier, B. J. Murray, J. E. Shilling, S. T. Martin and A. K. Bertram (2013). "Viscosity of $\alpha-$ pinene secondary organic material and implications for particle growth and reactivity." Proceedings of the National Academy of Sciences 110(20): 8014-8019.

9. Sedlacek, A. J., E. R. Lewis, L. Kleinman, J. Xu and Q. Zhang (2012). "Determination of and evidence for non-core-shell structure of particles containing black carbon using the Single-Particle Soot Photometer (SP2)." Geophysical Research Letters 39(6).

10. Zaveri, R., W. Shaw, D. Cziczo, B. Schmid, R. Ferrare, M. Alexander, M. Alexandrov, R. Alvarez, W. Arnott and D. Atkinson (2012). "Overview of the 2010 Carbonaceous Aerosols and Radiative Effects Study(CARES)." Atmospheric Chemistry and Physics 12(16): 7647-7687. 